Aus der Klinik für Unfallchirurgie und Orthopädie - Abteilung für

Unfallchirurgie, Plastische- und Wiederherstellungschirurgie

(Prof. Dr. med. K. M. Stürmer)

im Zentrum Chirurgie

der Medizinischen Fakultät der Universität Göttingen

\title{
Einfluss der vertikalen Ganzkörpervibration auf die metaphysäre Frakturheilung der gesunden und osteoporotischen Tibia im Ratten-
} Tiermodell

\author{
INAUGURAL-DISSERTATION \\ zur Erlangung des Doktorgrades \\ der Medizinischen Fakultät der \\ Georg-August-Universität zu Göttingen \\ vorgelegt von \\ Clara Marianne Utesch \\ aus Berlin
}

Göttingen 2015 
Dekan:

I. Berichterstatter/in:

II. Berichterstatter/in:

III. Berichterstatter/in:

Tag der mündlichen Prüfung: $\quad$ 06.04.2016
Prof. Dr. med E. K. Stürmer

Prof. Dr. med. Dr. med. dent. F.-J. Kramer

Prof. Dr. hum. biol. M. Schön 


\section{Inhaltsverzeichnis}

INHALTSVERZEICHNIS

\section{ABKÜRZUNGSVERZEICHNIS}

1 EINLEITUNG

1.1 Einführung und Zielsetzung

$\begin{array}{ll}\text { 1.2 Theoretische Grundlagen } & 11\end{array}$

1.2.1 Knochengewebe 11

$\begin{array}{ll}\text { 1.2.2 Frakturen } & 17\end{array}$

$\begin{array}{ll}1.3 \text { Osteoporose } & 19\end{array}$

$\begin{array}{ll}\text { 1.3.1 Definition } & 19\end{array}$

1.3.2 Pathophysiologie der Osteoporose 20

1.3.3 Epidemiologie und sozioökonomische Bedeutung 21

1.3.4 Einteilungsformen der Osteoporose 22

1.3.5 Risikofaktoren 24

1.3.6 Osteoporose-induzierte Frakturen 25

1.3.7 Diagnostik 25

$\begin{array}{ll}\text { 1.3.8 Therapie } & 30\end{array}$

1.4 Die ovarektomierte Ratte als Modelltier der postmenopausalen Osteoporose 37

$\begin{array}{ll}1.5 \text { Vibration } & 37\end{array}$

2 MATERIAL UND METHODEN 41

$\begin{array}{ll}2.1 \text { Versuchsaufbau } & 41\end{array}$

2.2 Versuchstiere und Versuchstierhaltung 42 
2.7 Knochenanalyse

2.7.1 Fluoreszenzmarkierung

2.8 Biomechanischer Biegetest

2.8.1 Prinzip des biomechanischen Biegetests

2.8.2 Versuchsaufbau und -ablauf

2.8.3 Auswertung des biomechanischen Tests

2.9.1 Aufarbeitung der Präparate und Anfertigung der Mikroradiographien

2.9.2 Auswertung der Mikroradiographien

2.9.3 Histomorphologische Auswertung

2.10.1 Auswertung der polychromen Sequenzmarkierung 
$\begin{array}{ll}\text { 3.4 Auswertung der Mikroradiographien } & 68\end{array}$

3.4.1 Kortikalisdicke distal-ventromedial $\quad 69$

$\begin{array}{ll}\text { 3.4.2 Kortikalisdicke distal-dorsal } & 70\end{array}$

3.4.3 Kortikalisdichte distal-ventromedial $\quad 71$

3.4.4 Kortikalisdichte distal-dorsal $\quad 72$

3.4.5 Kallusdicke ventromedial $\quad 73$

$\begin{array}{ll}\text { 3.4.6 Kallusdicke dorsal } & 74\end{array}$

3.4.7 Kallusdichte ventromedial 75

$\begin{array}{ll}\text { 3.4.8 Kallusdichte dorsal } & 76\end{array}$

$\begin{array}{ll}3.4 .9 \text { Kallusdichte endostal } & 77\end{array}$

3.4.10 Trabekeldichte distal 78

$\begin{array}{ll}\text { 3.4.11 Anzahl Trabekelkreuzungen } & 79\end{array}$

3.4.12 Dichte Trabekelkreuzungen $\quad 80$

3.4.13 Mittlere Trabekeldicke $\quad 81$

3.5 Auswertung der polychromen Sequenzmarkierung 83

3.5.1 Gesamtfläche Kallus ventromedial 84

3.5.2 CG-Fläche Kallus ventromedial 85

3.5.3 AK-Fläche Kallus ventromedial 86

3.5.4 TC-Fläche Kallus ventromedial

3.5.5 Gesamtfläche Kallus dorsal $\quad 88$

3.5.6 CG-Fläche Kallus dorsal $\quad 89$

3.5.7 AK-Fläche Kallus dorsal 90

3.5.8 TC-Fläche Kallus dorsal 91

3.5.9 Gesamtfläche Kallus endostal 92

3.5.10 CG-Fläche Kallus endostal 93

3.5.11 AK-Fläche Kallus endostal $\quad 94$

3.5.12 TC-Fläche Kallus endostal 95

$\begin{array}{ll}\text { 3.6 Zusammenfassung der Ergebnisse } & 97\end{array}$ 
4 DISKUSSION

4.1 Metaphysäres Frakturmodell

4.2 Einfluss der Ovarektomie und der Ganzkörpervibration auf den Knochen 100

4.3 Somatische Effekte der Ovarektomie und der Ganzkörpervibration 103

4.4 Schlussfolgerung 104

5 ZUSAMMENFASSUNG

6 TABELLENVERZEICHNIS

7 ABBILDUNGSVERZEICHNIS

8 LITERATURVERZEICHNIS 


\section{Abkürzungsverzeichnis}

$\mu \mathrm{CT} \quad$ Mikro-Computertomographie

AK Alizarin-Komplexon

ANOVA Varianzanalyse/Analysis of Variance

BMC Knochenmineralgehalt/bone mineral content

BMD Knochenmineraldichte/bone mineral density

BMI Body-Mass-Index

CG Calceingrün-Komplexon

$\mathrm{CO}_{2} \quad$ Kohlenstoffdioxid

CT Computertomographie

DVO Dachverband Osteologie

DXA Dual-X-ray-Absorptiometrie

ER Östrogenrezeptor/estrogen receptor

FDA Food and Drug Administration

$g \quad$ Erdbeschleunigung: $g=9,81 \mathrm{~m} / \mathrm{s}^{2}$

HRT Hormonersatztherapie/hormon replacement therapy

IL Interleukin

KG Körpergewicht

LMHFV low-magnitude high-frequency vibration

LWS Lendenwirbelsäule

MMA Methylmethacrylsäure

MW Mittelwert

$\mathrm{NaCl} \quad$ Natriumchlorid

NO Stickstoffmonoxid

Osteo Osteotomie

OVX Ovarektomie/ovarektomiert

$\mathrm{pH} \quad$ potentia hydrogenii

PSM polychrome Sequenzmarkierung

PTH Parathormon

QCT quantitative Computertomographie

QUS quantitative Ultrasonographie 


$\begin{array}{ll}\text { RANK } & \text { Receptor Activator of } N F-\kappa B \\ \text { RANKL } & \text { Receptor Activator of } N F-\kappa B \text { Ligand } \\ \text { SD } & \text { Standardabweichung/standard deviation } \\ \text { TC } & \text { Tetracyclin-Hydrochlorid } \\ \text { WBV } & \text { Ganzkörpervibration/whole-body vibration } \\ \text { WHI } & \text { Women's Health Initiative } \\ \text { WHO } & \text { World Health Organization } \\ \text { XO } & \text { Xylenolorange-Tetranatriumsalz } \\ \text { ZTE } & \text { Zentrale Tierexperimentelle Einrichtung }\end{array}$




\section{Einleitung}

\subsection{Einführung und Zielsetzung}

Die Osteoporose gilt laut World Health Organization (WHO) als eine der zehn bedeutendsten Volkskrankheiten. Weltweit sind rund 200 Millionen Menschen von dieser Erkrankung und deren Folgeschäden betroffen (Lin und Lane 2004; Lane 2006; Ström et al. 2011). Durch häufige Komplikationen und einen wesentlichen Verlust an Lebensqualität durch Schmerzen und Immobilisation besitzt die Osteoporose eine enorme Wichtigkeit auf sozioökonomischer und sozialer Ebene. Sich ändernde Lebensgewohnheiten und eine steigende Lebenserwartung lassen zudem eine starke Zunahme der Inzidenz altersassoziierter und postmenopausaler Osteoporose über die nächsten Jahrzehnte erwarten, weshalb diese Erkrankung stetig an Bedeutung gewinnt.

Die Systemerkrankung zeichnet sich durch eine Abnahme der Knochenmineraldichte (BMD) und eine veränderte, weniger stabile Mikroarchitektur des gesamten Skeletts aus. Die dadurch entstehende Knochenfragilität begünstigt das Auftreten von Frakturen. Vor allem betrifft sie Knochen, die einem besonders hohen Knochenumbau unterliegen. So sind vornehmlich der Bereich der Wirbelsäule, des proximalen Femurs, des Schenkelhalses und des distalen Radius betroffen (Bartl 2011). Es folgen häufig Immobilität, lebenslange Invalidität und eine gesteigerte Mortalität (Cauley et al. 2000). Jährlich resultieren ca. neun Millionen Frakturen durch osteoporotische Skelettveränderungen, ein Drittel davon in Europa (Johnell und Kanis 2006; Ström et al. 2011). Allein in Deutschland belaufen sich Schätzungen zufolge - die jährlichen Kosten in der Behandlung osteoporosebedingter Frakturen und deren Folgen auf über fünf Milliarden Euro (Häussler et al. 2007).

Durch die veränderte Struktur des osteoporotischen Knochens ist dieser nicht nur weniger belastbar, sondern im Falle einer Fraktur ist auch dessen Regenerationsfähigkeit vermindert. Der Heilungsprozess wird qualitativ und quantitativ beeinträchtigt. Nach dem heutigen Wissensstand läuft der Frakturheilungsprozess im Vergleich zum gesunden Knochen um ca. 30 \% verzögert ab (Lill et al. 2002 a,b). 
Es werden zur Zeit verschiedene Therapieansätze untersucht, wie die Regenerationsfähigkeit des osteoporotischen Knochens so beeinflusst werden kann, dass der Heilungsprozess gefördert wird und gleichzeitig dem Voranschreiten von osteoporotischen Veränderungen vorgebeugt werden kann. Lösungsansätze finden sich derzeit im Einsatz von Medikamenten und verschiedenen Hormonen. Da diese allerdings oft, vor allem auf lange Sicht betrachtet, gravierende Nebenwirkungen sowie Folgeerkrankungen mit sich bringen können (Rossouw et al. 2002), stellt sich die Frage nach einer verträglicheren Alternative. Diese fand sich vor einigen Jahren in dem nebenwirkungsarmen Einsetzen von Ganzkörpervibration. Es gilt als bewiesen, dass Mikrobewegungen den Muskelaufbau unterstützen, aber auch den Frakturheilungsprozess positiv beeinflussen können (Judex et al. 2007; Flieger 1998; Rubin 2007). Die vorliegende Arbeit untersucht die Auswirkungen vertikaler Ganzkörpervibration bei $90 \mathrm{Hertz}(\mathrm{Hz})$ auf die metaphysäre Frakturheilung des osteoporotischen Knochens.

Im Vorfeld zu der hier vorliegenden Untersuchung fanden in dieser Arbeitsgruppe bereits Projekte anhand des weltweit meistgenutzten Osteoporosemodells, der ovarektomierten Ratte, statt. Sie gilt als anerkanntes Modelltier in der Erforschung der postmenopausalen Osteoporose (Kalu 1991). In vorangegangenen Studien konnte beobachtet werden, dass sich bei ovarektomierten Ratten nach kurzer Zeit eine deutliche Osteoporose der metaphysären Tibia einstellt (Kalu 1991; Wronski et al.1985; Seidlova-Wuttke et al. 2003 a u. b). Es wurde dann eine standardisierte Osteotomie mit anschließender Osteosynthese der Tibiametaphysen entwickelt, die eine direkte Untersuchung der Frakturheilung am Ort der Osteoporosemanifestation ermöglicht. Die qualitative und quantitative Beurteilung des Heilungsprozesses wurde mittels biomechanischer und histomorphologischer Kriterien erfasst und zeitlich anhand polychromer Sequenzmarkierung untersucht. Nach dem aktuellen Stand der Wissenschaft liegen derzeit bei moderater Vibration im Bereich von 90 $\mathrm{Hz}$ keine Hinweise auf eine systemische Beeinflussung vor. Deshalb wäre es ein kostengünstiges und relativ nebenwirkungsarmes und damit unter sozioökonomischen Aspekten attraktives Mittel in der additiven Therapie osteoporotischer Frakturen. 
Die vorliegende Arbeit befasst sich mit folgenden Fragestellungen:

1. Auf welche Weise beeinflusst vertikale Ganzkörpervibration die Frakturheilung des osteoporotischen und des intakten Knochens?

2. Lässt sich eine Verbesserung der Frakturheilung durch diese erzielen?

\subsection{Theoretische Grundlagen}

\subsubsection{Knochengewebe}

Der Knochen ist ein dynamisches Organ, welches sich durch eine hohe Stoffwechselaktivität und Durchblutung auszeichnet. Er unterliegt ständigen Umbauprozessen und kann sich dadurch verschiedenen Belastungssituationen anpassen. Im Wesentlichen besteht Knochen aus einer kalziumhaltigen Extrazellulärsubstanz, der Knochenmatrix, den Knochenzellen (Osteoblasten, Osteozyten und Osteoklasten) und Mineralien. Weitere Bestandteile sind Bindegewebe, Knorpel, rotes und gelbes Knochenmark sowie Versorgungsstrukturen, Nerven und Gefäße. Das Skelett erfüllt eine Stütz- und Schutzfunktion und zählt durch die enge Verknüpfung mit dem blutbildenden System zum Knochen-Knochenmark-System. Durch die Speicherung von 99 \% des im Körper vorkommenden Kalziums, 85 \% des Phosphats und 50 \% des Magnesiums ist es das größte Mineraldepot des menschlichen Körpers und übernimmt somit eine zentrale metabolische Funktion (Bartl 2011; Benninghoff und Drenckhahn 2008; Junqueira und Carneiro 2005; Welsch 2003).

\subsubsection{Knochenaufbau}

Elastizität sowie Zug- und Druckfestigkeit bei effizienter Leichtbauweise sind die wesentlichen Charaktereigenschaften des gesunden Knochens. Histologisch unterscheidet man zwei Arten von Knochengewebe: Geflechtknochen (Primärknochen) und Lamellenknochen (Sekundärknochen).

Bei Knochenneubildung entsteht zunächst Geflechtknochen, der im Laufe der Entwicklung durch Lamellenknochen ersetzt wird. So findet sich im Erwachsenenalter hauptsächlich lamellärer Knochen. Die Kollagenfasern im Sekundärknochen sind regelmäßig ausgerichtet. Sie bilden in Form einer 3 bis $7 \mu \mathrm{m}$ dicken Knochenlamelle, die sich um einen zentralen Kanal (Havers-Kanal, Zentralkanal) anordnet, ein Osteon (Havers-System). Die Kollagenfasern innerhalb der Lamellen verlaufen parallel, die verschiedenen Lamellen 
$90^{\circ}$ versetzt zueinander. Dadurch entsteht die hohe Festigkeit des Knochens. Die Osteone verlaufen längs zur Kortikalis. Die einzelnen Havers-Kanäle sind durch Volkmann-Kanäle miteinander verbunden.

Makroskopisch besteht der (metaphysäre) Knochen aus einer äußeren Kortikalis (Kompakta, Substantia compacta) und einer inneren, schwammartig aufgebauten Schicht (Spongiosa, Substantia spongiosa). Die Spongiosa setzt sich aus vielen miteinander vernetzten Knochenbälkchen (Trabekeln) zusammen, welche sich in Richtung der größten Druckbeanspruchung ausrichten. Hierdurch wird eine hohe mechanische Robustheit bei geringem Gewicht erzielt. Besonders stark ausgebildet findet sich trabekulärer Knochen im axialen Skelett (u.a. Wirbelsäule und Schenkelhals), da hier das Skelett der stärksten mechanischen Beanspruchung unterliegt. Die äußere Oberfläche des Knochens außerhalb der Gelenkflächen wird von Periost bedeckt, von innen ist er mit Endost ausgekleidet. Durch ihre hohe osteogene Aktivität sind Peri- und Endost bei der Frakturheilung in hohem Maße beteiligt (Benninghoff und Drenckhahn 2008; Junqueira und Carneiro 2005; Schiebler und Schmidt 2002).

Hinsichtlich ihrer Form unterscheidet man kurze, lange und platte Knochen. Da in der vorliegenden Arbeit lange Knochen (Röhrenknochen) von übergeordneter Bedeutung sind, wird nachfolgend nur deren Anatomie genauer erläutert. Hierzu gehören u.a. Tibia, Fibula und Femur. Das lange röhrenförmige Mittelstück, die Diaphyse, enthält eine dicke Kortikalis und nur einen kleinen Anteil spongiösen Knochens. Die beiden Enden, die Epiphysen, bestehen überwiegend aus Spongiosa und weisen nur einen dünnen äußeren Saum an Kompakta auf. Befindet sich der Knochen im Wachstum, so weist dieser zwischen Epi- und Diaphyse einen knorpeligen Abschnitt, die Epiphysenfuge, auf. Hier findet das Längenwachstum statt. Ist der Knochen ausgewachsen, verknöchert dieser Anteil. Es bleibt lediglich eine Epiphysenlinie sichtbar. Bei dem Knochenabschnitt, in dem die sich verbreiternde Diaphyse an die Epiphysenlinie grenzt, handelt es sich um die Metaphyse (Junqueira und Carneiro 2005; Schiebler und Schmidt 2002) (s. Abb.1). Dies ist der Hauptmanifestationsort der Osteoporose. 


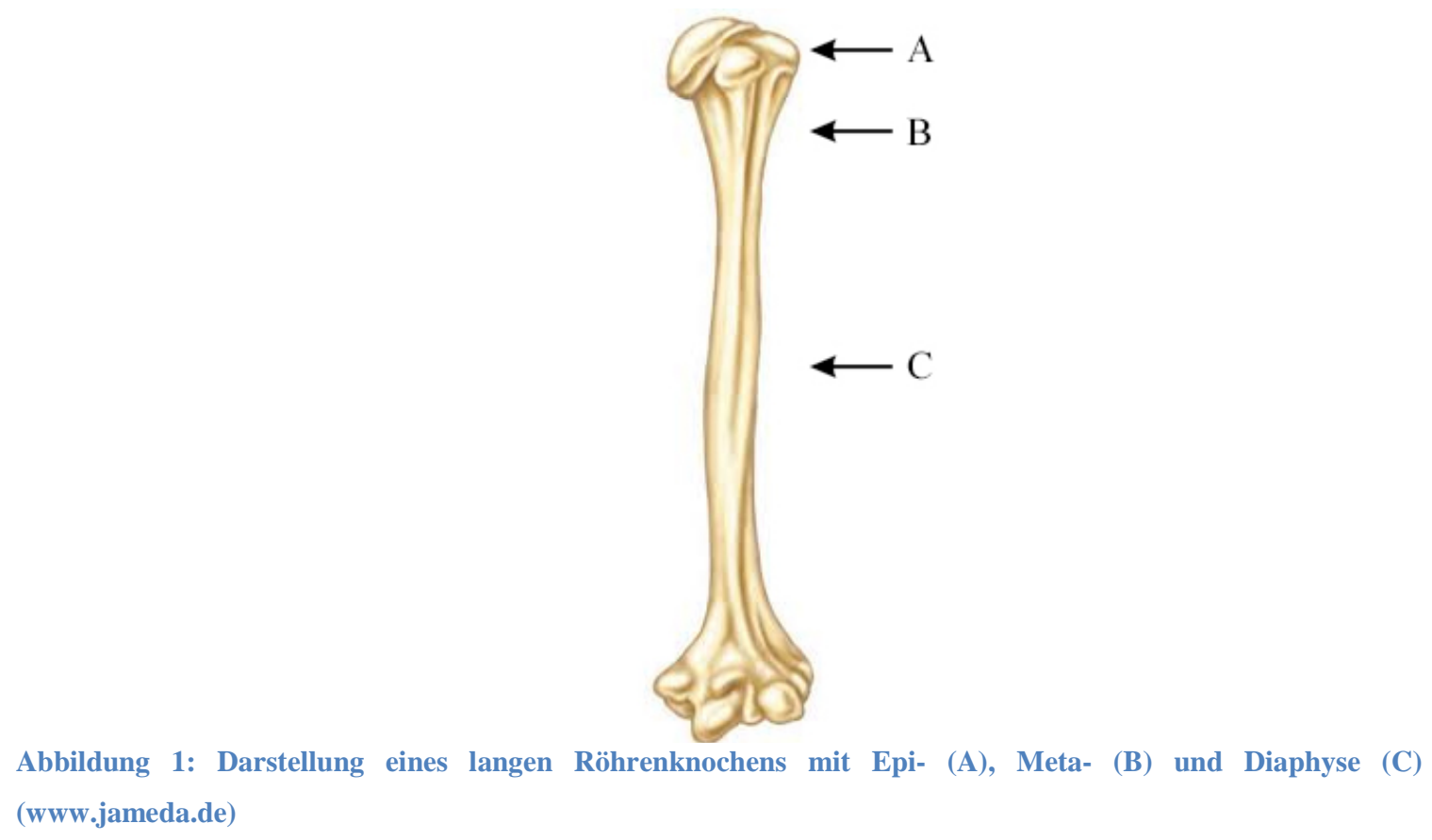

\subsubsection{Knochenzellen}

\section{Osteoblasten}

Osteoblasten entwickeln sich aus undifferenzierten Mesenchymzellen. Ihre Hauptaufgabe ist die Bildung von Knochen. Dieser Vorgang dauert mehrere Wochen und wird von einer Vielzahl verschiedener Zytokine, Hormone und Vitamine reguliert. Dazu zählen z.B. Parathormon (PTH), Östrogene, Statine, Prostaglandine, Kalzitriol und Androgene. Bei Aktivierung lagern sie sich in epithelartiger Anordnung an die Knochenoberfläche an und sezernieren aktiv die organischen Anteile der Knochenmatrix, insbesondere Kollagen Typ 1, Proteoglykane und Glykoproteine. Die zunächst unverkalkte Substanz wird als Osteoid bezeichnet, welche im Anschluss durch Einlagerung von Kalziumphosphat mineralisiert wird (Junqueira und Carneiro 2005). Das Kalziumphosphat wandelt sich zu Hydroxylappatit um. Dieser Mineralisierungsprozess wird als Apposition bezeichnet. Ruhende Osteoblasten, die 80 - 95 \% der Knochenoberfläche bedecken und diese schützen, werden endostal lining cells genannt. Sie nehmen eine wichtige Rolle bei der Osteoklastenaktivierung ein (Junqueira und Carneiro 2005; Lüllmann-Rauch 2009; Manolagas 2000). 


\section{Osteozyten}

In die Knochenmatrix eingeschlossene, morphologisch veränderte Osteoblasten nennt man Osteozyten. Sie liegen in linsenförmigen Lakunen und sind untereinander durch Canaliculi (Knochenkanälchen) verbunden. Sie besitzen zahlreiche Fortsätze, mit denen sie über die Canaliculi zu den benachbarten Osteozyten gap junctions für den Stoffaustausch ausbilden (Barragan-Adjemian et al. 2006; Lüllmann-Rauch 2009). Ihre Funktion ist noch nicht restlos erforscht, sie scheinen aber eine wichtige Rolle beim ständigen Umbau der Matrix einzunehmen. Außerdem sind sie entscheidend für die Aufrechterhaltung der Knochenhomöostase, indem sie beim Austausch organischer und anorganischer Stoffe zwischen der Knochenmatrix und den Blutgefäßen vermitteln (Junqueira und Carneiro 2005; Welsch 2003).

\section{Osteoklasten}

Osteoklasten gehören dem hämatopoetischen System an. Die Vorläuferzellen dieser mehrkernigen Riesenzellen entstammen dem monozytären Phagozytensystem und entstehen durch Fusion von bis zu 100 einkernigen Vorläufern. Sie übernehmen die Aufgabe der Knochenresorption, indem sie das Knochengewebe demineralisieren und die entstandenen Abbauprodukte resorbieren. Die knochenabbauende Aktivität wird über verschiedene Wachstumsfaktoren und Hormone (u.a. PTH, Östrogen, Leptin, Schilddrüsenhormone) beeinflusst (Junqueira und Carneiro 2005; Lüllmann-Rauch 2009; Welsch 2003).

\subsubsection{Knochenmatrix}

Die mineralisierte Substanz zwischen den Knochenzellen ist die Knochenmatrix. Sie setzt sich aus Kollagenfibrillen, Wasser und anorganischen Salzen zusammen, wobei der Salzgehalt ca. 60 \% ausmacht. Dieser besteht hauptsächlich aus Kalziumphoshat, das in Form von Hydroxylapatitkristallen an Kollagenfibrillen gelagert wird. Hydroxylapatitkristalle bestehen aus Kalzium-, Phosphat- und Hydroxyl-Ionen. 45 \% des Feuchtgewichts des Knochens ist auf diese zurückzuführen. Der organische Anteil der Knochenmatrix beläuft sich auf 35 \%. Er enthält zu ca. 95 \% Kollagen Typ I und zu ca. 5 \% Proteoglykane und Glykoproteine wie Osteocalcin und Sialoprotein. Interzellulär besteht die Knochenmatrix zu einem Viertel aus Wasser. Die Festigkeit des Knochens wird vor allem durch die 
anorganischen Bestandteile erreicht, während die Elastizität durch den kollagenen Anteil erzielt wird (Junqueira und Carneiro 2005; Lüllmann-Rauch 2009; Welsch 2003).

\subsubsection{Knochenumbau}

Der Knochen unterliegt in der Wachstumsphase bis zum Erreichen seiner endgültigen Form stetigen An- und Umbauphasen. Es erfolgt die Umwandlung von Geflechtknochen in Lamellenknochen, was auch modeling genannt wird. Um seine Funktionen den unterschiedlichen Belastungen anpassen zu können, finden im Knochen lebenslang Umbauprozesse statt. Dies bezeichnet man als remodeling (Manolagas 2000). Dadurch kann eine funktionelle Adaption an mechanische Beanspruchung, Erneuerung und die Aufrechterhaltung der Kalziumhomöostase gewährleistet werden. Besonders der spongiöse Anteil des Knochens weist durch sein großes Oberflächen/Volumen-Verhältnis eine hohe Umbaurate auf. Während im Rahmen des remodeling jährlich etwa 28 \% der Spongiosa erneuert werden, beträgt die Neubildungsrate in der Kortikalis lediglich $4 \%$. In der Kindheit und Pubertät findet überwiegend Knochenaufbau statt, so dass im Alter von 25 bis 30 Jahren ein Höchstwert der Knochendichte (peak bone mass) erreicht wird. In dieser Zeit übersteigt der Knochenaufbau den Knochenabbau. Dieser Prozess ist von endogenen und exogenen Faktoren abhängig. So spielen das genetische Potenzial, Hormone, Ernährung und die körperliche Aktivität eine große Rolle (Bartl 2011).

Nach Erreichen der peak bone mass nimmt diese über die folgenden Jahre kontinuierlich wieder ab, der Knochenabbau übersteigt den Knochenaufbau mit etwa 1 \% Knochenmasseverlust pro Jahr. Durch den Östrogenmangel bei postmenopausalen Frauen wird der Knochenabbau zusätzlich gefördert. Der Verlust der Knochenmasse kann dadurch auf bis zu 4 \% im Jahr ansteigen. Zwischen dem 40. und 70. Lebensjahr verlieren Frauen durchschnittlich 40 \% ihrer Knochenmasse. Je stärker die peak bone mass in Jugendzeiten aufgebaut wird, umso besser ist der Knochen im Alter vor Osteoporose geschützt. Denn dadurch kann die Knochendichte trotz des physiologischen Knochenverlustes länger oberhalb eines kritischen Schwellenwertes bleiben. 
Neben dem Substanzverlust kommt es bei zunehmendem Alter durch sich rarefizierende Verknüpfungspunkte in der Trabekelstruktur auch zu einer Modifikation der statischen Beschaffenheit des Knochens (Bartl 2011).

\subsubsection{Kalziumstoffwechsel}

Das Knochengewebe ist einer der wichtigsten Speicherorte für Mineralstoffe. So spielt es eine große Rolle bei der Aufrechterhaltung der Kalzium- und Phosphathomöostase. Da Kalziumphosphationen nur bedingt löslich sind, hängen beide Stoffwechsel direkt voneinander ab. Ändert sich die extrazelluläre Kalziumkonzentration, während die Phosphatkonzentration gleich bleibt, so kann es zum Ausfallen von Kalziumphosphat kommen. Zur Regulierung der Kalziumkonzentration im Blut werden verschiedene Hormone ausgeschüttet, wie z.B. PTH, Kalzitriol und Kalzitonin sind als wichtigste zu nennen. Zu einer Ausschüttung von PTH aus den Epithelkörperchen der Nebenschilddrüse kommt es bei einem Abfall der Kalziumkonzentration im Blut (Hypokalzämie). Dadurch werden verschiedene Mechanismen in Gang gesetzt, die zu einem Kalziumanstieg im Blut führen. PTH begünstigt die Osteoklastenaktivität. Dadurch kommt es zur vermehrten Knochenresorption und Kalzium und Phophat werden freigesetzt. An der Niere wirkt PTH hemmend auf die Kalziumausscheidung und fördernd auf die renale Phosphatelimination. Die Kalzitriolsynthese wird durch PTH und Hypokalzämie stimuliert. Aus Vitamin D3 wird durch verschiedene Hydroxylierungsvorgänge in Leber und Niere Kalzitriol $\left(1,25\left(\mathrm{OH}_{2}\right)\right.$-Vitamin D3) gebildet. Vitamin D3 wird entweder exogen über die Nahrung aufgenommen oder kann vom Körper synthetisiert werden, wobei es einer UV-Exposition der Haut bedarf. Im Darm stimuliert Kalzitriol die Kalzium- und Phophatresorption, im Knochen die Knochenresorption. In der Folge kommt es zu einem extrazellulären Anstieg der Konzentrationen von Kalzium und Phosphat. Über einen Rückkopplungsmechanismus wird die Ausschüttung von PTH gehemmt, zudem wird durch die angestiegenen Blutkonzentrationen eine Mineralisierung des Knochens gefördert. Zu einer Ausschüttung von Kalzitonin aus den C-Zellen der Schilddrüse kommt es bei Hyperkalzämie. Kalzitonin sorgt im Knochengewebe als Gegenspieler des PTH zu einem vermehrten Einbau von Kalziumionen, wodurch die Kalziumkonzentration im Blut gesenkt wird (Löffler und Petrides 2003; Lüllmann-Rauch 2009). 


\subsubsection{Frakturen}

\subsubsection{Definition}

Eine Fraktur ist eine akut auftretende Kontinuitätsunterbrechung des Knochens. Man unterscheidet eine physiologische (traumatische) Fraktur, durch eine akute äußere Gewalteinwirkung auftretend, von einer pathologischen Fraktur (Fragilitätsfraktur). Letztere tritt ohne ein vorausgegangenes adäquates Trauma auf. Dies ist zurückzuführen auf eine Vorschädigung des Knochengewebes, wie dies zum Beispiel im osteoporotischen Knochen der Fall ist. Eine dritte Form stellt die Ermüdungsfraktur dar. Hierbei führt die Summation von über einen längeren Zeitraum auftretenden Mikrotraumen zum Bruch des Knochengewebes (Bartl 2011).

\subsubsection{Frakturheilung}

Die Frakturheilung dient dem Ziel der strukturellen und funktionellen Rekonstruktion des Knochens in seinen ursprünglichen Zustand. Dies geschieht durch die Aktivierung unterschiedlicher komplexer Mechanismen. Hierbei spielen verschiedene Wachstumsfaktoren, Zytokine und der Kalzium-, PTH- und Vitamin-D-Stoffwechsel eine maßgebliche Rolle. Die Art der Heilung hängt von der Stellung und der Beweglichkeit der Frakturenden zu- bzw. gegeneinander ab. Sie erfolgt entweder primär oder sekundär.

\section{Primäre Frakturheilung}

Die primäre (direkte) Frakturheilung findet sich nur bei rigider Fixation, wodurch eine Kontaktheilung stattfinden kann. Hierfür müssen die Frakturenden direkt aufeinander liegen. Die Bildung von endostalem und periostalem Kallus mit anschließender Resorption bleibt aus. Liegen die Frakturenden direkt aufeinander, können die Havers’schen Systeme von einem Frakturfragment mit dem des anderen zusammenwachsen und es bildet sich direkt Lamellenknochen. Die Kontinuität des Knochens ist somit wiederhergestellt. Eine Sonderform stellt die Spaltheilung dar. Dabei wird ein interfragmentärer Bruchspalt von 0,5 mm ohne vorangegangene Entzündungs- und Granulationsphase direkt von Geflechtknochen überbrückt, der dann darauffolgend in Lamelllenknochen umgewandelt wird. Es bildet sich bei der primären Form der Frakturheilung anders als bei der indirekten Frakturüberbrückung direkt Knochen ohne vorherige Kallusbildung. In der Klinik lässt 
sich die primäre Frakturheilung bei Kompressionsosteosynthesen finden (Berchtold et al. 2008).

\section{Sekundäre Frakturheilung}

Sekundäre (indirekte) Frakturheilung findet bei einem breiten Frakturspalt, der durch ein Hämatom ausgefüllt wird, statt. Es erfolgt eine periostale, endostale und interfragmentäre Kallusbildung. Dabei wirken Mikrobewegungen der Frakturfragmente auf die Kallusbildung förderlich. Durch den sich bildenden Kallus wird die Beweglichkeit zunehmend eingeschränkt, so dass eine knöcherne Überbrückung des Frakturspalts erfolgen kann. Im Laufe des Heilungsprozesses vergrößern sich die Querschnittsfläche und die mechanische Festigkeit des Kallusgewebes. Bei instabilen Verhältnissen, also einem sehr großen Frakturspalt oder zu starker interfragmentärer Beweglichkeit, kann keine knöcherne Überbrückung und somit keine Heilung stattfinden. Es besteht die Gefahr der Entstehung einer Pseudarthrose (Welsch 2003).

Die sekundäre Frakturheilung verläuft in vier Phasen, die sich teilweise überschneiden:

a) Stadium I (Entzündungsphase):

In der ersten Phase entsteht durch Abriss von Blutgefäßen im Frakturspalt ein interfragmentäres Hämatom. Es kommt zum Einstrom von Granulozyten, Monozyten und Mastzellen. Eine verstärkte periostale Perfusion und Kapillaraussprossung unterstützt die Rekrutierung weiterer Zellen und versorgt diese mit Nährstoffen. Dies dauert bis zu vier Wochen.

b) Stadium II (Granulationsphase):

In den nächsten drei bis acht Wochen wird das Hämatom zunehmend durch Granulationsgewebe ersetzt. Durch die Synthese extrazellulärer Bestandteile durch Osteoblasten, Chondroblasten und Fibroblasten kommt es zu einer zunächst weichen Überbrückung des Interfragmentärspalts. Osteoklasten sorgen für den Abbau nekrotischen Knochenmaterials vorwiegend in der Nähe der Frakturenden.

c) Stadium III (Kallushärtung):

Durch eine Mineralisation des Granulationsgewebes entsteht Geflechtknochen. Dieser Vorgang dauert ca. sechs Wochen bis vier Monate. Diese Knochenneubildung geht von der 
endostalen und periostalen Kortikalis aus. Es bildet sich ein Fixationskallus, wodurch sich zwar die Beweglichkeit im Frakturspalt vermindert, der Knochen jedoch noch nicht mechanisch belastbar ist.

d) Stadium IV (modeling und remodeling):

Im weiteren Verlauf wird der Geflechtknochen in Lamellenknochen umgewandelt. Dabei wird die ursprüngliche Kontur des Knochens mitsamt dem Markraum wiederhergestellt. Dieser Vorgang dauert ca. drei bis 24 Monate. Der Ablauf einer sekundären Frakturheilung lässt sich z. B. nach Marknagelung oder konservativer Therapie mit Gipsverband beobachten (Rössler und Rüther 2007; Siewert 2012).

\subsection{Osteoporose}

\subsubsection{Definition}

Den aktuellen Leitlinien des Dachverbandes Osteologie (DVO) wird die Osteoporose wie folgt definiert:

„Die Osteoporose ist eine systemische Skeletterkrankung, die durch eine niedrige Knochenmasse und eine mikroarchitektonische Verschlechterung des Knochengewebes charakterisiert ist, mit einem konsekutiven Anstieg der Knochenfragilität und der Neigung zu Frakturen“ (Leitlinie Osteoporose 2009).

Hilfreicher für Diagnostik und Therapie ist die Definition der WHO, nach der eine osteoporotische Erkrankung dann vorliegt, wenn die Knochendichte mehr als 2,5 Standardabweichungen (SD) unterhalb eines statistischen Durchschnittswerts der Knochendichte prämenopausaler Frauen bzw. jüngerer Männer liegt. Dieser Wert wird als T-Score bezeichnet und anhand der Dual-X-Ray-Absorptiometrie (DXA) ermittelt. Bei einer Standardabweichung von -1 bis -2,5 liegt eine Osteopenie vor (WHO 1994). Kommt es neben einem T-Score von -2,5 zu dem Auftreten von Frakturen, liegt eine manifeste Osteoporose vor. 


\subsubsection{Pathophysiologie der Osteoporose}

Liegt bei den lebenslangen Umbauvorgängen (remodeling) ein Ungleichgewicht zwischen Knochenaufbau und -abbau zugunsten der Knochenresorption vor, so kann eine Osteopenie oder Osteoporose entstehen. Osteoporotische Veränderungen betreffen zunächst die Substantia spongiosa, da hier aufgrund des großen Oberflächen/VolumenVerhältnisses vermehrt Umbauvorgänge stattfinden. Die Kortikalis ist weniger anfällig für Störungen des Knochenstoffwechsels. Osteoporotische Veränderungen sind hier erst in der Folge erkennbar. Bei voranschreitender Kochenresorption kommt es in der Spongiosa zu Erosion, Perforation und teilweise zu Verlust der Trabekel (s. Abb. 2). Durch die Abnahme der Anzahl der Trabekel und deren Vernetzung kommt es zu einer Verschlechterung der Mikroarchitektur mit der Folge der erhöhten Knochenbrüchigkeit und der gesteigerten Anfälligkeit für Frakturen (Leitlinie Osteoporose 2009).

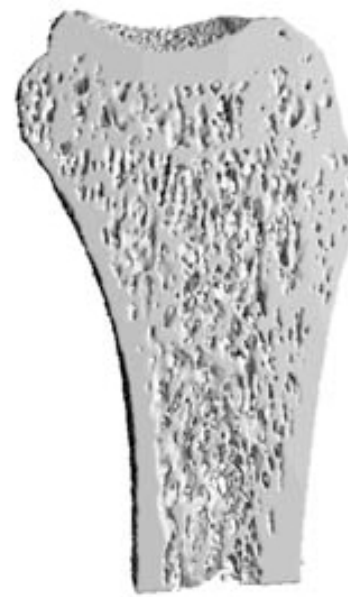

A

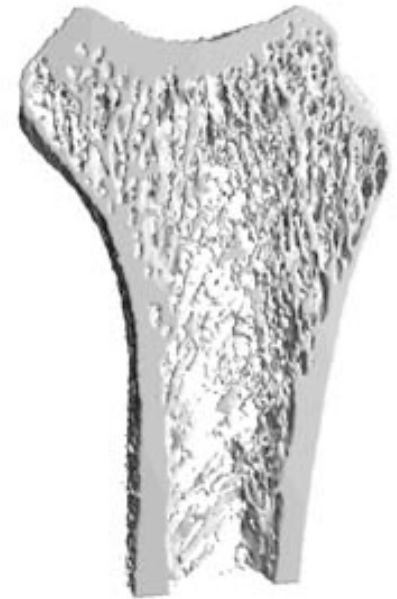

B

Abbildung 2: Darstellung der Trabekelstruktur im gesunden (A) und osteoporotischen (B) Knochen (www.scinexx.de)

$\mathrm{Zu}$ den wichtigsten pathogenetischen Faktoren bei der Entstehung der Osteoporose zählt der postmenopausal auftretende Östrogenmangel. Die gesteigerte Ausschüttung von Zytokinen (u.a. IL-1, IL-6, TNF-alpha) aus dem Knochenmark und den Knochenzellen führt zu einer vermehrten Osteoklastogenese und Aktivität der Osteoklasten sowie einer Verlängerung ihrer Lebenszeit (Manolagas 2000). Zusätzlich kommt es durch die Zytokine zu einer gesteigerten Osteoblastogenese (high-turnover-osteoporosis, postmenopausale 
Osteoporose), die Lebensdauer der Osteozyten und -blasten verkürzt sich jedoch. Somit resultiert das Hormondefizit hier in einer negativen Knochenbilanz durch eine gesteigerte Knochenresorption (Manolagas 2000).

Als Folge wird vermehrt Kalzium in den Extrazellulärraum freigesetzt und dadurch eine Hemmung der Ausschüttung bewirkt. Der gesunkene PTH-Spiegel führt einerseits zu einer gesteigerten Kalziumausscheidung in der Niere und andererseits zu einer Hemmung der Kalzitriolsynthese in der Schilddrüse. Durch den Mangel an Kalzitriol wird die Kalziumaufnahme im Darm gehemmt, was wiederum zu einer negativen Kalziumbilanz mit einhergehendem Knochenmasseverlust führt (Siegenthaler und Blum 2006).

$\mathrm{Zu}$ einer verminderten Kalzitriolsynthese und dem damit verbundenen Kalziummangel kann es auch allgemein im höheren Lebensalter durch einen Mangel an Vitamin D3 kommen. Dieses wird häufig bedingt durch eine Änderung der Lebensgewohnheiten, sowie durch verminderte Sonnenlichtexposition. Reaktiv kommt es zu einem leichten sekundären Hyperparathyroidismus mit nachfolgend erhöhter Knochenresorption mit Freisetzung von Kalzium (Siegenthaler und Blum 2006). Da im höheren Alter zusätzlich die Osteoblastogenese abnimmt, wird die negative Knochenbilanz noch weiter gefördert (low-turnover osteoporosis, senile Osteoporose).

\subsubsection{Epidemiologie und sozioökonomische Bedeutung}

Mit rund 200 Millionen Betroffenen ist die Osteoporose die weltweit am häufigsten auftretende metabolische Knochenerkrankung (Gardner et al. 2006; Lane 2006; Lin und Lane 2004). Im Jahr 2003 betrug die Prävalenz mit 7,8 Millionen erkrankten über 50Jährigen in der Bundesrepublik Deutschland 26 \%. Dabei waren Frauen mit einer Prävalenz von 39 \% im Vergleich zu Männern mit 9,7 \% weitaus häufiger betroffen (Häussler et al 2007). Die Inzidenz der postmenopausalen und senilen Osteoporose nimmt mit steigender Lebenserwartung $\mathrm{zu}$, ebenso die Zahl der osteoporotischen Frakturen. Schätzungen zufolge kommt es bei 30-50 \% aller postmenopausalen Frauen zu einer Osteoporose-assoziierten Fraktur (Randell et al. 1995). Durch die starke Beeinträchtigung der Gesundheit und Lebensqualität der betroffenen Menschen und die hohe finanzielle Belastung der Gesundheitssysteme stellt die Osteoporose mit ihren Folgen ein großes Problem auf sozialer und ökonomischer Ebene dar (Häussler et al. 2007). Hinzu kommt, 
dass durch den demographischen Wandel und die steigende Lebenserwartung in der Bevölkerung auch die senile Osteoporose beim Mann an klinischer Relevanz zunimmt (Cummings und Melton 2002).

\subsubsection{Einteilungsformen der Osteoporose}

\subsubsection{Einteilung nach Ätiologie}

Primäre und sekundäre Formen der Osteoporose werden nach ihrer Ätiologie eingeteilt:

Die primären oder idiopathischen Formen treten am häufigsten auf. Ihr Anteil beträgt etwa 95 \%. Hier ist die Bestimmung einer genauen Ursache für die Entstehung einer Osteoporose nicht möglich. Oft sind sie multifaktoriell bedingt. Es werden u.a. die idiopathische, juvenile, postmenopausale und senile Osteoporose $\mathrm{zu}$ den primären Osteoporosen gezählt.

$\mathrm{Zu}$ einer Manifestation der postmenopausalen Osteoporose (Typ-I-Osteoporose) kommt es ungefähr 10 bis 15 Jahre nach der Menopause. Etwa ein Drittel aller Frauen sind davon betroffen. Der postmenopausale Östrogenmangel führt zu einem Knochenmasseverlust im spongiösen Knochen, wobei besonders die Wirbelkörper, der distale Radius und das proximale Femur betroffen sind (Melton et al. 1993; Jones et al. 1994).

Bei Männern kommt es im Rahmen eines Testosteronmangels im höheren Alter ebenso zu einem gesteigerten Abbau der Spongiosa. Allerdings tritt diese Form bei Männern deutlich seltener auf.

Ab einem Alter von 70 Jahren spricht man per definitionem von seniler Osteoporose (Typ II). Durch eine generalisierte Knocheninvolution werden spongiöser und kortikaler Knochen gleichermaßen stark abgebaut. Ursächlich hierfür sind physiologische Altersprozesse, Bewegungsmangel und Kalzium- und/oder Vitamin D-Mangel. Im Vergleich zu Männern sind Frauen ca. doppelt so häufig betroffen (Bartl 2011).

Die Ätiologie ist bei sekundären Osteoporosen bekannt. So können Osteoporosen sekundär bei einer anderen Grunderkrankung (z.B. Morbus Cushing, Diabetes mellitus, Hyperthyreose, Plasmozytom) oder durch Einnahme bestimmter Medikamente (z.B. 
Cortisol) auftreten (s. Tab.1). Nur bei 5 \% der osteoporotischen Erkrankungen handelt es sich um die sekundäre Form.

Tabelle 1: Darstellung der möglichen Ursachen einer sekundären Osteoporose mit Beispielen für die entsprechende Grunderkrankung, modifiziert nach Classen et al. 2004

\begin{tabular}{|c|c|}
\hline Ursache & Grunderkrankung \\
\hline - endokrinologisch & $\begin{array}{ll}\text { - } & \text { Diabetes mellitus } \\
\text { - } & \text { Hyperthyreose } \\
\text { - } & \text { Morbus Cushing } \\
\text { - } & \text { Hyperparathyreoidismus } \\
\text { - } & \text { Hypogonadismus }\end{array}$ \\
\hline - neoplastisch & $\begin{array}{ll}\text { - } & \text { Non-Hogkin-Lymphom } \\
\text { - } & \text { Plasmozytom } \\
\text { - } & \text { Diffuse Knochenmarkskarzinose }\end{array}$ \\
\hline • hereditär & $\begin{array}{ll}\text { - } & \text { Marfan-Syndrom } \\
\text { - } & \text { Ehrlers-Danlos-Syndrom } \\
\text { - } & \text { Osteogenesis imperfecta } \\
\text { - } & \text { Turner-Syndrom }\end{array}$ \\
\hline - pharmakologisch & $\begin{array}{ll}\text { - } & \text { Glukokortikoide } \\
\text { - } & \text { Antikoagulanzien }\end{array}$ \\
\hline - gastrointestinal & $\begin{array}{l}\text { - } \text { Morbus Crohn } \\
\text { - } \quad \text { Pankreasinsuffizienz } \\
\text { - } \quad \text { Primär biliäre Zirrhose } \\
\text { - } \quad \text { Sprue }\end{array}$ \\
\hline - rheumatologisch & - Chronische Polyarthritis \\
\hline - nephrologisch & - $\quad$ Chronische Niereninsuffizienz \\
\hline
\end{tabular}

\subsubsection{Einteilung nach Dynamik der pathophysiologischen Vorgänge}

Kommt es zur Osteoporose durch gesteigerten Knochenumbau handelt es sich um eine high-turnover-osteoporosis. Dabei ist die Osteoklastenaktivität gegenüber der normalen 
Osteoblastenaktivität erhöht. Durch die stattfindende fast-loser-Situation verliert der Betroffene über 3,5 \% seiner trabekulären Knochenmasse pro Jahr. Typisch ist das Auftreten bei der frühen postmenopausalen Osteoporose (bis ca. zehn Jahre nach der Menopause). Eine Low-turnover-ostoporosis entsteht durch verminderten Knochenumbau bei normaler Osteoklastenaktivität. Diese slow-loser-Situation tritt bei der späten postmenopausalen und der senilen Osteoporose auf (Herold 2009).

Bei der Auswahl der medikamentösen Therapie ist es von großer Relevanz den metabolischen Mechanismus zu kennen. Man wendet entsprechend der Ursache des Substanzverlustes ein antiresorptiv oder ein osteoanabol wirkendes Medikament an (Bartl 2011) (s. Kapitel 1.3.8.2).

\subsubsection{Einteilung nach Ausmaß}

Je nachdem, ob das gesamte Skelett von osteoporotischen Veränderungen befallen ist oder nur teilweise, kann man zwischen einer generalisiert (systemisch) oder lokalisiert (fokal) auftretenden Osteoporose unterscheiden. Beim Morbus Sudeck, der rheumatoiden Arthritis und bei der Inaktivitätsosteoporose, z.B. bei Verletzungen, treten die Veränderungen fokal auf. Ein systemischer Befall findet sich bei der postmenopausalen (Typ I) und der senilen (Typ II) Form. Dabei ist das gesamte Skelett nicht homogen betroffen ist, sondern v.a. Prädilektionsstellen wie Wirbelkörper, Schenkelhals und distaler Radius (Bartl 2011).

\subsubsection{Risikofaktoren}

Die bedeutendsten Risikofaktoren für das Entstehen einer Osteoporose finden sich in Tabelle 2:

Tabelle 2: Darstellung der bedeutendsten nicht-modifizierbaren und modifizierbaren Risikofaktoren für die Entstehung einer Osteoporose (Leitlinie Osteoporose 2009)

\begin{tabular}{|l|l|}
\hline Nicht-modifizierbare Risiken & Modifizierbare Risiken \\
\hline Genetische Prädisposition & BMI $<20$ \\
\hline Alter & Körperliche Inaktivität/Immobilität \\
\hline Weibliches Geschlecht & Kalzium- und/oder Vitamin D-Mangel \\
\hline & Nikotinkonsum \\
\hline
\end{tabular}




\subsubsection{Osteoporose-induzierte Frakturen}

Klinisch manifestiert sich eine Osteoporose in der Regel erst durch das Auftreten von Frakturen (Kubo et al. 1999; Hao et al. 2007). Der präklinische Substanzverlust des Knochens geht meist schleichend und ohne Symptome einher. Deshalb bleibt eine Osteoporose meist unbemerkt bis die erste Fraktur auftritt. Die Haupmanifestationsorte sind v.a. die Wirbelkörper, der Schenkelhals, das proximale Femur und der distale Radius. Nach Vollendung des 50. Lebensjahres beträgt das Risiko für das Auftreten Osteoporosebedingter Frakturen bei Frauen 40 \% und bei Männern 13 \% (Melton et al. 1992). Das Risiko für eine Zweitfraktur erhöht sich um ca. 86 \% (Kanis et al. 2004). Wie schon im vorangegangenen Teil erwähnt, zeigt der osteoporotische Knochen eine schlechte Regenerationsfähigkeit. Die Frakturheilung ist in qualitativer und quantitativer Hinsicht um ca. $30 \%$ beeinträchtigt (Lill et al. 2002 a,b). In früheren experimentellen Untersuchungen am Femurschaft ovarektomierter Ratten konnte man einen um 40 \% größengeminderten Kallusquerschnitt und eine um 23 \% reduzierte BMD im Stadium I (Woche 1-3) der Frakturheilung messen. Auch zeigte der Kallus deutlich schlechtere Eigenschaften im biomechanischen Test. Die Elastizität der Frakturüberbrückung zeigte sich im biomechanischen Test deutlich verringert (Namkung-Matthai et al. 2001). In den späteren Heilungsphasen konnte man ebenfalls eine geringere Stabilität und Elastizität und einen niedrigeren BMD der Frakturüberbrückung nachweisen. Es wird angenommen, dass die beeinträchtigte Regeneration durch eine erhöhte Aktivität der Osteoklasten und eine langsamere Mineralisierung bedingt wird (Wang et al. 2005).

\subsubsection{Diagnostik}

Nach Empfehlung des DVO setzt sich die Basisdiagnostik der Osteoporose aus Anamnese, klinischer Untersuchung, DXA-Knochendichtemessung, konventioneller Röntgenuntersuchung der Brust- und Lendenwirbelsäule und Labordiagnostik zusammen (Leitlinie Osteoporose 2009). Eine gezielte Diagnostik ist von entscheidender Wichtigkeit für die frühzeitige therapeutische Intervention und trägt somit insbesondere zur Prävention von pathologischen Frakturen bei. Ein 10-Jahres-Frakturrisiko lässt sich durch die klinischen Risikofaktoren abschätzen. Es dient der Indikationsstellung zur Durchführung der Basisdiagnostik. Dies gilt ab einem Risiko von $20 \%$. 


\subsubsection{Anamnese}

Den ersten wichtigen Schritt in der Osteoporosediagnostik stellt die sorgfältige Anamnese dar. Sie liefert Informationen zu aktuellen Beschwerden (Schmerzen und Funktionseinschränkungen), vorliegenden Risikofaktoren, Vorerkrankungen und eingenommenen Medikamenten. Zusätzlich sollte nach Ernährungsgewohnheiten, der körperlichen Aktivität, Veränderungen des Gewichts und der Körpergröße sowie nach dem Alter und nach bereits abgelaufenen Stürzen und Frakturen gefragt werden. Eine gründliche Anamnese erleichtert eine gezielte weiterführende Diagnostik und kann zur Unterscheidung zwischen primärer und sekundärer Osteoporose erste Hinweise liefern (Leitlinie Osteoporose 2009).

\subsubsection{Klinische Untersuchung}

Im Mittelpunkt der klinischen Untersuchung steht die Erhebung von bereits eingetretenen pathologischen Veränderungen als Folge von Wirbelkörperfrakturen. Dafür kann die Untersuchung auf Größenverlust, Körperhaltung, Wirbelsäulenklopfschmerz, Bewegungseinschränkung und Verhärtungen der Muskulatur wegweisend sein. Es kommt bei fortgeschrittener Osteoporose $\mathrm{zu}$ einer merklichen Größenabnahme. Eine Hyperkyphosierung der Brustwirbelsäule („Witwenbuckel“) kommt durch Sinterungs- und Kopressionsfrakturen der Wirbelkörper zustande. Durch eine Höhenminderung der Wirbelsäule von mehr als $4 \mathrm{~cm}$ zeigen sich typischerweise Hautfalten im unteren Bereich des Rückens. Diese verlaufen von kraniomedial nach kaudolateral und werden als „Tannenbaumphänomen“ bezeichnet (Leitlinie Osteoporose 2009). Um die Koordination und die Muskelkraft einzuschätzen und damit eine Sturzneigung zu erkennen, bieten sich der „Timed up-and-go-Test“ (Podsiadlo und Richardson 1991) oder der „Chair-risingTest“ (Guralnik et al.1995) an.

\subsubsection{Konventionelle Röntgenuntersuchung}

Das konventionelle Röntgen dient in der Osteoporosediagnostik der Entdeckung und Verlaufskontrolle von Wirbelkörperfrakturen und ist hilfreich bei der Abgrenzung möglicher Differentialdiagnosen. So lassen sich beispielsweise Osteomalazie, degenerativentzündliche Gelenkveränderungen oder Knochenläsionen auf dem Boden maligner Prozesse feststellen. Da sich eine Substanzabnahme im Knochen erst bei einem Verlust 
von 30-40 \% im Röntgenbild darstellt, ist dieses Bildgebungsverfahren nicht zur Frühdiagnostik geeignet (Leitlinie Osteoporose 2009). Bei fortgeschrittener Osteoporose werden im Röntgenbild charakteristische Wirbelkörperdeformierungen sichtbar. Dazu gehört die Entwicklung von sogenannten Fisch-, Keil- und Plattwirbeln aufgrund von Sinterungsfrakturen und Grund- und Deckplatteneinbrüchen. Durch den trabekulären Knochenschwund bei erhaltener Kortikalis imponiert der innen weniger röntgendichte Wirbelkörper im Röntgenbild als „Rahmenwirbel“ (Bartl 2011).

\subsubsection{Osteodensitometrie}

Osteodensitometrie dient als Oberbegriff für verschiedene Verfahren zur Bestimmung von Mineralgehalt (bone mineral content; $\mathrm{BMC}$; in g) und Mineraldichte (bone mineral density; BMD; in $\mathrm{g} / \mathrm{cm}^{2}$ oder $\mathrm{g} / \mathrm{cm}^{3}$ ) des Knochens. Diese finden Anwendung in der Frühdiagnostik und Verlaufskontrolle.

So lässt sich mithilfe der gemessenen Knochendichte das bestehende Frakturrisiko abschätzen. Es zeigte sich in verschiedenen Untersuchungen, dass eine abnehmende Dichte das Auftreten einer osteoporotischen Fraktur unabhängig von anderen Risikofaktoren erhöht. Folgende Verfahren zählen zur Osteodensitometrie:

- Röntgenabsorptiometrie (Dual-X-Ray-Absorptiometrie)

- Quantitative Computertomographie

- Quantitative Ultrasonographie

- Mikro-Computertomographie

Dual-X-Ray-Absorptiometrie (DXA)

Die DXA wird als Goldstandard zur Bestimmung der Knochendichte genutzt (Gardner et al. 2006) und dient als Grundlage zur Definition und zur Stadieneinteilung der Osteoporose, sowie zur Verlaufskontrolle. Diese Methode ist bei einer geringen Strahlenbelastung kostengünstig, schnell und nicht invasiv. Gemessen wird vornehmlich das proximale Femur und die Lendenwirbelkörper L1 bis L4.

\section{Quantitative Computertomographie (QCT)}

Eine Alternative zur DXA-Methode ist die quantitative Computertomographie (QCT). Mit ihr ist es möglich, das Volumen der Knochendichte in mg Kalziumhydroxylapatit $/ \mathrm{cm}^{3} \mathrm{zu}$ bestimmen. Weiterhin ermöglicht sie die separate Beurteilung von Kortikalis und 
trabekulärem Knochen. Dabei dient der trabekuläre Anteil der Lendenwirbelsäule (LWS) als Standardmessort (Stammosteoporose), da hier vermehrt Umbauvorgänge stattfinden. Der Lumbalwirbelkörper unterliegt einer großen Umbaudynamik, die bei Osteoporose frühzeitig Veränderungen der BMD aufweist. Einen weiteren standardisierten Messort stellt in der Klinik der Schenkelhals (periphere Osteoporose) dar. Für die Untersuchung verwendet man einen konventionellen klinischen Ganzkörpertomographen, welcher zuvor mit einem Hydroxylapatit-Referenzphantom kalibriert worden sein muss (Link und Majumdar 2003). Im Vergleich zur DXA bietet die Computertomographie die Möglichkeit der exakten dreidimensionalen Lokalisation des Messvolumens und dessen isolierte Erfassung ohne Überlagerung des umliegenden Gewebes. Nachteilig jedoch wirken sich die wesentlich größere Strahlenbelastung, die höheren Kosten und die längere Untersuchungszeit aus, weshalb dieses Mittel in der Regel weitaus weniger eingesetzt wird. Insbesondere niedergelassene Ärzte haben oft keinen direkten Zugang zu einem CTScanner. So wird dieses Verfahren vorwiegend bei speziellen Fragestellungen und zur alternativen Diagnostik bei nicht eindeutigen DXA-Ergebnissen angewandt (Leitlinie Osteoporose 2009).

\section{Quantitative Ultrasonographie (QUS)}

Ein weiteres nichtinvasives Verfahren zur Osteodensitometrie stellt die quantitative Ultrasonographie (QUS) dar. Vorteilhaft sind hierbei die fehlende Strahlenbelastung, sowie die schnelle, unkomplizierte Handhabung durch transportable Geräte und geringe Kosten. Periphere Knochen wie Radius, Kalkaneus, Tibia und Phalangen lassen sich gut untersuchen. Durch den ähnlichen strukturellen Aufbau des Kalkaneus zur Wirbelsäule wird dieser als Standardmessort gewählt. In mehreren Studien konnte gezeigt werden, dass das Frakturrisiko bei postmenopausalen Frauen durch Einsatz der QUS abgeschätzt werden kann. So hat diese Methode ihren Platz im Screening. Jedoch lässt sich mit ihr keine Osteoporose diagnostizieren. Zum einen, weil im Kalkaneus Osteoporose sehr selten auftritt und die häufiger von Osteoporose betroffenen Skelettanteile, wie Wirbelsäule, Schenkelhals und Femur nicht direkt beurteilt werden können und zum anderen, weil es bisher keine Möglichkeit der Standardisierung und Qualitätssicherung gibt (Pallamar und Friedrich 2005). Dadurch sollte bei Verdacht auf eine Osteoporose in der QUSUntersuchung eine weitere Abklärung mittels DXA erfolgen (Leitlinie Osteoporose 2009). 


\section{Mikro-Computertomographie $(\mu C T)$}

Zu den neueren, hochauflösenden Verfahren zählt die Mikro-Computertomographie ( $\mu \mathrm{CT}$ ). Durch die hohe Auflösung von 10-100 $\mu$ m lässt sich die dreidimensionale Mikrostruktur des Knochens durch Darstellung der Trabekelanordnungen bestimmen, gleichzeitig kommt es zu einer deutlich höheren Strahlenbelastung als durch die konventionelle CT. Entsprechend findet die $\mu \mathrm{CT}$ bislang nur zur Untersuchung von kleinen Tieren sowie für Knochenstanzbiopsien Anwendung (Kalpakcioglu et al. 2008). Es bestehen jedoch signifikante Korrelationen $(\mathrm{p}<0,0001)$ zwischen den Resultaten der histologischen Untersuchung und der $\mu \mathrm{CT}$ von Knochenbiopsien des menschlichen Beckenkamms, wie in vergangenen Studien belegt werden konnte (Muller et al. 1998).

\subsubsection{Laborchemische Untersuchung}

Da bei der primären Osteoporose die üblichen Laborparameter in der Regel im Normbereich liegen, hat die Labordiagnostik eher eine Bedeutung in der Aufdeckung sekundärer Osteoporosen (Bartl 2011). Laut aktueller DVO-Leitlinie wird die Durchführung eines Basislabors empfohlen. Dies gilt vor allem bei anamnestischen Auffälligkeiten, wie beispielsweise Frakturen nach Bagatelltraumen und einem T-Score < 2 (DXA) (Leitlinie Osteoporose 2009). Neben den Parametern des Basislabors gibt es verschiedene Marker um den Knochenstoffwechsel zu beurteilen. So sprechen beispielsweise erhöhte Werte knochenspezifischer Alkalischer Phosphatase und Osteocalcin für eine gesteigerte Osteoblastenaktivität und damit eine erhöhte Knochensynthese. Lassen sich vermehrt Desoxypyridinolin, Pyridinolin, C- und Nterminales Telopeptid im Blut messen, gilt dies als Hinweis auf eine erhöhte Knochenresorption. Ebenfalls kann man mittels dieser Marker zwischen high- und lowturnover-Osteoporose unterscheiden und die Krankheitsaktivität beurteilen (Garnero und Delmas 2004; Seibel 2003).

Es liegen mehrere Studien vor, in denen eine Beziehung zwischen dem Knochenstoffwechsel und dem Risiko einer osteoporotischen Fraktur aufgezeigt werden konnte (Meier et al. 2005). 


\subsubsection{Therapie}

\subsubsection{Prävention und Basistherapie}

Maßnahmen zur Prävention zielen darauf ab, bei Menschen mit erkennbarem Risiko das spätere Auftreten einer Osteoporose zu minimieren. Dabei handelt es sich um Kriterien, die die Ausbildung der Knochendichte beeinflussen, wie etwa die Ernährung, die körperliche Aktivität, das Körpergewicht, das Geschlecht und genetische Faktoren. Die körperlichen Aktivitäten betreffend, handelt es sich im Jugendalter um sogenannte highimpact-Sportarten wie beispielsweise Judo, Tennis, Squash oder Step-Aerobic. So können diese bei Ausübung im Alter von sechs bis zwölf Jahren bei Mädchen zu überdurchschnittlichen Knochenzuwachsraten führen (Kannus et al. 1995).

Im höheren Alter zählen zur Prävention Maßnahmen zur Sturz- und Frakturprophylaxe. Diese schließen Programme zur Erhebung des Sturzrisikos und der Sturzprophylaxe mit ein (Gillespie et al. 2003, 2009 u. 2012). Eine Empfehlung zur Basistherapie und Prävention laut DVO-Leitlinie ist eine ausreichende Zufuhr von Vitamin D und Kalzium. Wird eine Tagesdosis von 1200 - 1500 mg Kalzium und eine tägliche Sonnenlichtsexposition nicht erreicht, so kann man von einer Unterversorgung ausgehen. Eine osteoprotektive Wirkung ist bei Kombinationstherapie aus Kalzium und Vitamin D bei Frauen ab dem 45. Lebensjahr bewiesen (Di Daniele et al 2004). Für eine frühe Mobilisierung nach osteoporotischen Frakturen wird laut der DVO-Leitlinie additional zu Rehabilitationsmaßnahmen, Physiotherapie, psychosozialer Betreuung und antiosteoporotischer Pharmakotherapie eine Schmerztherapie nach dem WHO-Stufenschema angeraten. Hier ist auf die Wahl des Medikaments zu achten, da es u.a. durch nichtsteriodale Antirheumatika wie Ibuprofen, Indometacin und Diclofenac zu einer osteoblastenhemmmenden Wirkung kommen kann (Krischak et al. 2007).

\subsubsection{Medikamentöse Osteoporosetherapie}

Eine Indikation für die medikamentöse Therapie liegt vor, wenn das erwartete 10Jahresrisiko für Wirbelkörper- und Femurfrakturen anhand von vorliegenden epidemiologischen Daten über 30 \% beträgt und die T-Werte der DXA an mindestens einer dieser Lokalisationen vermindert sind (Leitlinie Osteoporose 2009). Unabhängig von 
Geschlecht und Alter sollte dann mit einer medikamentösen Therapie begonnen werden. Dies gilt auch für Patienten, die täglich mehr als 7,5 mg Prednisolonäquivalent für länger als drei Monate in Kombination mit einem DXA T-Wert $\leq-1,5$ einnehmen. Eine Reduktion des Frakturrisikos um 30 - 40 \% mittels einer spezifischen medikamentösen Therapie wird bei DXA T-Werten $<-2$ erreicht. Um eine osteoporotische Fraktur bei einem Patienten zu verhindern, müssen 15 behandelt werden (number needed to treat von 15). Dementsprechend kann die Knochendichtemessung mittels DXA nicht nur ein Bild über das Ausmaß der osteoporotisch bedingten Knochenschädigung darstellen, sondern auch Auskunft über die Erfolgsaussichten einer medikamentösen Therapie liefern. Liegen additional Risikofaktoren wie eine stattgefundene periphere Fraktur nach Bagatelltrauma oder eine positive Familienanamnese für proximale Femurfrakturen, Nikotinkonsum, Gangunsicherheit sowie Immobilität vor, sollte eine Therapie früher begonnen werden.

In der medikamentösen Osteoporoseprophylaxe und -therapie lassen sich zwei Gruppen an antiosteoporotischen Substanzen bezüglich ihrer Wirkweise unterteilen. So vermindern die antiresorptiven Substanzen bei insgesamt positiver Knochenbilanz den Knochenumbau und die Knochenresorption im Rahmen des remodelings. Eine signifikante Reduktion des Frakturrisikos um 50 - 60 \% im Vergleich zur Kontrollgruppe wird selten überschritten. In diese Gruppe fallen Bisphosphonate, Kalzitonin, Kalzium und Vitamin D.

Die zweite Gruppe wird von den osteoanabolen Substanzen gebildet. Ihre Wirkweise beruht in erster Linie auf der Aktivierung der Osteoblasten und Stromazellen und damit der Stimulation des Knochenumbaus. In der Folge kommt es zu einer Zunahme der Knochenmasse und Knochenfestigkeit, wodurch das Risiko für das Auftreten von Frakturen vermindert wird. In diese Substanzgruppe fallen die Fluoride und das Strontium. Allerdings kommt es durch die Wirkung von Fluoriden zwar zu einer Erhöhung der Knochenmasse, während der sich neu bildende Knochen keine ausreichende Belastbarkeit gegenüber mechanischer Belastung aufweist (Bartl 2011). Unter Östrogeneinfluss ließ sich in aktuelleren Studien eine knochenaufbauende Wirkung feststellen. In einem Forschungsprojekt von Stürmer et al. (2010 a) konnte man den Frakturheilungsprozess der osteoporotischen Tibiae ovarektomierter Ratten unter Einfluss von Östrogen annähernd auf die gleiche Stufe der Frakturheilung gesunder Versuchstiere anheben (Stürmer et al. 2010 a). 


\subsubsection{Hormonersatztherapie (HRT)}

Als eine der bedeutendsten Ursachen für das Auftreten einer Osteoporose bei Frauen gilt der postmenopausale Östrogenmangel. Dieser sinkt schon einige Jahre vor der Menopause, wodurch es kontinuierlich zu einem Verlust von Knochenmasse kommt. Je nach genetischer Prädisposition und Risikofaktoren kommt es unbehandelt nach der Menopause zu einem jährlichen Verlust von Knochensubstanz von bis zu 4 \%.

Nach Bekanntwerden des Einflusses von Sexualhormonen auf die Synthese von Zytokinen und Wachstumshormonen im Gewebe des Knochens wurden verschiedene Studien, u.a. die amerikanische „Women’s Health Initiative“ (WHI) (Rossouw et al. 2002) und die britische „Million Women Study“ (Beral 2003), konzipiert. Dafür analysierte die WHI zwischen 1993 und 1998 an 161.809 postmenopausalen Frauen mit intaktem Uterus in einem randomisierten Verfahren die Wirkung von Östrogen, Östrogen in Kombination mit Progesteron und von Placebos. 2002 erstmals veröffentliche Ergebnisse zeigten, dass bei beiden HRT-Kollektiven signifikant weniger Frakturereignisse resultierten als in der Placebo-Kontrollgruppe. Gleichzeitig kam es im Östrogen-Progesteron-Kollektiv zu einem deutlichem Anstieg des relativen Risikos für Mammakarzinome, Lungenembolie, Apoplex und koronare Herzkrankheit. Als Folge wurde die Studie nach 5,2 Jahren vorzeitig abgebrochen, obwohl ursprünglich 8,5 Jahre eingeplant waren (Rossouw et al. 2002). Die alleinige Gabe von Östrogen wurde ebenfalls vorzeitig nach 6,8 Jahren abgebrochen, da es zu einer Häufung des Auftretens von Apoplexen kam (Anderson et al. 2004). In der „Million Women Study“ wurden zwischen 1996 und 2001 1.084.110 Frauen im Alter von 50 bis 64 Jahren zur HRT befragt, von denen etwa die Hälfte zum Befragungszeitpunkt oder in der Vergangenheit Hormone einnahmen. Die im August 2003 publizierten Resultate ergaben ähnlich den Ergebnissen der WHI eine Erhöhung des relativen Risikos, an einem Mammakarzinom zu erkranken oder zu versterben. Dies war am ausgeprägtesten bei Frauen, die ein Kombinationspräparat aus Östrogen und Progesteron eingenommen hatten (Beral 2003).

Den neu gewonnenen Erkenntnissen zufolge werden Östrogene im Rahmen der HRT lediglich noch in wenigen Ausnahmefällen zur Behandlung klimakterischer Beschwerden und postmenopausaler Osteoporose eingesetzt. Dies sollte dann in enger Zusammenarbeit mit dem behandelnden Gynäkologen erfolgen. 


\subsubsection{4 Östrogen-Rezeptor-Agonisten/Antagonisten (SERMs)}

Östrogen-Rezeptor-Agonisten/Antagonisten („Selective Estrogen Receptor Modulators“, SERMs) zählen nicht zu den Steroidhormonen. Sie haben aber die Fähigkeit an den Östrogenrezeptoren ER- $\alpha$ und ER- $\beta$ zu binden und dadurch, ähnlich dem Östrogen, gewebsspezifisch agonistisch oder antagonistisch zu wirken. Im Knochengewebe wirkt das umfassend untersuchte Raloxifen als Östrogenagonist. Gleichzeitig zeigt es keinen Effekt an Mamma oder Uterus. Den Nachweis der positiven Wirkung des Raloxifens auf den Knochen lieferten die Ergebnisse einer randomisierten, Placebo-kontrollierten-Phase-IIIStudie mit 7705 postmenopausalen Osteoporosepatientinnen („Multiple Outcomes of Raloxifene Evaluation“, MORE). Die Probandinnen erhielten täglich 60 mg Raloxifen, woraufhin eine erhöhte Knochendichte am Femur und an der Wirbelsäule nachgewiesen werden konnte. Das Frakturrisiko für Wirbelkörper konnte dadurch auf annähernd die Hälfte im Vergleich zur Placebo-Gruppe gesenkt werden. Das Frakturrisiko an extravertebralen Knochen wurde nicht signifikant gesenkt, jedoch verminderte sich das Risiko an einem Mammakarzinom zu erkranken um 54 - 74 \% (Ettinger et al. 1999).

\subsubsection{Bisphoshonate}

Vor 30 Jahren kam es durch die Entdeckung der Bisphosphonate und deren Effekt am Knochen zu einem Wandel im Hinblick auf die Behandlung von Knochenkrankheiten. Bisphosphonate wirken durch Anreicherung auf der Knochenoberfläche, indem sie Osteoklasten hemmen und inaktive Osteoblasten mobilisieren. Folglich kommt es zu einer Hemmung der Knochenresorption und zu einer positiven Knochenbilanz. Bisphosphonate werden analog ihrer Wirkweise zu den antiresorptiven Substanzen gezählt. Man kann sie anhand ihrer Stickstoffhaltigkeit in stickstoffhaltig und nicht-stickstoffhaltig unterteilen. Im Hinblick auf die Behandlung der Osteoporose spielen die Stickstoffhaltigen eine größere Rolle, da diese eine höhere Potenz aufweisen. Durch verschiedene klinische Studien zu der Wirkung des Aminobisphosphonats Alendronat an über 17.000 Patienten konnte dessen Wirksamkeit bewiesen werden. So zeigte ein Kollektiv von 6459 postmenopausalen Frauen zwischen 55 und 81 Jahren in der „Fracture Intervention Trial“ (FIT) bzw. der „Fracture Intervention Trial Long-term Extension“ (FLEX) ein deutlich geringeres relatives Risiko für das Auftreten von Wirbel-, Hüft-, und Handgelenksfrakturen nach einer drei- bis vier-jährigen täglichen Gabe von Alendronat im Vergleich zum 
Placebo-Kollektiv (Black et al. 2000). Wurde die Alendronateinnahme nach fünf Jahren abgebrochen, so fand sich bei diesen Probandinnen im Vergleich zu dem Kollektiv, welches die Behandlung für weitere fünf Jahre fortführte, eine leicht verminderte BMD, das Frakturrisiko unterschied sich jedoch nicht (Black et al. 2006). Alendronat weist eine gute Verträglichkeit auf, im Vergleich mit der Placebogruppe kam es zu keinen unerwünschten Arzneimittelwirkungen.

Ebenfalls anhand von großen internationalen klinischen Studien erforscht ist das Bisphoshonat Risedronat. Durch die tägliche Einnahme von $5 \mathrm{mg}$ Risedronat über drei Jahre Studiendauer verringerte sich das Auftreten von Wirbelfrakturen nachweislich um 41 \%. Dies wurde von der VERT-Gruppe („Vertebral Efficacy with Risedronate Therapy“) in einer randomisierten, doppelblinden, Placebo-kontrollierten Studie an 2458 postmenopausalen Frauen unter 85 Jahren nachgewiesen (Harris et al. 1999). Auch konnte durch weitere Studien durch eine Einnahmedauer von Risedronat über sechs Monate ein signifikantes Absinken des Risikos für Wirbelfrakturen bei postmenopausalen Patientinnen gezeigt werden (Roux et al. 2004).

\subsubsection{Strontium-Ranelat (SR)}

Auf dem deutschen Markt zugelassen seit 2004, zählt Strontium-Ranelat (SR) zu den neueren Substanzen in der Behandlung der postmenopausalen Osteoporose. Es stammt aus der Gruppe der Erdalkalimetalle, besitzt knochenaffine Eigenschaften und verhält sich chemisch ähnlich dem Kalzium. Durch eine Steigerung der Differenzierung der Präosteoblasten und der Kollagensynthese in Osteoblasten, sowie eine gleichzeitige Hemmung der Osteoklasten und deren Vorläuferzellen wirkt es osteoanabol sowie antiresorptiv (Reginster et al. 2005).

Über eine Zeitspanne von drei Jahren nahmen 1649 an postmenopausaler Osteoporose leidende Patientinnen im Rahmen der SOTI-Studie („Spinal Osteoporosis Therapeutic Intervention“) täglich einen Placebo oder 2 g SR ein. Im Verlauf der Studien kam es in dem Placebo-Kollektiv zu wesentlich mehr Wirbelkörperfrakturen. Des Weiteren hatte sich die Knochendichte nach Einnahme von SR nach den drei Jahren um 8,3 \% am Schenkelhals und um 14,4 \% an der LWS erhöht (Meunier et al. 2004). 
Ferner konnte die TROPOS-Studie („Treatment of Peripheral Osteoporosis“) eine Minderung des Risikos für nicht-vertebrale Frakturen nach SR-Gabe belegen. Dafür erhielten 5091 postmenopausale Osteoporosepatientinnen fünf Jahre lang entweder täglich 2 g SR oder einen Placebo. Beim SR-Kollektiv der etwa 2714 Probandinnen ohne vorzeitigen Abbruch reduzierte sich das Risiko für extra-vertebrale Frakturen im Vergleich zur Placebo-Gruppe um 15 \% (Reginster et al. 2008).

\subsubsection{Parathormon (PTH)}

Das in der Nebenschilddrüse synthetisierte PTH wird bei einem Absinken des extrazellulären Kalziumspiegels ins Blut freigesetzt. Hier sorgt es durch eine vermehrte Kalziummobilisierung aus dem Knochen und eine erhöhte Kalziumrückresorption in der Niere zu einem Ansteigen des Kalziumspiegels. Gleichzeitig wird die Kalzitriolsynthese angekurbelt und die Phosphatausscheidung in der Niere erhöht. Erfolgt die PTHApplikation pulsatil, so zeigt sich eine osteoanabole Wirkung. Bei kontinuierlicher Gabe können Osteolysen auftreten (Canalis et al. 2007; Gao et al. 2008).

Der osteoanabole Effekt des Parathormons konnte in einer Studie an 1637 postmenopausalen Osteoporosepatientinnen nachgewiesen werden. Hierfür wurde das rekombinante humane Parathormonfragment 1-34 (Teriparatid, rhPTH 1-34) pulsatil über 21 Tage appliziert. Die Probandinnen wurden in eine Placebo-Gruppe und zwei Gruppen mit rhPTH 1-34-Applikation eingeteilt, welche jeweils 20 oder $40 \mu$ g rhPTH 1-34 subkutan erhielten. Die Aufteilung erfolgte randomisiert. Nach 21 Tagen sank die Zahl neuer Wirbelkörperfrakturen um 65 \%, gleichzeitig erhöhte sich die Knochendichte um 9 \% an der LWS und um $3 \%$ am Schenkelhals (Neer et al. 2001). Während sich die Dichte des Knochens nur geringfügig vergrößert, erhöht sich die periostale Knochenneubildung, das kortikale Volumen und die Querschnittsfläche der langen Röhrenknochen, wodurch der Knochen biomechanisch stabiler wird (Bartl 2011).

\subsubsection{Denosumab}

Seit 2010 ist das subkutan zu applizierende Biologikum Denosumab in der Therapie postmenopausaler Osteoporose sowie bei Knochenschwund (verursacht durch Hormontherapie bei Männern mit Prostatakarzinomen) zugelassen. Es handelt sich hierbei um einen monoklonalen Antikörper, der in die Steuerung der Osteoklastentätigkeit 
eingreift. Er bindet als IgG2-anti-RANKL-Antikörper mit hoher Affinität an RANKLigand und verhindert so dessen aktivierende Bindung an RANK, wodurch es in der Folge zu einer starken Hemmung der Knochenresorption durch Osteoklasten kommt.

Die Daten zur Wirksamkeit des Denosumabs in der Risikoreduktion der klinisch bedeutsamen osteoporosebedingten Frakturen entstammen der bislang größten Studie in der Osteoporoseforschung, der FREEDOM-Studie ("Fracture Reduction Evaluation of Denosumab in Osteoporosis Every 6 Months"). Es handelt sich hierbei um eine multizentrische, doppelblinde, Placebo-kontollierte Phase-III-Frakturstudie, in der die Anwendung von Denosumab bei postmenopausalen Frauen zwischen 60 und 90 Jahren untersucht wurde:

Bei sechsmonatiger Gabe von 60 mg Denosumab subkutan oder Placebo über 36 Monate konnte bei 7686, randomisiert auf zwei Gruppen (T-Score von $<-2,5$ und $>-4,0$ an der Lendenwirbelsäule oder Gesamthüfte) aufgeteilten Frauen eine Reduktion des relativen Risikos im Vergleich zur Placebogruppe für das Auftreten von neuen vertebralen Frakturen von $68 \%$, sowie für nichtvertebrale um $20 \%$ nachgewiesen werden. Gleichzeitig ergaben sich keine signifikanten Unterschiede bezüglich des Auftretens von unerwünschten Ereignissen zwischen Denosumab- und Placebogruppe. So konnte kein höheres Risiko bezüglich der Gesamthäufigkeit von Tumoren, Infektionen, kardiovaskulären Ereignissen, verzögerter Frakturheilung oder Hypokalzämie nachgewiesen werden. Signifikant öfter hingegen traten Ekzeme, Flatulenz sowie Hautinfektionen auf. Hinsichtlich der Compliance ergeben sich aufgrund der lediglich zweimal jährlich zu erfolgenden Applikation insbesondere gegenüber den oralen Osteoporosepräparaten deutliche Vorteile. Die pharmakologischen Eigenschaften des Denosumabs erfordern keine Einschränkungen bei der Anwendung bei nieren- und leberinsuffizienten Patienten. Insgesamt bietet Denosumab durch Verminderung der Knochenresorption und Erhöhung der Knochenmineraldichte einen alternativen Ansatz einer spezifischen Osteoporosetherapie (Cummings et al. 2009). 


\subsection{Die ovarektomierte Ratte als Modelltier der postmenopausalen Osteoporose}

In vielen Bereichen der Osteoporoseforschung hat sich die ovarektomierte Ratte als gut geeignetes Modelltier etabliert. So empfiehlt die FDA-Richtlinie (Food and Drug Administration; USA) (Thompson et al. 1995), die Ratte in Studien zur medikamentösen Prävention und Therapie einzusetzen. Nach Frost und Jee (1992) eignet sie sich im Rahmen von Untersuchungen zur Frakturheilung. Der durch die Ovarektomie induzierte Hormonmangel zeigt seine Wirkung vor allem in der Spongiosa der proximalen Tibia, des distalen Femurs und der Lendenwirbelsäule des Tieres. Somit lassen sich die Auswirkungen verschiedener Therapiemethoden an diesen Skelettarealen gut erforschen (Thompson et al. 1995). Insbesondere an der Tibiametaphyse konnte durch Wronski et al. (1985) und Seidlova-Wuttke et al. (2003 a u. b) ein Knochenmasseverlust von 50 \% nach einer drei Monate zurückliegenden Ovarektomie nachgewiesen werden. Auch viele ältere Forschungsprojekte zur Frakturheilung beruhen auf der Untersuchung der Diaphysen von Tibia und Femur, obwohl sich hier osteoporotische Veränderungen nur unwesentlich manifestieren. Darum konzentriert sich die vorliegende Arbeit direkt auf den Ort der Osteoporosemanifestation, auf die proximale Tibiametaphyse.

\subsection{Vibration}

Bei der Entstehung der Osteoporose spielt auch Immobilisation eine maßgebliche Rolle. Dabei wird das Auftreten einer osteoporotischen Fraktur durch die mechanische Stabilität des Knochens, die Sturzneigung und die Effektivität der neuromuskulären Reaktion zum Schutz des Knochens beeinflusst. Neben pharmakologischen Behandlungsmöglichkeiten sorgt körperliche Aktivität dafür, dem Knochenmasseverlust entgegenzuwirken und ein besseres Gleichgewicht sowie Reaktionsvermögen $\mathrm{zu}$ trainieren, wodurch sich die Sturzneigung vermindert. Somit kann mithilfe von körperlicher Betätigung das Frakturrisiko gesenkt werden (Smith und Gilligan 1991).

Erstmalig wurde die Adaption des Knochengewebes an mechanische Belastung durch strukturellen Umbau durch Julius Wolff beschrieben (Wolff 1892). Weiterführend verfasste der US-amerikanische Orthopäde und Chirurg Harold Frost 1960 die Utah Paradigm of Skeletal Physiology. Der darin beschriebene Regelkreis der konsequenten 
Anpassung des Knochengewebes an die auf ihn einwirkenden Kräfte wird als Mechanostat bezeichnet. Hiernach gelten die maximale elastische Verformbarkeit des Knochens und die auf ihn einwirkenden Maximalkräfte als die ursächlichen Reize für Knochenwachstum und -umbau. Durch die stetige Anpassung an die an ihn gestellten biomechanischen Ansprüche erreicht der Knochen seine maximale Festigkeit (Frost 2000).

Die Verformung des Knochens wird in Strain angegeben, wobei $1000 \mu$ Strain einer Längenänderung von 0,1 \% entsprechen. Die auf den Knochen einwirkenden Kräfte lassen sich in vier unterschiedliche Intensitäten einteilen:

- Disuse: $\quad \leq 800 \mu$ Strain, remodeling, negative Knochenbilanz

- Adapted State: 800 bis $1500 \mu$ Strain, remodeling, konstante Knochenbilanz

- Overload: $\quad>1500 \mu$ Strain, modeling, positive Knochenbilanz

- Fracture: $\quad>15000 \mu$ Strain, Bruchgrenze, Knochen frakturiert.

So besteht beispielsweise bei der Tibia ein Sicherheitsfaktor von ungefähr fünf bis sieben zwischen den üblicherweise einwirkenden Maximalkräften und den zum Bruch führenden Belastungen (Frost 1960).

Bewegungstherapie nimmt eine wichtige Rolle für Prävention und Therapie der Osteoporose ein. Durch gesteigerte körperliche Aktivität und regelmäßige Übungen lässt sich ein Knochenmasseverlust nach der Menopause vermindern. Es kann sogar zu einer Zunahme der Knochenmasse kommen (Dalsky et al. 1988; Smith et al. 1989; Chesnut 1993). Weiterhin lässt sich durch eine Verbesserung der Balance sowie der Muskelkraft das Sturzrisiko senken, worin der DVO die Hauptursache für osteoporotische Frakturen sieht. Die aktuellen Leitlinien des DVO (2009) zur Prävention und Therapie der Osteoporose zielen demnach darauf ab, in erster Linie das Sturzrisiko und den Abbau von neuromuskulären Kapazitäten durch Bewegungstherapie zu reduzieren.

Den Beobachtungen zufolge, dass es vielen Osteoporosepatienten nicht möglich ist, sich ausreichend körperlich zu betätigen, wurde das Konzept der mechanischen Stimulation entwickelt. Ursprünglich fand das Vibrationstraining (whole-body vibration, WBV) Anwendung in der Behandlung von Muskelatrophien und Verlust der Knochenmasse bei russischen Kosmonauten. Durch eine auf unterschiedlichen Frequenzen vibrierende Plattform, auf welcher der Patient steht, werden in der Muskulatur monosynaptisch 
propriozeptive Eigenreflexe ausgelöst. Die Dehnung des Muskels aktiviert Rezeptoren in der Muskelspindel, wodurch über Ia-Fasern Impulse zu den Alphamotoneuronen geleitet werden, die eine reflektorische Verkürzung des Muskels bewirken (Delank und Gehlen 2006). Die WBV bewirkt im Knochen bei zweckmäßiger Anwendung eine leichte elastische Verformung des Knochens und Aktivierung des remodelings, wodurch einem Verlust von Knochenmasse entgegengewirkt werden kann (Armbrecht et al. 2009; Rittweger et al. 2009). Die für Umbauvorgänge hauptverantwortliche Kraft entsteht durch Muskelzug (Burr 1997).

In verschiedenen Studien ließen sich bereits osteoanabole Auswirkungen auf den Knochen durch mechanische Stimulation nachweisen. So konnte eine randomisierte Studie an 70 postmenopausalen Frauen im Alter von 58 bis 74 Jahren eine signifikante Zunahme der Knochendichte im Bereich des proximalen Femurs durch Vibrationstraining aufzeigen (Verschueren et al. 2004). Auch Xie et al. (2006) konnten in einem Versuch mit acht Wochen alten Mäusen, die über einen Zeitraum von drei Wochen täglich 15 Minuten bei einer Frequenz von $45 \mathrm{~Hz}$ vibriert wurden, eine zu 30 \% reduzierte Osteoklastentätigkeit im wachsenden Skelett, verglichen mit der Kontrollgruppe, nachweisen. Diese Effekte traten bei gleichzeitig um 30 \% gesteigerter Knochenbildungsrate auf (Xie et al. 2006). Um in einem weiteren Versuch die Auswirkungen auf das muskuloskelettale System zu untersuchen, setzten Xie et al. ausgewachsene Mäuse sechs Wochen lang täglich 15 Minuten mit einer Frequenz von $45 \mathrm{~Hz}$ einer mechanischen Stimulation durch WBV aus. Bei der nachfolgenden Untersuchung des Knochens zeigte sich eine signifikante Verbesserung der strukturellen Knochenqualität und eine Vergrößerung des trabekulären Knochenvolumens der Tibiae um $14 \%$ der vibrierten Tiere im Vergleich zur Kontrollgruppe (Xie et al. 2008). Ebenso zeigten weitere Arbeiten von Sehmisch et al. (2009) und Tezval et al. (2011) an weiblichen Ratten eine Verbesserung der Knochenstruktur und der Knochenmasse des osteoporotischen Knochens nach Anwendung von WBV. Die Ratten wurden zweimal täglich bei $90 \mathrm{~Hz}$ für 15 Minuten mechanischer Stimulation ausgesetzt. Nach fünf Wochen wurden die Wirbelkörper und Femora untersucht. Die vibrierten Tiere wiesen im Vergleich zu den nicht-vibrierten Tieren deutliche Verbesserungen der biomechanischen Stabilität, der strukturellen Knochenqualität sowie der Knochendichte auf (Sehmisch et al. 2009; Tezval et al. 2011). 
Es scheint, dass die Empfänglichkeit des Knochens gegenüber mechanischer Stimulation durch Östrogen beeinflusst wird. Dies konnte mithilfe peripherer quantitativer Computertomographie von ovarektomierten Ratten im Vergleich zu einer nicht ovarektomierten Kontrollgruppe nachgewiesen werden. Es zeigte sich, dass bei der Kontrollgruppe durch achtwöchige WBV (fünf Tage pro Woche für 20 Minuten) keine osteoanabolen Effekte nachweisbar waren, während die ovarektomierten Tiere eine signifikante Verbesserung der Knochenstruktur aufwiesen. Mit steigender Vibrationsamplitude ließ sich der Effekt noch verstärken (Rubinacci et al. 2008). In einer weiteren Studie zum Einfluss von mechanischer Stimulation auf die osteotomierten Tibiae von Schafen wurde nach einem Zeitraum von zehn Wochen, in denen die Tiere an fünf Tagen der Woche für jeweils 17 Minuten mit einer Frequenz von $30 \mathrm{~Hz}$ und einer Amplitude von $25 \mu \mathrm{m}$ vibriert wurden, ein um 29 \% vermehrter und stabilerer Kallus im Vergleich zur nicht mechanisch stimulierten Kontrollgruppe gemessen. Außerdem konnte eine Vermehrung des Mineralgehalts des Knochen um 52 \% nachgewiesen werden (Goodship et al. 2009).

Die publizierten Daten deuten auf die potentiellen therapeutischen Effekte von WBV hin. Somit könnte die mechanische Stimulation durch WBV eine nicht-pharmakologische und nicht-invasive Therapieoption bei Osteoporose darstellen. Weiterhin gilt zu analysieren auf welcher Frequenz, in welcher Vibrationsrichtung (vertikal, horizontal, sinusförmig), mit welcher Amplitude und über welchen Zeitraum sich die Resultate optimieren lassen. Dabei sollte ferner Rücksicht auf die unterschiedliche Wirksamkeit auf die verschiedenen Körperareale und die Beeinflussung durch verschiedene Faktoren genommen werden (Judex et al. 2009). Die mechanische Stimulierung durch WBV bietet neben den Auswirkungen auf den Knochen auch eine Verbesserung der Muskelkraft und -stärke.

Die vorliegende Arbeit untersucht, ob die für den osteoporotischen Knochen dargelegten positiven Veränderungen durch WBV sich auch bei der Frakturheilung des osteoporotischen Knochens wiederfinden. 


\section{Material und Methoden}

Der im Rahmen dieses Forschungsprojekts durchgeführte Tierversuch wurde gemäß den Richtlinien des Deutschen Tierschutzgesetzes und mit Genehmigung der Bezirksregierung Braunschweig durchgeführt (21. Dezember 2006, AZ 33.42502-04-011/07).

\subsection{Versuchsaufbau}

Die Durchführung des Versuchs dauerte insgesamt 15 Wochen. Dabei kamen 60 weibliche Ratten zum Einsatz, die zunächst in zwei Gruppen eingeteilt wurden. 30 Tiere wurden bilateral ovarektomiert, die anderen 30 Tiere blieben intakt. In vorangegangenen Studien konnte gezeigt werden, dass weibliche Ratten zehn Wochen nach bilateraler Ovarektomie (OVX) einen teils fünfzigprozentigen Knochenmasseverlust im metaphysären Bereich der Tibia aufweisen (Wronski et al. 1985; Seidlova-Wuttke et al. 2003 a u. b). Zehn Wochen nach OVX, also am 70. Versuchstag, zeigte sich bei den ovarektomierten Tieren durch Östrogenmangel induziert eine manifeste Osteoporose. Nun wurde bei allen Versuchstieren eine bilaterale transverse Osteotomie an der metaphysären Tibia durchgeführt. Anschließend erfolgte eine osteosynthetische Stabilisierung der Osteotomien mittels MiniT-Platte.

Ab dem fünften postoperativen Tag wurde jeweils die Hälfte beider Gruppen einer regelmäßigen mechanischen Stimulation mittels vertikaler WBV mit einer Frequenz von $90 \mathrm{~Hz}$ ausgesetzt. Dies erfolgte zweimal täglich für 15 Minuten über einen Zeitraum von 30 Tagen. Die anderen Ratten wurden als Kontrollgruppe nicht vibriert. Somit ergaben sich folgende vier Gruppen (s. Tab. 3): Ovarektomiert+vibriert (OVX+Vib), ovarektomiert (OVX), intakt+vibriert (Intakt+Vib) und intakt (Intakt).

Tabelle 3: Darstellung der verschiedenen Gruppen und der entsprechenden Behandlung

\begin{tabular}{|l|l|}
\hline Gruppenbezeichnung & Behandlung \\
\hline OVX+Vib & ovarektomiert + vibriert \\
\hline OVX & ovarektomiert \\
\hline Intakt+Vib & intakt + vibriert \\
\hline Intakt & intakt \\
\hline
\end{tabular}


Den Ratten wurden vier verschiedene Fluoreszenzen (Xylenolorange-Tetranatriumsalz (XO), Fluoresceinkomplexon (CG), Alizarin-Komplexon (AK), Tetracyclinehydrochloride (TC)) zu unterschiedlichen Zeitpunkten der Frakturheilung subkutan injiziert, um eine polychrome Sequenzmarkierung des Heilungsprozesses zu ermöglichen und damit bei der Auswertung der Kallusflächen Rückschlüsse auf die zeitliche Abfolge der Frakturheilung zu ziehen. Am 105. Versuchstag erfolgte die Dekapitation der Tiere. Im Anschluss wurden die Tibiae nach der Präparation biomechanisch, histomorphologisch und -morphometrisch untersucht.

Insgesamt starben im Laufe des Versuchs zwei Tiere, eines aus der ovarektomierten Gruppe, das andere aus der intakten. Die Auswertung konnte entsprechend an einem Gesamtkollektiv von 58 Ratten erfolgen.

\subsection{Versuchstiere und Versuchstierhaltung}

Der Versuch wurde an 60 weiblichen drei Monate alten Sprague Dawley Ratten der Firma Harlan Winkelmann aus Borken in Deutschland durchgeführt. Zu Beginn des Versuchs betrug das durchschnittliche Körpergewicht (KG) der Tiere 233,8 g (211- 262 g).

Die Ratten wurden über den gesamten Zeitraum der Versuchsdurchführung in der Zentralen Tierexperimentellen Einrichtung (ZTE) der Universitätsmedizin Göttingen untergebracht. Dort erfolgte die Haltung in Makrolon ${ }^{\circledR}-I V-K a ̈ f i g e n$, die sich die Tiere entweder mit vier oder mit fünf Artgenossen teilten. Jeden dritten Tag erfolgte ein Austausch mit desinfizierten Käfigen, die mit Sägespänen ausgelegt waren. Es wurde eine Hell-Dunkel-Periodik von jeweils zwölf Stunden eingehalten. Die Umgebungstemperatur betrug konstant $20^{\circ} \mathrm{C}$ bei einer Luftfeuchtigkeit von $55 \%$.

Das Haltungsfutter (ssniff SM R/M, 10 mm-Pellets; ssniff Spezialdiäten GmbH, Soest, Deutschland) wurde einmal wöchentlich gewogen und aufgefüllt. Der Nahrungsverbrauch und das Körpergewicht der Ratten wurden während des Versuchs einmal in der Woche gemessen und dokumentiert.

Zusätzliche Messungen des Körpergewichts wurden jeweils vor der Durchführung der Ovarektomie, der Osteotomie/Osteosynthese und der Dekapitation durchgeführt. Innerhalb der Käfige konnten sich die Tiere frei bewegen, die Nahrungs- und Wasseraufnahme erfolgte ad libitum. 


\subsection{Ovarektomie}

Vor der Anästhesie wurden die Ratten kurz mit $\mathrm{CO}_{2}$ narkotisiert. Als weitere Narkotika wurden Ketamin (40 mg/kg KG, Medistar, Holzwickede, Deutschland) und Xylazin (10 mg/kg KG, Riemser, Greifswald-Insel Riems, Deutschland) im Mischverhältnis von 5:3 in einer Dosis von 0,01 ml/g Körpergewicht (KG) intraperitoneal appliziert. Nachdem das Operationsgebiet zwischen Rippenbogen und Hinterläufen sorgfältig rasiert und desinfiziert wurde, folgte die Inzision der Haut. Darauf schloss sich die Präparation in die Tiefe bis zum Peritoneum und die Eröffnung der Bauchhöhle an. Die Adnexen wurden dargestellt und anschließend die Ligatur der Tubae uterinae und die Abtrennung der Ovarien durchgeführt. Der Peritoneal- und Muskelverschluss wurde mit 4.0 Vicryl-Nähten (Ethicon, Johnson \& Johnson, Norderstedt, Deutschland) durchgeführt, die Hautadaption erfolgte mittels Klammern (Michel woundbrackets 12 x 3 mm, Gebrüder Martin GmbH \& Co.KG. Tuttlingen, Deutschland). Postoperativ wurde den Tieren ein Depot von $3 \mathrm{ml} \mathrm{NaCl}$ 0,9 \% subkutan appliziert, welches einem postoperativen Volumenmangel entgegenwirkte. Nach der Operation wurden die Ratten in einen vorgewärmten, mit Zellstoff ausgekleideten Käfig gelegt, in welchem sie bis zum Ende der Narkose unter Beobachtung blieben.

In gleicher Narkose erhielten die Tiere einen Transponder (Uno Micro-Id-System. IsoTransponder (12 mm), UNO Roestvaststaal BV, Zevenaar, Niederlande) in das subkutane Fettgewebe des Nackens, welcher mittels eines Injektors eingesetzt wurde. Damit konnte jedes Tier im Versuchsverlauf mithilfe eines Lesegerätes leicht identifiziert werden.

\subsection{Osteotomie und Osteosynthese der Tibiae}

Die Narkose erfolgte analog dem Verfahren bei der Ovarektomie. Für den Eingriff wurden den Ratten beide Hinterläufe rasiert und anschließend desinfiziert. Daraufhin wurde ein 3 cm langer Hautschnitt über der medio-ventralen Tibia gesetzt. Im Anschluss wurden die Muskulatur und die ventrale Tibiakante dargestellt und die Muskulatur unter Schonung des Periosts scharf vom Knochen abgetrennt. Dann wurde eine 5-Loch-Leibinger-Platte aus Titan (57-05140 XS-Titanfixationsplatte T-Form 90, Stryker Trauma, Selzach, Schweiz) so am Knochen fixiert, dass die beiden proximalen Plattenlöcher in Höhe der Epiphyse 
platziert wurden. Anschließend erfolgte die Vorbohrung des proximalen Schraubenkanals und die anschließende lockere Fixierung der Platte durch Einsetzen einer Schraube. Analog verfuhr man mit dem am weitesten distal gelegenen Schraubenkanal. Danach wurden der zweite proximale und der zweite distale Schraubenkanal gebohrt, die jedoch zunächst nicht mit Schrauben besetzt wurden. Im zentralen Plattenloch wurde keine Bohrung durchgeführt, da dort die Osteotomielinie verlaufen sollte. Im Anschluss wurde das Osteosynthesematerial vorübergehend entfernt und die Tibiae unter Schonung der angrenzenden Strukturen $7 \mathrm{~mm}$ distal des Tibiaplateaus osteotomiert. Dies erfolgte mithilfe gepulsten Ultraschalls (Piezosurgery ${ }^{\circledR}$, Mectron Medical Technology, Carasco, Italien). Danach wurde die Titanplatte proximal mit zwei $7 \mathrm{~mm}$ 1.1er Schrauben und distal mit jeweils einer $5 \mathrm{~mm}$ und einer $4 \mathrm{~mm}$ 1.1er Schraube refixiert (s. Abb. 3). Der durch diese Vorgehensweise entstehende standardisierte Osteotomiespalt von 0,5 mm entspricht der Dicke des verwendeten OT 7 Piezosurgery ${ }^{\circledR}$ Sägeblattes.

Die Refixation der Beugemuskulatur erfolgte mittels 4.0 Vicryl-Naht (Ethicon, Johnson\&Johnson, Norderstedt, Deutschland). Abschließend wurde die Haut durch Klammern (Michel woundbrackets 12 x 3 mm, Gebrüder Martin GmbH \& Co. KG Tuttlingen, Deutschland) readaptiert. Am kontralateralen Hinterlauf wurde nach dem gleichen Operationsverfahren vorgegangen.

Nach der Operation wurde jedem Tier eine einmalige Dosis von 100 mg/kg KG Decentan (Merck, Darmstadt, Deutschland) und eine Injektion von $3 \mathrm{ml}$ 0,9\%-iger NaCl-Lösung subkutan injiziert. Danach wurden sie in einen vorgewärmten, mit Zellstoff ausgelegten Käfig gelegt und bis zum Aufwachen beaufsichtigt.

An den folgenden zwei postoperativen Tagen bekamen die Ratten zweimal täglich jeweils eine Subkutaninjektion von 4 mg/kg KG Rimadyl (Pfizer, Karlsruhe, Deutschland) um die Fortführung einer adäquaten Schmerztherapie zu gewährleisten (Stürmer et al. 2010 a).

Bei der Darstellung der Ergebnisse werden die Begriffe Plattenebene und Schraubenebene benutzt, die sich an der zuvor erläuterten Platzierung der Osteosynthese orientieren. Die Plattenebene beschreibt die flächige Ausbreitung der 5-Loch-Leibinger-Platte über der medio-ventralen Tibiakante. In der Schraubenebene verlaufen die Bohrkanäle. Sie steht im rechten Winkel zur Plattenebene. 


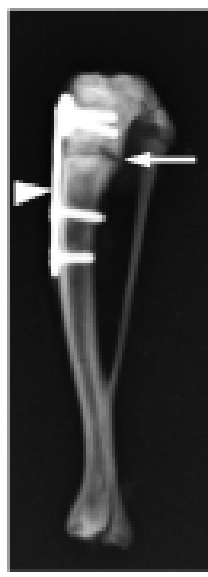

A

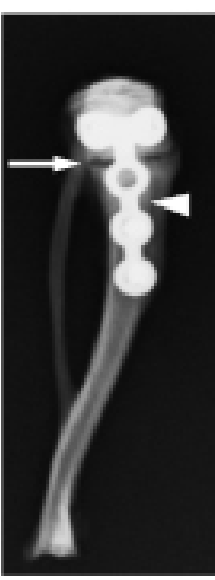

B

Abbildung 3: Tibia/Fibulaverbund mit Darstellung des metaphysären Osteotomiespalts (Pfeil) und der Plattenosteosynthese (Pfeilspitze); A: Ansicht von lateral, B: Ansicht von frontal (Komrakova et al. 2010)

\subsection{Vibration}

Fünf Tage nach Durchführung der Osteotomien wurde jeweils die Hälfte der ovarektomierten und die Hälfte der intakten Ratten, zehn Tiere zur gleichen Zeit, zweimal täglich für jeweils 15 Minuten vertikaler WBV ausgesetzt. Dies erfolgte über einen Zeitraum von fünf Wochen bei einer Frequenz von $90 \mathrm{~Hz}$. Die Amplitude betrug dabei 0.5 mm und die Beschleunigung 4xg, welche mithilfe eines SWM Gerätes 3000 (REO Elektronik, Berlin, Deutschland) geprüft wurde. Während dieser Zeit konnten sich die Tiere auf der Vibrationsfläche innerhalb der Käfigwände frei bewegen. Um eine Abschwächung des Effekts der Vibration zu vermeiden, wurde dabei auf einen möglichst konstanten Fuß-Boden-Kontakt geachtet.

Das Vibrationsgerät bestand aus einem speziell für diesen Versuch angefertigten Plastikkäfig (50 x 50 × $25 \mathrm{~cm}^{3}$ ), welcher auf einem Vibrationstisch fixiert war. Diese Konstruktion sollte die Sicherheit der Tiere gewährleisten und den Verlust der Vibrationsintensität minimieren. Der Vibrationstisch bestand aus zwei alternierenden Motoren und einem Übertragungsgerät (Vibra Maschinenfabrik Schultheis GmbH\&Co, Offenbach, Deutschland), welches die Monitordarstellung der Frequenz ermöglichte (vgl. Abb.4). 


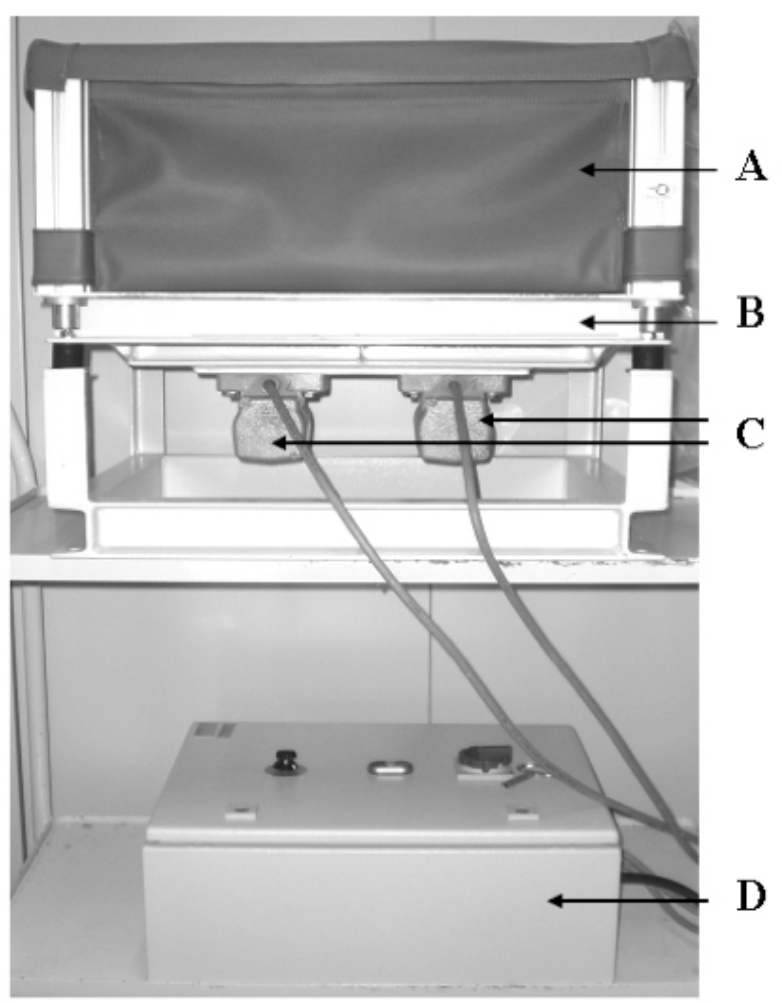

Abbildung 4: Darstellung der Vibrationsvorrichtung: $\mathrm{A}=$ Plastikkäfig, $\mathrm{B}=$ Vibrationstisch, $\mathrm{C}=$ Motoren, $\mathrm{D}=$ Kraftüberträger (Stürmer et al. 2010 b)

\subsection{Präparation der Tibiae}

Am Ende des Versuchs, am 35. Tag nach Durchführung der Osteotomie, wurden alle Ratten in tiefer $\mathrm{CO}_{2}$ - Narkose durch Dekapitation getötet. Zu diesem Zeitpunkt befand sich der zu untersuchende Kallus noch nicht in der Resorptionsphase.

Eine jeweils randomisierte linke oder rechte Tibia wurde im Kniegelenk und oberen Sprunggelenk exartikuliert und sorgfältig vom umliegenden Gewebe wie Muskeln, Nerven und Gefäßen befreit. Dabei war auf die Erhaltung des Verbundes von Tibia und Fibula besonders zu achten. Hiernach folgte die Entfernung des Osteosynthesematerials. Die Tibiae wurden bei $-20^{\circ} \mathrm{C}$ gelagert um später für biomechanische, histologische und mikroradiographische Analysen verwendet zu werden. Zusätzlich wurden die Uteri entfernt und gewogen um die Effektivität der Ovarektomie zu verifizieren. 


\subsection{Knochenanalyse}

\subsubsection{Fluoreszenzmarkierung}

Die polychrome Sequenzmarkierung (PSM) macht es möglich, dynamische Umbauvorgänge im Knochen während der Frakturheilung sichtbar zu machen. Während sich die Mikroradiographie lediglich für isolierte Momentaufnahmen eignet, dient die PSM auch als Lieferant von Informationen über Zeitpunkt, Lokalisation und Ausmaß von knöchernen Wachstumsprozessen. So erhält man ein dynamisches Bild der Frakturheilung.

Für die PSM wurden den Versuchstieren intravital Fluorochrome unterschiedlicher Farben zu bestimmten festgelegten Zeitpunkten während verschiedener Phasen der Frakturheilung subkutan injiziert (s. Tab. 4). Zusammen mit Kalzium bilden diese einen fluoreszierenden Chelatkomplex, der in stoffwechselaktive Knochenbereiche im Rahmen der Mineralisierung eingebaut wird, so auch insbesondere in den für diesen Versuch zu analysierenden Frakturkallus. Farblich unterschiedlich gekennzeichnete Banden kommen durch die zeitlich versetzte Applikation der verschiedenfarbigen Fluoreszenzen zustande. Im Anschluss an deren Präparation und Aufarbeitung wird eine quantitative fluoreszenzmikroskopische Untersuchung durchgeführt. Dabei ist es möglich, die jeweils neu gebildeten Knochenbereiche durch unterschiedliche fluoreszierende Eigenschaften einem bestimmten Zeitraum der Frakturheilung zuzuordnen.

Tabelle 4: Darstellung der Applikationszeitpunkte, Markierungszeiträume und Dosierungen der unterschiedlichen Fluorochrome

\begin{tabular}{|l|l|l|l|}
\hline Fluorochrom & $\begin{array}{l}\text { Applikations- } \\
\text { zeitpunkt } \\
\text { (Angabe in Tagen } \\
\text { nach Osteotomie) }\end{array}$ & $\begin{array}{l}\text { Markierungs- } \\
\text { zeitraum } \\
\text { (Angabe in Tagen } \\
\text { nach Osteotomie) }\end{array}$ & $\begin{array}{l}\text { Dosierung } \\
\text { (Angabe in mg/kg } \\
\text { KG) }\end{array}$ \\
\hline XO & 13 & $0-13$ & 90 \\
\hline GC & 18 & $14-18$ & 10 \\
\hline AK & 24,26 & $19-26$ & 30 \\
\hline TC & 35 & $27-35$ & 25 \\
\hline
\end{tabular}


In Anlehnung an Rahn (1976) wurden Xylenolorange-Tetranatriumsalz (XO), Calceingrün-Komplexon (CG), Alizarin-Komplexon (AK) und Tetracyclin-Hydrochlorid (TC) (alle: Merck, Darmstadt, Deutschland) als Fluorochrome verwendet. Vor der subkutanen Bolusgabe wurden die Fluorochrome mittels isotoner Kochsalzlösung (TC) bzw. destilliertem Wasser (XO, CG, AK) in Lösung gesetzt. Die Fluoreszenzfarbstoffe lagerten sich in dem Bereich des Knochens an, der sich bis zum Zeitpunkt der Injektion neu gebildet hatte und der noch nicht von einem anderen Farbstoff markiert worden war (siehe Abb. 5). Je nach Intensität der Anfärbung ließen sich durch Betrachtung von bis zu 11 histologischen Schnitten Rückschlüsse auf die früheste Frakturspaltüberbrückung jeder einzelnen Tibia ziehen. Anschließend wurde aus den ermittelten Zeitpunkten ein Mittelwert für jede Versuchsgruppe gebildet.

$\begin{array}{lllll} & \text { XO } & \text { CG } & \text { AK AK } & \text { TC } \\ 1 & 13 & 18 & 2426 & 35\end{array}$

Tage nach Osteotomie

Abbildung 5: Darstellung der Applikationszeitpunkte der verschiedenen Fluorochrome und deren Markierungszeiträume

\subsection{Biomechanischer Biegetest}

\subsubsection{Prinzip des biomechanischen Biegetests}

Das Ziel des biomechanischen Tests ist es, ein biomechanisches Profil des Kallus zu erstellen. Der Untersucher übte hierzu mithilfe einer Werkstoffprüfmaschine eine Kraft senkrecht zur Längsachse der Tibia aus. Angriffspunkt für die Krafteinwirkung war dabei die ventrale Tibiakante auf Höhe der Ostetomielinie. Um eine widerstandslose Dehnung des Knochens zu gewährleisten und entstehende Reibungskräfte möglichst gering zu halten, wurde die Tibia während der Durchführung des Tests lediglich stabilisiert und nicht fixiert. Die ausgeübte Kraft wurde dabei gegen den Weg (Verbiegung der Tibia) aufgezeichnet. 


\subsubsection{Versuchsaufbau und -ablauf}

Zunächst wurden die zu untersuchenden Tibiae zur Gewebeschonung über mindestens fünf Stunden bei Raumtemperatur aufgetaut. Danach wurden alle Fibulae von den Tibiae abgetrennt, da diese für die Durchführung des Tests hinderlich gewesen wären. Während des Versuchsablaufs wurden die Tibiae mit isotoner Kochsalzlösung konstant feucht gehalten, um ein Austrocknen zu verhindern. Für den Test wurden Knochen, die im Bruchspalt nicht zusammengewachsen waren nicht verwendet. Zur Durchführung des Tests wurden die Tibiae jeweils einzeln auf eine speziell für diesen Versuch angefertigte Bruchvorrichtung aus Aluminium gelegt. Die Basis bildete ein 9 x 5,5 cm messender Aluminiumblock, in dessen Mitte eine 2,7 cm lange und 0,6 cm breite, längs verlaufende Einkerbung verlief. Eine weitere 2,5 cm lange und 0,3 cm breite Furche befand sich quer zur Längsachse der Basis. Die Furche enthielt eine, nach dorsal ausgerichtete, bogenförmige Erweiterung. Diese diente zusätzlich als Auflagefläche. Dadurch konnte eine sichere und effektive Positionierung des Knochens gewährleistet werden. Um ein seitliches Verrutschen der Tibiae zu verhindern, wurden diese mithilfe von vier beliebig verstellbaren und rotierenden Sicherungsbolzen leicht fixiert. Das freie Durchbiegen der Knochen, insbesondere im Bereich der Osteotomielinie während der Prüfung, wurde durch Positionierung des proximalen Knochenanteils (Kondylen) in die Erweiterung am Kopfende der Basisplatte und der Extremitas distalis tibiae innerhalb der längsverlaufenden Einkerbung (vgl. Abb. 6) ermöglicht. Eine Validierung der dargestellten Bruchvorrichtung wurde bereits in Vorversuchen mit Rattentibiae vorgenommen.

a)

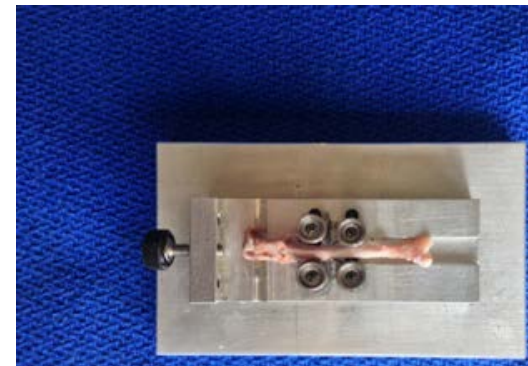

Abbildung 6: a) Darstellung der Tibia auf der Trägerplatte (Ansicht von oben); b) Darstellung der Trägerplatte inklusive Tibia in der Werkstoffprüfmaschine mit korrekt positioniertem Rollenstempel (Ansicht von vorn) 
$\mathrm{Zu}$ Beginn der Testdurchführung wurde die Bruchvorrichtung mitsamt der aufgelegten Tibia so in der Werkstoffprüfmaschine (Typ 145660Z020/TND Zwick/Roell, Ulm, Deutschland) platziert, dass die ventrale Tibiakante unterhalb eines Rollenstempels mit zirkulärer Nut (Stürmer et al. 2006) zu liegen kam. Dadurch wurde eine direkte vertikale Kraftübertragung auf den metaphysären Kallus gewährleistet. Bei der genauen Einstellung der Position half das Programm „testXpert®“ (Zwick/Roell, Ulm, Deutschland), dessen Software für die Steuerung der Werkstoffprüfmaschine und die Aufzeichnung der Daten verantwortlich war. Hierfür fuhr der Rollenstempel so weit vertikal nach unten, bis es zu einem Kontakt mit der Tibiakante kam und eine Vorkraft von $1 \mathrm{~N}$ erzeugt wurde. Im Anschluss konnte die korrekte Position der Tibiakante in der Nut des Stempels überprüft und gegebenenfalls korrigiert werden.

Nach visueller Kontrolle wurde die Elastizitätsprüfung gestartet. Mit einer Geschwindigkeit von $5 \mathrm{~mm} / \mathrm{min}$ erhöhte sich der Druck auf den ventralen Tibiakallus durch Auslenkung des Rollenstempels, wobei es zu einer Biegung des Knochens kam. Die dabei angewandte Kraft wurde währenddessen alle 0,1 mm gemessen und zeitgleich zeichnete die testXpert®-Software ein Kraft-Weg-Diagramm. Bei der Untersuchung lag der Messbereich der mechanischen Kompression zwischen $2 \mathrm{~N}$ und maximal $500 \mathrm{~N}$ bei einer relativen Genauigkeit von 0,2 bis 0,4 \%. Der Untersucher verfolgte den Kurvenverlauf am Monitor direkt mit, um ein Frakturieren des Kallus zu vermeiden. Bei einem plötzlichen Steigungsabfall des zuvor linear ansteigenden Kurvenverlaufs wurde der Versuch vom Prüfer manuell abgebrochen. Eine besondere Bedeutung kam hierfür den Vorversuchen für die Validierung zuteil. Es zeigte sich, dass der Steigungsabfall hierbei den Endpunkt der Elastizität des Knochens abbildete und somit die Vorankündigung für dessen Frakturierung aufzeigte (Stürmer et al. 2006). Für die Datenaufzeichnung sorgte ebenfalls die Software „testXpert®“ (Zwick/ Roell, Ulm, Deutschland). Nach Abschluss des Tests fuhr der Rollenstempel wieder hoch, der Knochen wurde aus seiner Position entfernt und für spätere Untersuchungen erneut bei $-20^{\circ} \mathrm{C}$ eingefroren. 


\subsubsection{Auswertung des biomechanischen Tests}

Die aufgezeichneten Kraft-Weg-Diagramme stellen sich durch einen von Stürmer et al. (2006) beschriebenen typischen Kurvenverlauf dar. Diese unterteilen den Graphen wie folgt in vier Phasen:

1. Elastizität, 2. Streckgrenze (yield load), 3. Maximalkraft und 4. Bruchkraft (frakturbedingter Abfall der Kurve).

Die erste Phase zeichnet sich durch eine elastische und damit reversible Biegung des Knochens aus, wobei vorwiegend kollagene Fasern gedehnt werden. Bei Abnahme der Druck ausübenden Kraft kann zum jetzigen Zeitpunkt der Knochen wieder seine ursprüngliche Form annehmen. Die erste Phase wird im Kurvendiagramm als lineare Steigung sichtbar, die Deformierung ist reversibel. Dieser Messparameter (Elastizität) wird in $\mathrm{N} / \mathrm{mm}$ angegeben.

Bei einer Zunahme der Kraft kommt es zu Mikrofrakturen im Sinne von Trabekelbrüchen und damit zu einer irreversiblen plastischen Deformation des Knochens, der zweiten Phase des Kurvenverlaufs.

Die Belastungsgrenze beim Übergang von der ersten in die zweite Phase ist dabei bei jedem Knochen individuell verschieden. Sie wird als Streckgrenze (yield load) definiert und besitzt die Einheit N.

Im Anschluss käme es zu einem verlangsamten Kurvenanstieg (Steigung geringer) bis die Kurve ihr Maximum (Maximalkraft) erreicht hätte und dann bei kompletter Fraktur des Testknochens steil abfiele. Da ein frakturiertes Präparat für histologische Untersuchungen unbrauchbar gewesen wäre, wurde der Test bereits nach Beendigung der zweiten Phase vom Untersucher manuell abgebrochen. Dadurch ließ sich ein vollständiger Bruch des Knochens zuverlässig vermeiden; Maximalkraft und Bruchkraft wurden somit nicht bestimmt (Stürmer et al. 2006). 


\subsection{Mikroradiographie}

\subsubsection{Aufarbeitung der Präparate und Anfertigung der Mikroradiographien}

Für die Anfertigung der histologischen Präparate wurden die Tibiae zunächst in einer aufsteigenden Alkoholreihe (40 \%, 70 \%, 80 \%, 100 \% für jeweils eine Woche) entfettet und entwässert. Danach wurden die Knochen mithilfe eines Gemischs aus $1000 \mathrm{ml}$ Methylmethacrylsäure (MMA), $200 \mathrm{ml}$ Dibutylphthalat und 29 g Benzolperoxid einzeln in Rollrandflaschen (40 ml, 80 x 30 mm) eingebettet. Nach ca. drei Wochen, in denen die Präparate zu MMA-Blöcken aushärteten, wurden diese aus den Behältern herausgelöst und anschließend mit einer Innenlochsäge (Leica So 1600 Sägemikrotom; Bensheim, Deutschland) in $150 \mu \mathrm{m}( \pm 10 \mu \mathrm{m})$ dicke Sagittalschnitte senkrecht zur Plattenebene gesägt. Von den zehn Sagittalschnitten jedes einzelnen Knochens wurden die drei zentralen, aufeinander folgenden Schnitte ausgewählt, um sie als histologische Präparate und für die mikroradiographische Analyse zu verwenden.

Zur Anfertigung der Mikroradiographien diente ein Faxitron-Röntgengerät (Modell-Nr. 43855 A, Faxitron X-raysystem, Hewlett-Packard, San Diego, USA). Die Bilder der drei zentralen Schnitte entstanden auf Kodak Professional Film (INDUSTREX SR 45 Film ISO 9002, Rochester, New York). Bei einer Röhrenspannung von 40 kV und einer Stromstärke von 0,3 mA wurden die Bilder jeweils über drei Minuten belichtet. Um nachfolgend die Analyse der PSM durchzuführen, wurden die histologischen Schnitte mit Eukitt ${ }^{\circledR}$ (Fa. Kindler, Freiburg, Deutschland) auf Objektträgern (52 x 76 mm) fixiert.

\subsubsection{Auswertung der Mikroradiographien}

Die Begutachtung der Mikroradiographien erfolgte mithilfe eines Leica Stereomakroskops (MZ 7-5, Bensheim, Deutschland), das mit einer Kaltlichtlampe (Leica KL 1500 LCD, Bensheim, Deutschland) versehen war. Für das Übertragen der Bilder auf den Computer (Intel Pentium 4, 2.6 GHz) diente eineam Makroskop installierte Kamera (Leica DC 300F; Bensheim, Deutschland). Anschließend ließen sich die eingelesenen Mikroradiographien mit der Software Leica QuantimetQwin 2003 (Leica Dm-RXE, Bensheim, Deutschland) morphometrisch analysieren und auswerten. In Vorversuchen konnten die folgenden Konfigurationseinstellungen der Kamera und der Software als optimal ermittelt werden: 
Für das Makroskop wurde ein 10,0er Okular und ein 1,0er Objektiv gewählt, wodurch eine zehnfache Vergrößerung erzielt werden konnte. Dadurch war es möglich, die zur Auswertung notwendigen Strukturen bei bestmöglich verwendeter Nutzung der Monitorfläche komplett darzustellen. Um eine mäßige Blendenöffnung zu erhalten, wurde die mechanische Blende der Kaltlichtlampe auf die Schalterposition B eingestellt (A: minimale Blendenöffnung; E: maximale Blendenöffnung). Die Halogenlampe wies eine Temperatur von $2750 \mathrm{~K}$ auf. Die Belichtungszeit wurde für jede Mikroradiographie individuell abgestimmt, da diese unterschiedliche Helligkeiten aufwiesen. Dies kam dadurch zustande, dass die geröntgen Schnittpräparate eine leicht variierende Dicke aufwiesen. Die Belichtungszeit befand sich dabei immer in einem Bereich von 345 bis 460 ms.

\subsubsection{Histomorphologische Auswertung}

Das Arbeitsverfahren folgte einem für diese Untersuchung festgelegten Programm. Des Weiteren war dem Untersucher während der Messungen die Zugehörigkeit der verschiedenen Gruppen der Radiographien nicht bekannt, die Auswertung erfolgte demnach verblindet.

\section{Arbeitsschritt 1: Einlesen der Mikroradiographien}

Für das Einlesen der Mikroradiographien in den Computer fanden die im vorigen Abschnitt beschriebenen Geräte und Einstellungen erneut Anwendung. Bei der Positionierung der Aufnahmen war es wichtig, dass sie sich mit den ventromedialen Knochenanteilen links, den dorsalen rechts, den proximalen oben und den distalen unten auf dem Bildschirm darstellten. Dabei konnten sie mithilfe einer auf dem Bildschirm horizontal verlaufenden Orientierungslinie, an der die Osteotomielinie ausgerichtet wurde, immer in gleicher Weise innerhalb eines standardisierten Messrahmens $\left(2 \times 5 \mathrm{~mm}^{2}\right.$; vertikal x horizontal) platziert werden. 


\section{Arbeitsschritt 2: Optimierung der Bildschärfe}

Mithilfe eines Reglers am Makroskop ließ sich die Bildschärfe manuell optimieren. Für die optimale Kontrasteinstellung sorgte die Software.

\section{Arbeitsschritt 3: Graudetektion}

Durch die Graudetektion erfasste die Software alle sichtbaren Knochenstrukturen. Die zunächst automatische computergesteuerte Detektion konnte im Anschluss durch den Untersucher individuell angepasst bzw. korrigiert werden, um so eine Fehlinterpretation im Sinne einer Über- oder Unterdetektion zu vermeiden.

\section{Arbeitsschritt 4: Flächendefinition}

Um die einzelnen Flächen zu bestimmen, umfuhr man sie mit dem Mauszeiger. Dabei wurde die Flächengrenze als Linie (Linienstärke 2,1 Pixel entspricht 6,73 $\mu \mathrm{m}$ ) sichtbar. Dies diente zur Kontrolle. Korrekturen konnten so bei Bedarf nachträglich am Linienverlauf vorgenommen werden. Bei Flächen, die Kontinuitätsunterbrechungen aufwiesen, gab es die Möglichkeit, diese durch Umfahren der einzelnen Teilflächen zu einer Fläche zusammenzufassen. Dabei verhinderte die Software eine Mehrfachdetektion desselben Areals.

Bei der Flächenbestimmung ging man in folgender Reihenfolge vor:

a) Gesamte Knochenfläche inklusive Kallus

Die gesamte $\mathrm{zu}$ bestimmende Knochenfläche wurde über den Messrahmen hinaus umrandet. Dadurch konnten abgesprengte oder dislozierte Knochenstücke in den weiteren Messungen übergangen werden.

b) Kortikalisfläche proximal-ventromedial

Durch Umfahren ließ sich die proximale ventromediale Kortikalisfläche von der gesamten Knochenfläche abgrenzen. Die Kortikalis weist eine hohe Knochendichte auf.

c) Kortikalisfläche proximal-dorsal

Es wurde die dorsale, proximal des Osteotomiespalts gelegene Kortikalisfläche umfahren.

d) Kortikalisfläche distal-ventromedial (vgl. Flächendefinition b u. c)

e) Kortikalisfläche distal-dorsal (vgl. Flächendefinition b u. c)

f) Kallusfläche ventromedial 
Der ventromediale und endostale Kallus wurde durch eine mittige Verbindungslinie zwischen proximaler und distaler Kortikalis voneinander abgegrenzt. Ventral dieser Grenzlinie und ventral der Kortikalis befand sich der zu umfahrene Kallus.

g) Kallusfläche dorsal (vgl. Flächendefinfition f)

h) Kallusfläche endostal

Eine Abgrenzung der Kallusfläche von der Kortikalis erfolgte bereits indirekt durch die vorangegangenen Arbeitsschritte. Nach kranial und kaudal wurde die endostale Kallusfläche durch Umfahren abgeschnitten. Endostaler Kallus zeichnet sich durch eine wesentlich höhere Knochendichte und deutlich kompaktere Struktur aus als das angrenzende Trabekelwerk.

i) Trabekelfläche proximal

Die Bestimmung der proximalen Trabekelfläche konnte schon in den vorangehenden Arbeitsschritten erfolgen. Eine separate Kennzeichnung war demnach nicht nötig. Allerdings kam es in manchen Präparaten zur Angrenzung eines Schraubenkanals, der vermehrt Kallus enthielt. Dieser „Schraubenkallus“ wurde nicht der Trabekelfläche zugerechnet.

j) Trabekelfläche distal (vgl. Flächendefinition i)

\section{Arbeitsschritt 5: Kortikalisdicke distal-ventromedial}

Für die Bestimmung der distalen ventromedialen Kortikalis fuhr der Untersucher fünf Vektoren orthogonal zur Knochenlängsachse durch die Kortikalis nach, wobei die Vektoren die jeweilige Fläche überragen sollten. Darauffolgend konnte die Software mithilfe der zuvor ermittelten Kortikalisfläche die tatsächliche Kortikalisdicke bestimmen.

\section{Arbeitsschritt 6: Kortikalisdicke distal-dorsal}

Vergleiche Arbeitsschritt 5

\section{Arbeitsschritt 7: Kallusdicke ventromedial}

Für die Auswertung des ventromedialen Kallus wurden zehn Vektoren orthogonal zur Knochenlängsachse durch den Kallus gezogen. Jeweils fünf lagen oberhalb, fünf Vektoren unterhalb der Osteotomielinie. Diese Vektoren überragten die Grenze des Kallus. Im 
weiteren Verlauf wurde die tatsächliche Kallusdicke bestimmt, indem die Software die Vektoren auf die vorher bestimmte ventromediale Kallusfläche beschränkte.

\section{Arbeitsschritt 8: Kallusdicke dorsal}

Vergleiche Arbeitsschritt 7.

\section{Messparameter}

\section{Kortikalis}

Tabelle 5: Messgrößen Kortikalis mit Einheit und Bedeutung

\begin{tabular}{|l|l|l|}
\hline Messgröße & Einheit & Bedeutung \\
\hline $\begin{array}{l}\text { Kortikalisdicke distal- } \\
\text { ventromedial }\end{array}$ & $\mathrm{mm}$ & $\begin{array}{l}\text { Mittelwert der fünf Vektorenbeträge aus } \\
\text { Arbeitsschritt 5 }\end{array}$ \\
\hline $\begin{array}{l}\text { Kortikalisdicke distal- } \\
\text { dorsal }\end{array}$ & $\mathrm{mm}$ & $\begin{array}{l}\text { Mittelwert der fünf Verktorenbeträge aus } \\
\text { Arbeitsschritt 6 }\end{array}$ \\
\hline $\begin{array}{l}\text { Kortikalisdichte distal- } \\
\text { ventromedial }\end{array}$ & $\%$ & $\begin{array}{l}\text { Anteil an mineralisiertem Knochen bezogen auf die } \\
\text { ventromediale distale Kortikalisfläche }\end{array}$ \\
\hline $\begin{array}{l}\text { Kortikalisdichte distal- } \\
\text { dorsal }\end{array}$ & $\%$ & $\begin{array}{l}\text { Anteil an mineralisiertem Knochen bezogen auf die } \\
\text { dorsale distale Kortikalisfläche }\end{array}$ \\
\hline
\end{tabular}

\section{Kallus}

Tabelle 6: Messgrößen Kallus mit Einheit und Bedeutung

\begin{tabular}{|l|l|l|}
\hline Messgröße & Einheit & Bedeutung \\
\hline $\begin{array}{l}\text { Kallusdicke } \\
\text { ventromedial }\end{array}$ & $\mathrm{mm}$ & $\begin{array}{l}\text { Mittelwert der fünf Vektorenbeträge aus } \\
\text { Arbeitsschritt 7 }\end{array}$ \\
\hline Kallussdicke dorsal & $\mathrm{mm}$ & $\begin{array}{l}\text { Mittelwert der fünf Verktorenbeträge aus } \\
\text { Arbeitsschritt 8 }\end{array}$ \\
\hline $\begin{array}{l}\text { Kallussdichte } \\
\text { ventromedial }\end{array}$ & $\%$ & $\begin{array}{l}\text { Anteil an mineralisiertem Knochen bezogen auf die } \\
\text { ventromediale Kallusfläche }\end{array}$ \\
\hline Kallusdichte dorsal & $\%$ & $\begin{array}{l}\text { Anteil an mineralisiertem Knochen bezogen auf die } \\
\text { dorsale Kallusfläche }\end{array}$ \\
\hline Kallusdichte endostal & $\%$ & $\begin{array}{l}\text { Anteil an mineralisiertem Knochen bezogen auf die } \\
\text { endostale Kallusfläche }\end{array}$ \\
\hline
\end{tabular}




\section{Trabekel}

Tabelle 7: Messgrößen Trabekel mit Einheit und Bedeutung

\begin{tabular}{|l|l|l|}
\hline Messgröße & Einheit & Bedeutung \\
\hline Trabekeldichte distal & $\%$ & $\begin{array}{l}\text { Anteil an mineralisiertem Knochen bezogen auf die } \\
\text { distale Trabekelfläche }\end{array}$ \\
\hline $\begin{array}{l}\text { Anzahl der } \\
\text { Trabekelkreuzungen }\end{array}$ & $\mathrm{n}$ & $\begin{array}{l}\text { absolute Anzahl der Trabekelkreuzungen in der } \\
\text { distalen Trabekelfläche }\end{array}$ \\
\hline $\begin{array}{l}\text { Dichte der } \\
\text { Trabekelkreuzungen }\end{array}$ & $1 / \mathrm{mm}^{2}$ & $\begin{array}{l}\text { Anzahl der Trabekelkreuzungen pro } \mathrm{mm}^{2} \text { distaler } \\
\text { Trabekelfläche }\end{array}$ \\
\hline Mittlere Trabekeldicke & $\mu \mathrm{m}$ & $\begin{array}{l}\text { Mittelwert der Trabekeldurchmesser in der distalen } \\
\text { Trabekelfläche }\end{array}$ \\
\hline
\end{tabular}

Die Messgrößenbezeichnung erfolgte in Anlehnung an die ASBMR-Nomenklatur von Parfitt et al. (1987).

\subsection{Polychrome Sequenzmarkierung}

\subsubsection{Auswertung der polychromen Sequenzmarkierung}

Für die Begutachtung und Auswertung der histologischen Präparate wurde ein AuflichtFluoreszenz-Stereomakroskop (Leica Stereomakroskop MZ 7-5 mit Fluo-Combi III, Bensheim, Deutschland) unter Blaufluoreszenz verwendet sowie eine Quecksilberhöchstdrucklampe mit einer Leistung von 50 W (Leica KL 1500 LCD, Bensheim, Deutschland). Da die Fluorochrome zunächst durch blaues Licht angeregt werden mussten, um die gewünschte sichtbare Intensität zu erreichen, gebrauchte man einen Anregungsfilter für den Wellenlängenbereich von 450-490 nm. Das Einlesen der Bilder in den Computer (Intel Pentium 4, $2.6 \mathrm{GHz}$ ) erfolgte mithilfe einer Kamera (Leica DC 300F, Bensheim, Deutschland). Darauffolgend konnte mittels der Software Leica QuantimetQwin 2003 (Leica DM-RXE, Bensheim, Deutschland) die morphometrische Auswertung der Präparate durchgeführt werden.

In vorhergegangenen Versuchen wurden durch Austestung der Konfigurationsmöglichkeiten der Apparaturen die im Folgenden beschriebenen Einstellungen als optimal befunden:

Für das Makroskop wählte man ein 10,0er Okular und ein 1,0er Objektiv, wodurch eine 10fache Vergrößerung erzielt wurde. Diese ermöglichte die vollständige Abbildung der zu 
untersuchenden Strukturen bei bestmöglicher Ausnutzung des Monitors. Die Belichtungszeit erfolgte im Bereich von 9,7 bis 12,9s.

\subsubsection{Algorithmus zur digitalen morphometrischen Auswertung}

Für die digitale morphometrische Auswertung der PSM wurde ebenfalls die Software QuantimetQwin 2003 verwendet. Das Arbeitsverfahren folgte dabei wiederum einem für diese Untersuchung festgelegten Programm. Während der Messungen waren die den histologischen Schnitten zugehörigen Gruppen nicht bekannt, die Auswertung erfolgte demnach verblindet. Die Arbeitschritte stellten sich wie folgt dar:

\section{Arbeitsschritt 1: Einlesen der Präparate}

Die Positionierung der Aufnahmen auf dem Makroskop und das Einlesen der Präparate in den Computer erfolgte analog der Vorgehensweise wie bei der Mikroradiographie (s. 2.9.3).

\section{Arbeitsschritt 2: Flächendefinition}

Die Flächendefinition geschah analog zur Auswertung der Mikroradiographien (2.9.3). Der Kallus fluoreszierte aufgrund seiner hohen Umbaurate am stärksten, während die Kortikalis entsprechend ihrer niedrigen Umbaurate eine deutlich geringere Fluoreszenz aufwies.
a) Gesamte Knochenfläche mitsamt Kallus
b) Kortikalisfläche proximal-ventromedial
c) Kortikalisfläche proximal-dorsal
d) Kortikalisfläche distal-ventromedial
e) Kortikalisfläche distal-dorsal
f) Kallusfläche ventromedial
g) Kallusfläche dorsal
h) Kallusfläche endostal

\section{Arbeitsschritt 3: Bestimmung der Fluorochrom-markierten Knochenflächen}

Für die Flächen-Fluorochrom-Zuordnung genügte es, die ventromediale, die dorsale und die endostale Kallusfläche zu betrachten. Wie zuvor beschrieben, erfolgte anschließend die 
Abgrenzung der Bereiche mit gleichen fluoreszierenden Eigenschaften, deren Gruppierung und Zuordnung zu dem jeweiligen Fluorochrom.

Die Software gab folgende Reihenfolge der Flächen-Fluorochrom-Zuordnung vor: XO => $\mathrm{CG}=>\mathrm{AK}=>\mathrm{TC}$.

Während der Betrachtung der Präparate wurden viele winzige XO-Flächen sichtbar. Allerdings waren diese von CG-fluoreszierenden Knochenbereichen umgeben und es zeigte sich nur bei hoher Auflösung die Möglichkeit der Abgrenzung. Eine Flächendefinition der XO-Flächen war somit mit dem beschriebenen Verfahren nicht möglich und erfolgte entsprechend nur für die Fluorochrome CG, AK und TC. Dabei wurden nicht kalzifizierte Bereiche, die von Kallus umgeben waren, zu keiner der fluoreszierenden Flächen gezählt.

\section{Messparameter}

\section{Ventromedialer Kallus}

Tabelle 8: Messgrößen für den ventromedialen Kallus mit Einheit und Bedeutung

\begin{tabular}{|l|l|l|}
\hline $\begin{array}{l}\text { Kallusfläche } \\
\text { ventromedial }\end{array}$ & Einheit & Bedeutung \\
\hline Gesamt-Kallusfläche & $\mathrm{mm}^{2}$ & absolute Fläche des ventromedialen Kallus \\
\hline CG-markierte Fläche & $\mathrm{mm}^{2}$ & $\begin{array}{l}\text { absolute Fläche des CG-markierten ventromedialen } \\
\text { Kallus }\end{array}$ \\
\hline AK-markierte Fläche & $\mathrm{mm}^{2}$ & $\begin{array}{l}\text { absolute Fläche des AK-markierten ventromedialen } \\
\text { Kallus }\end{array}$ \\
\hline TC-markierte Fläche & $\mathrm{mm}^{2}$ & $\begin{array}{l}\text { absolute Fläche des TC-markierten ventromedialen } \\
\text { Kallus }\end{array}$ \\
\hline
\end{tabular}




\section{Dorsaler Kallus}

Tabelle 9: Messgrößen für den dorsalen Kallus mit Einheit und Bedeutung

\begin{tabular}{|l|l|l|}
\hline Kallusfläche dorsal & Einheit & Bedeutung \\
\hline Gesamtfläche Kallus & $\mathrm{mm}^{2}$ & absolute Fläche des dorsalen Kallus \\
\hline CG-markierte Fläche & $\mathrm{mm}^{2}$ & absolute Fläche des CG-markierten dorsalen Kallus \\
\hline AK-markierte Fläche & $\mathrm{mm}^{2}$ & absolute Fläche des AK-markierten dorsalen Kallus \\
\hline TC-markierte Fläche & $\mathrm{mm}^{2}$ & absolute Fläche des TC-markierten dorsalen Kallus \\
\hline
\end{tabular}

\section{Endostaler Kallus}

Tabelle 10: Messgrößen für den endostalen Kallus mit Einheit und Bedeutung

\begin{tabular}{|l|l|l|}
\hline Messgröße & Einheit & Bedeutung \\
\hline Gesamt-Kallusfläche & $\mathrm{mm}^{2}$ & absolute Fläche des endostalen Kallus \\
\hline CG-markierte Fläche & $\mathrm{mm}^{2}$ & $\begin{array}{l}\text { absolute Fläche des CG-markierten endostalen } \\
\text { Kallus }\end{array}$ \\
\hline AK-markierte Fläche & $\mathrm{mm}^{2}$ & $\begin{array}{l}\text { absolute Fläche des AK-markierten endostalen } \\
\text { Kallus }\end{array}$ \\
\hline TC-markierte Fläche & $\mathrm{mm}^{2}$ & $\begin{array}{l}\text { absolute Fläche des TC-markierten endostalen } \\
\text { Kallus }\end{array}$ \\
\hline
\end{tabular}

\section{Gesamter Kallus}

Tabelle 11: Messgrößen für den gesamten Kallus mit Einheit und Bedeutung

\begin{tabular}{|l|l|l|}
\hline Messgröße & Einheit & Bedeutung \\
\hline Kallusfläche total & $\mathrm{mm}^{2}$ & $\begin{array}{l}\text { Summe aus den Gesamt-Kallusflächen } \\
\text { ventromedial, dorsal und endostal }\end{array}$ \\
\hline
\end{tabular}




\subsection{Validierung}

Durch die benutzerabhängige Farbwahrnehmung kann es zu einer Beeinflussung der Methodenausführung und damit zu benutzerbedingten Messschwankungen kommen. Dem wurde Rechnung getragen, indem ein Untersucher alle Präparate auswertete und vor Auswertungsbeginn eine Prüfung auf Reproduzierbarkeit durchführte. Hierbei wurden fünf randomisiert ausgewählte Präparate an fünf aufeinander folgenden Tagen wiederholt ausgewertet. Kam es zu keiner Abweichung der Einzelergebnisse von mehr als $\pm 10 \%$ vom Mittelwert, konnte mit der Auswertung begonnen werden.

\subsection{Statistik}

Mit der Software GraphPad Prism (Version 4.00c, April 2003, GraphPad Software Inc., San Diego, USA) wurden die Ergebnisse statistisch ausgewertet. Hierfür wurden alle beschriebenen Messparameter, nach Testgruppen aufgeteilt, in erster Linie auf eine Gauß'sche Normalverteilung geprüft. Für alle Daten traf dies zu.

Daraufhin wurden jeweils Mittelwert und Standardabweichung bestimmt. Die Ermittlung signifikanter Unterschiede zwischen den einzelnen Testgruppen und deren genauere Identifizierung erfolgte im Anschluss durch Kombination aus one-way ANOVA und Tukey-Kramer post-hoc Test. Signifikanzniveau war dabei der p-Wert $\alpha<0,05$. 


\section{Ergebnisse}

\subsection{Körpergewicht und Futteraufnahme}

Die folgenden graphischen und tabellarischen Darstellungen liefern eine Übersicht über das Körpergewicht der Tiere und deren durchschnittliche tägliche Futteraufnahme im Versuchsverlauf. In den Tabellen wird jeweils das durchschnittliche Gewicht der Tiere einer Gruppe \pm Standardabweichung (SD) angegeben. Das Körpergewicht der Tiere wurde jeweils zu Beginn einer Versuchswoche dokumentiert. Die Berechnung der verbrauchten Futtermenge erfolgte am Ende einer Woche. Die Osteotomie mit anschließender Osteosynthese der Tibiae wurde in der zehnten Woche durchgeführt.

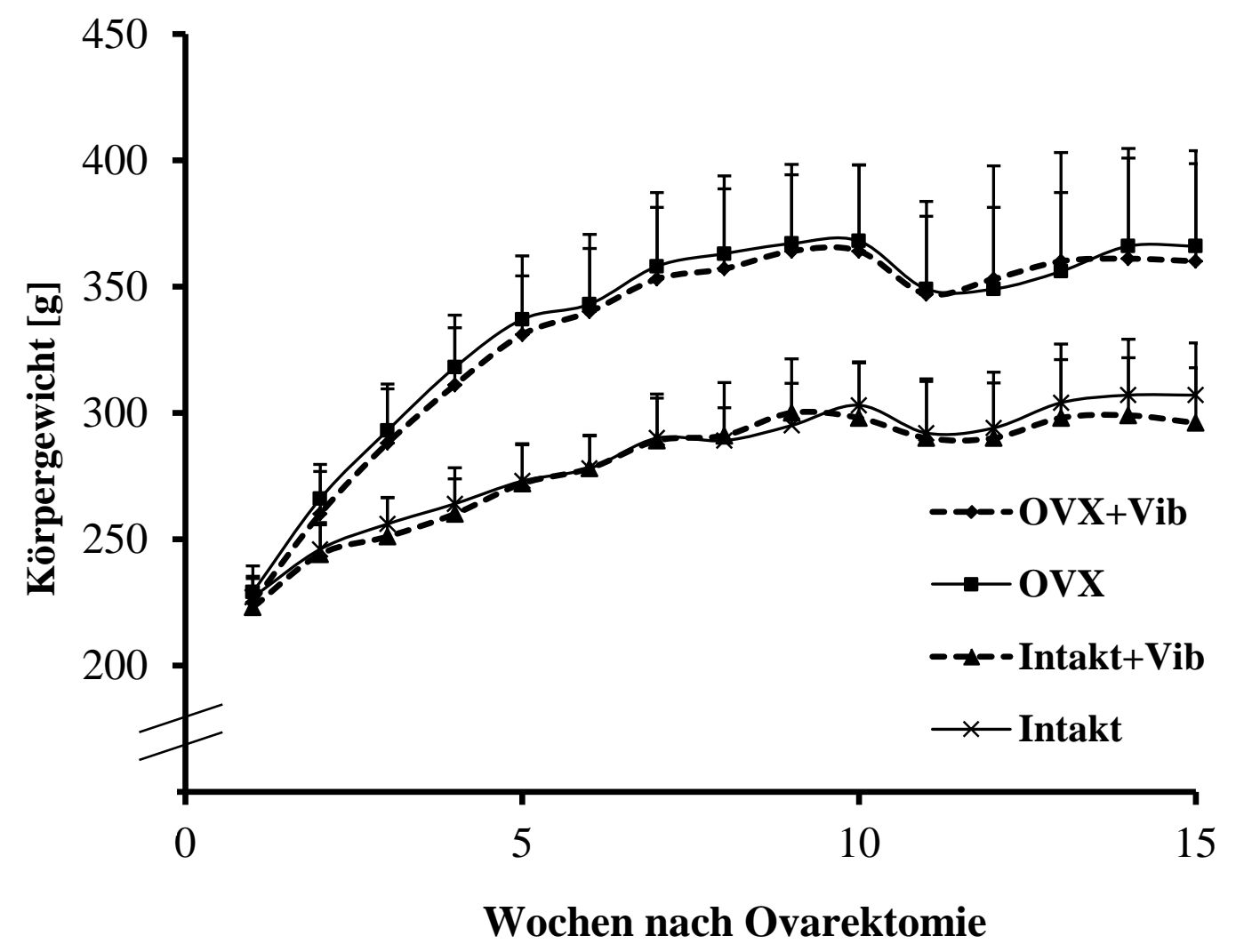

Abbildung 7: Darstellung des durchschnittlichen Körpergewichts der Ratten jeder Gruppe [g] in den Versuchswochen nach Ovarektomie (Angabe als Mittelwert (MW \pm SD) 
Tabelle 12: Darstellung des durchschnittlichen Körpergewichts der Tiere jeder Gruppe [g] in den Versuchswochen nach Ovarektomie (Angabe als MW \pm SD)

\begin{tabular}{|l|l|l|l|l|}
\hline Woche & OVX & OVX+Vib & Intakt & Intakt+Vib \\
\hline $\mathbf{1}$ & $228.63 \pm 10.36$ & $225.15 \pm 9.40$ & $227.02 \pm 8.32$ & $223.11 \pm 8.04$ \\
\hline $\mathbf{2}$ & $266.00 \pm 13.52$ & $259.53 \pm 16.83$ & $246.33 \pm 10.60$ & $243.57 \pm 11.67$ \\
\hline $\mathbf{3}$ & $293.21 \pm 18.35$ & $288.27 \pm 21.46$ & $256.06 \pm 10.59$ & $250.54 \pm 15.35$ \\
\hline $\mathbf{4}$ & $317.82 \pm 20.72$ & $310.81 \pm 22.68$ & $264.19 \pm 14.26$ & $260.44 \pm 13.81$ \\
\hline $\mathbf{5}$ & $336.89 \pm 25.17$ & $330.97 \pm 23.25$ & $272.97 \pm 14.38$ & $271.77 \pm 15.72$ \\
\hline $\mathbf{6}$ & $342.80 \pm 27.67$ & $339.57 \pm 25.05$ & $277.71 \pm 12.84$ & $278.18 \pm 13.22$ \\
\hline $\mathbf{7}$ & $357.75 \pm 29.26$ & $353.31 \pm 28.34$ & $289.80 \pm 15.78$ & $288.64 \pm 18.48$ \\
\hline $\mathbf{8}$ & $362.49 \pm 30.80$ & $357.43 \pm 31.62$ & $288.53 \pm 13.08$ & $290.83 \pm 20.93$ \\
\hline $\mathbf{9}$ & $367.33 \pm 31.32$ & $364.07 \pm 30.16$ & $294.58 \pm 16.64$ & $299.85 \pm 21.33$ \\
\hline $\mathbf{1 0}$ & $367.95 \pm 30.26$ & $363.45 \pm 34.05$ & $303.18 \pm 17.17$ & $297.60 \pm 21.74$ \\
\hline $\mathbf{1 1}$ & $349.03 \pm 28.82$ & $347.31 \pm 36.70$ & $291.71 \pm 21.46$ & $290.26 \pm 22.45$ \\
\hline $\mathbf{1 2}$ & $349.42 \pm 32.34$ & $352.51 \pm 44.77$ & $294.39 \pm 22.13$ & $290.24 \pm 21.76$ \\
\hline $\mathbf{1 3}$ & $355.99 \pm 31.19$ & $359.65 \pm 43.05$ & $303.94 \pm 23.28$ & $298.43 \pm 23.09$ \\
\hline $\mathbf{1 4}$ & $366.09 \pm 34.90$ & $361.03 \pm 43.67$ & $307.16 \pm 22.18$ & $298.96 \pm 22.77$ \\
\hline $\mathbf{1 5}$ & $366.44 \pm 32.61$ & $360.17 \pm 43.75$ & $304.30 \pm 20.70$ & $296.37 \pm 21.91$ \\
\hline
\end{tabular}

Bei Betrachtung des durchschnittlichen Körpergewichtsverlaufs in den einzelnen Gruppen lässt sich feststellen, dass WBV keinen signifikanten Effekt auf das Körpergewicht der Versuchstiere hat $(\mathrm{p}>0.05)$.

Anders verhält es sich nach Ovarektomie (vgl. Abb. 7; Tab. 12). Hier kam es schon nach einer Woche zu einer signifikanten Gewichtszunahme der ovarektomierten im Vergleich zu den intakten Tieren $(\mathrm{p}<0.05)$. Innerhalb der ersten vier Wochen erhöhte sich das Körpergewicht der ovarektomierten Ratten weiterhin deutlich, von $225 \pm 2.5$ g auf $334 \pm$ $6.2 \mathrm{~g}(\mathrm{p}<0.001)$. In den darauffolgenden Wochen verlangsamte sich die Gewichtzunahme und erreichte in der zehnten Woche ihr Maximum bei $368 \pm 6.5$ g vor Durchführung der Osteotomie. Im Kontrast dazu konnte bei den intakten Tieren innerhalb dieser zehn Wochen eine wesentlich langsamere Gewichtszunahme von $225 \pm 2.2$ g auf nur $303 \pm 4.5$ g gemessen werden. 
Nach der Osteotomie kam es zu einem leichten Abfall des Körpergewichts aller Tiere, welches aber innerhalb der folgenden Wochen bis zum Ende des Versuchs wieder bis auf das Gewicht vor der Osteotomie anstieg.

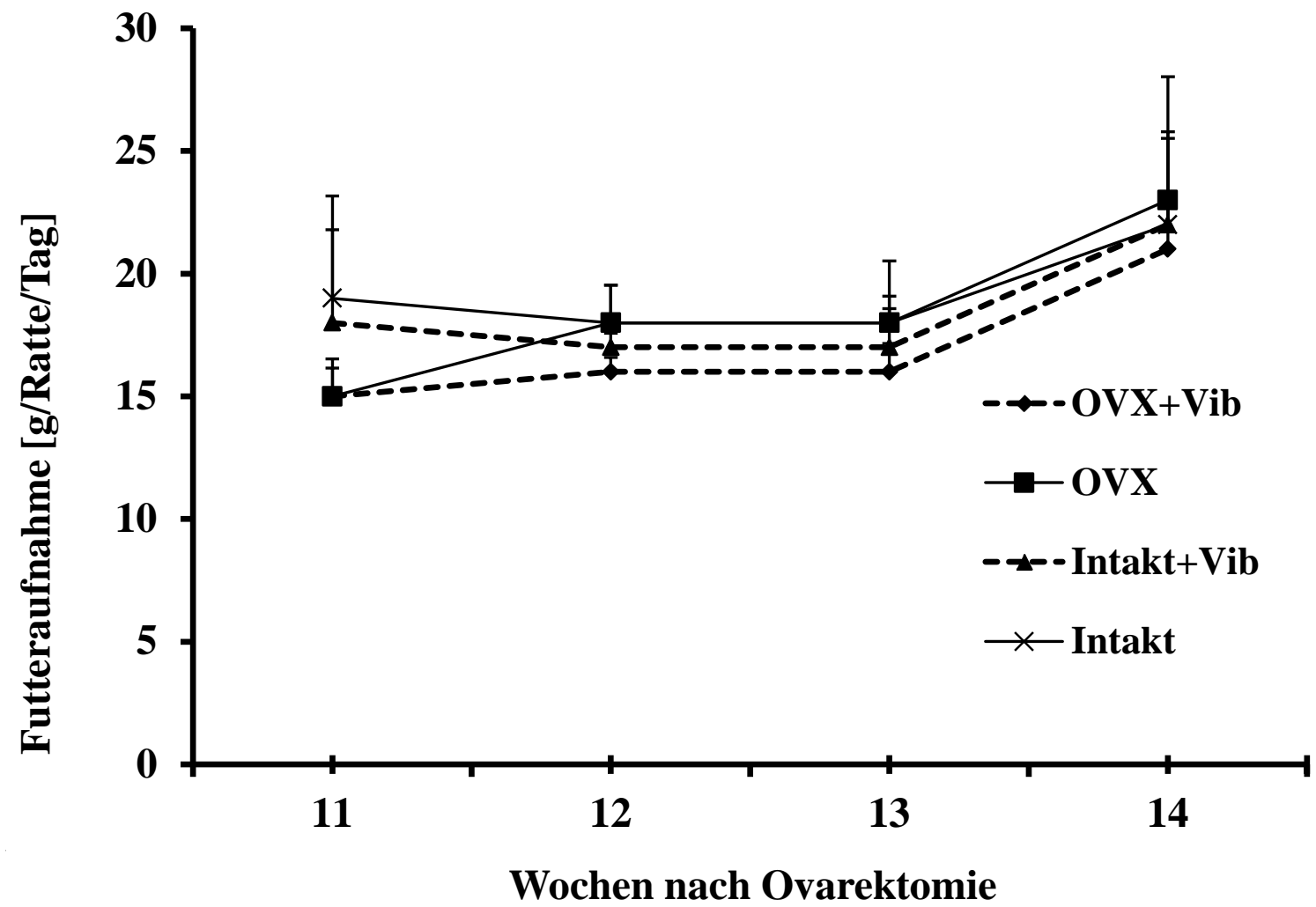

Abbildung 8: Darstellung der durchschnittlichen täglichen Futteraufnahme pro Tier jeder Gruppe [g] in den Wochen nach Osteotomie (Angabe als MW \pm SD)

Tabelle 13: Darstellung der durchschnittlichen täglichen Futteraufnahme pro Tier jeder Gruppe [g] in den Wochen nach Osteotomie (Angabe als MW \pm SD)

\begin{tabular}{|l|l|l|l|l|}
\hline $\begin{array}{l}\text { Woche nach } \\
\text { Osteotomie }\end{array}$ & OVX & OVX+Vib & Intakt & Intakt+Vib \\
\hline $\mathbf{1}$ & $15.33 \pm 1.53$ & $14.67 \pm 1.15$ & $18.67 \pm 3.79$ & $18.34 \pm 4.16$ \\
\hline $\mathbf{2}$ & $18.33 \pm 0.58$ & $16.30 \pm 1.53$ & $18.33 \pm 0.58$ & $17.33 \pm 1.53$ \\
\hline $\mathbf{3}$ & $17.67 \pm 1.15$ & $15.67 \pm 0.58$ & $17.67 \pm 2.08$ & $17.33 \pm 2.52$ \\
\hline $\mathbf{4}$ & $22.67 \pm 2.31$ & $20.67 \pm 5.03$ & $21.67 \pm 3.79$ & $22.33 \pm 3.51$ \\
\hline
\end{tabular}


Die durchschnittliche tägliche Futteraufnahme war während des Versuchs bei allen Gruppen ähnlich (vgl. Abb. 8; Tab. 13). So betrug die durchschnittlich täglich konsumierte Futtermenge in der fünften Woche nach Osteotomie $17 \mathrm{~g} \pm 1 \mathrm{~g}$ bei allen Tieren. WBV und Ovarektomie zeigten keinen signifikanten Effekt auf die Futteraufnahme ( $>0.05$ ).

\subsection{Uterusgewicht}

Tabelle 14: Darstellung des durchschnittlichen Uterusgewichts [mg] pro Tier jeder Gruppe am Tag der Tötung (Angabe als MW \pm SD)

\begin{tabular}{|l|l|l|l|l|}
\hline & OVX & OVX+Vib & Intakt & Intakt+Vib \\
\hline $\begin{array}{l}\text { Uterusgewicht } \\
\text { [mg] }\end{array}$ & $100 \pm 23$ & $100 \pm 20$ & $600 \pm 150$ & $560 \pm 160$ \\
\hline
\end{tabular}

Am Tag der Tötung war das durchschnittliche Uterusgewicht der intakten Ratten signifikant höher als bei den ovarektomierten Tieren ( $\mathrm{p}<0.001)$, während die WBV keine signifikanten Effekte auf das Uterusgewicht ( $\mathrm{p}>0.05$ ) zeigte (siehe Tab. 14).

\subsection{Auswertung des biomechanischen Biegetests}

Die Darstellung der Messungen erfolgt zunächst in Form von Säulendiagrammen, wobei jeweils die Mittelwerte und Standardabweichungen angegeben werden. Im Anschluss werden die ermittelten Werte tabellarisch zusammengefasst. 


\subsubsection{Elastizität}

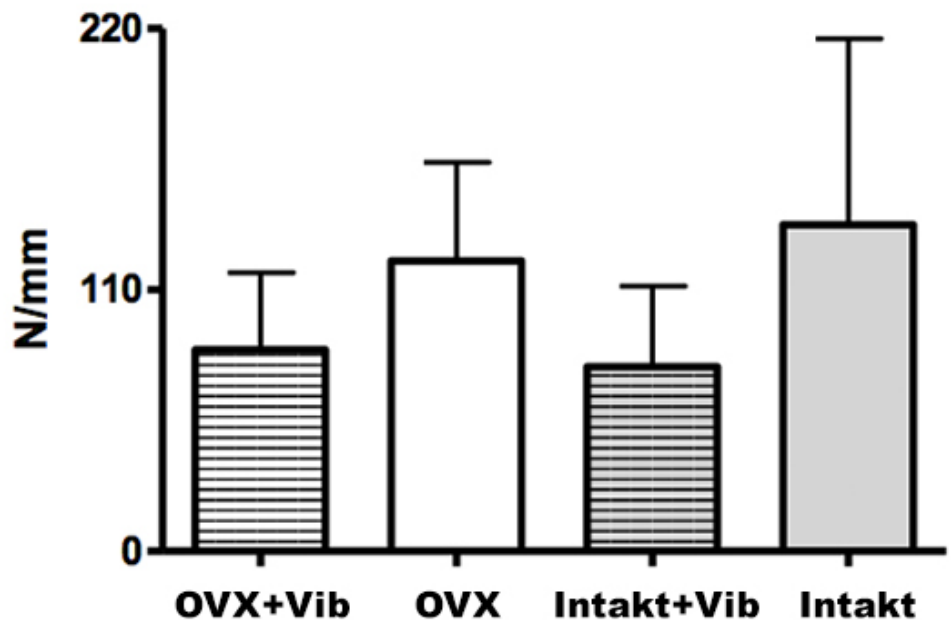

Abbildung 9: Elastizität $[\mathrm{N} / \mathrm{mm}]$ des metaphysären Tibiakallus im biomechanischen Biegetest bei ovarektomierten und intakten Ratten mit und ohne vertikale WBV von $90 \mathrm{~Hz}$ (Angabe als MW \pm SD)

Die Gruppen mit WBV weisen im Vergleich zu den nicht-vibrierten Kontrollgruppen niedrigere Werte für den Parameter der Elastizität auf (Abb. 9). Die Unterschiede sind statistisch jedoch nicht signifikant $(\mathrm{p}>0.05)$. 


\subsubsection{Streckgrenze}

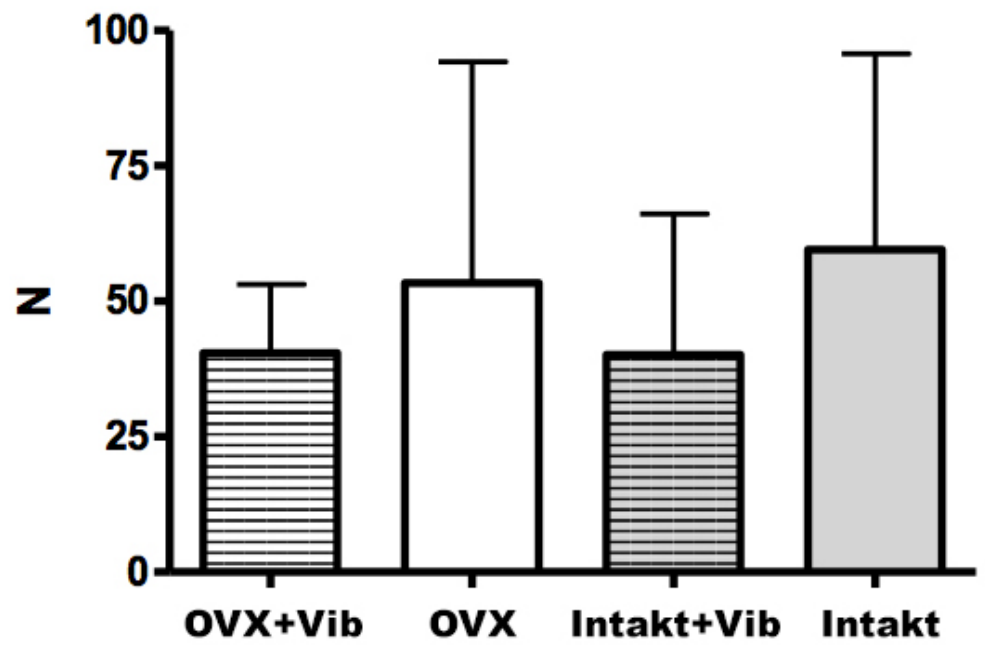

Abbildung 10: Streckgrenze [N] des metaphysären Tibiakallus im biomechanischen Biegetest bei ovarektomierten und intakten Ratten mit und ohne vertikale WBV von $90 \mathrm{~Hz}$ (Angabe als MW \pm SD)

Auch die die Streckgrenze betreffenden Ergebnisse ergeben keine signifikanten Unterschiede zwischen den einzelnen Gruppen ( $p$ > 0.05). Die Gruppen mit WBV weisen auch hier im Vergleich zu den nicht-vibrierten Kontrollgruppen niedrigere Werte auf (siehe Abb. 10; Tab. 15).

Tabelle 15: Elastizität [N/mm] und Streckgrenze [N] im biomechanischen Biegetest (Angabe als MW \pm SD)

\begin{tabular}{|l|l|l|l|l|}
\hline & OVX+Vib & OVX & Intakt+Vib & Intakt \\
\hline $\begin{array}{l}\text { Elastizität } \\
\text { [N/mm] }\end{array}$ & $84.81 \pm 32.82$ & $122.20 \pm 41.42$ & $77.62 \pm 33.40$ & $137.50 \pm 78.14$ \\
\hline $\begin{array}{l}\text { Streckgrenze } \\
\text { [N] }\end{array}$ & $40.42 \pm 12.73$ & $53.38 \pm 40.81$ & $40.11 \pm 25.99$ & $59.56 \pm 36.19$ \\
\hline
\end{tabular}




\subsection{Auswertung der Mikroradiographien}

Nach Darstellung der einzelnen Messparameter in Säulendiagrammen folgt wiederum eine tabellarische Zusammenfassung aller Ergebnisse unter Angabe der Mittelwerte und Standardabweichungen (s. Tab. 16).

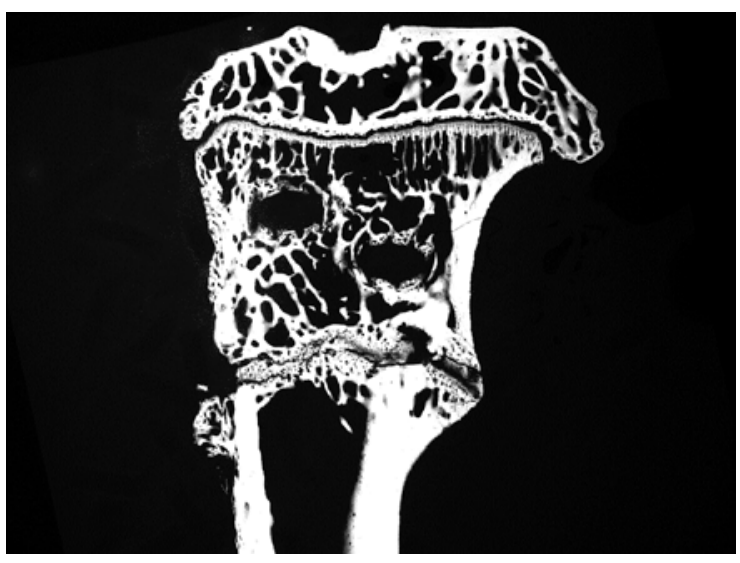

a) Mikroradiographie aus Gruppe OVX

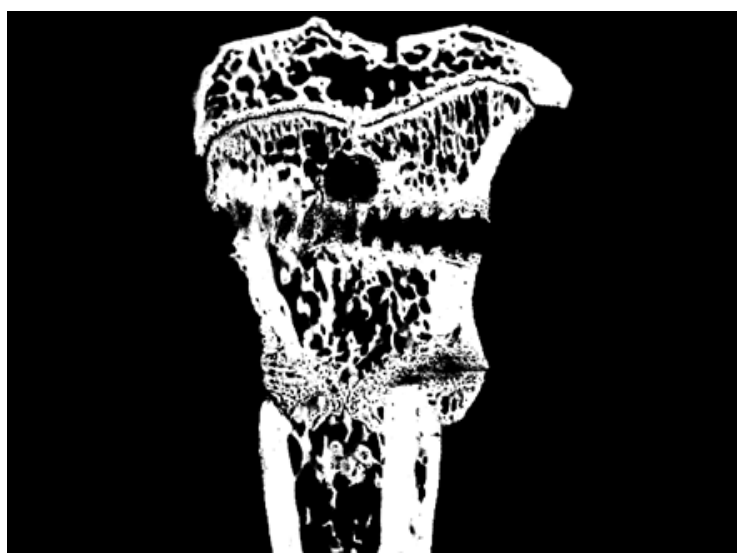

c) Mikroradiographie aus Gruppe Intakt

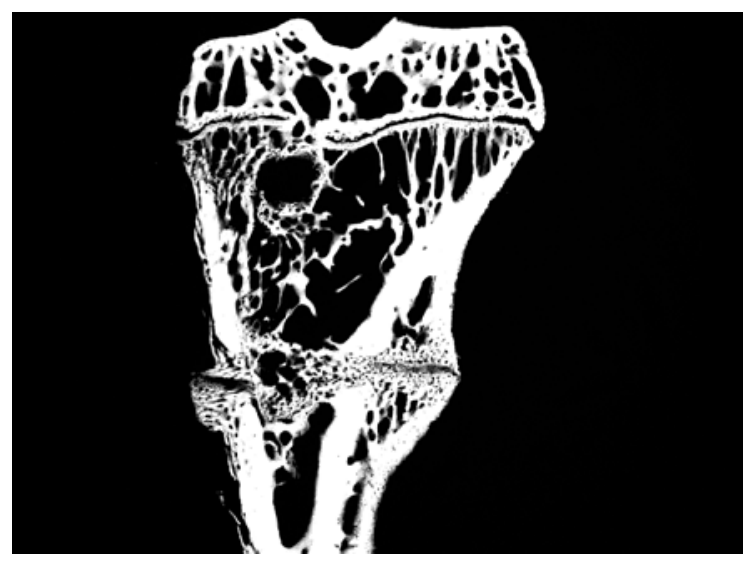

b) Mikroradiographie aus Gruppe OVX+Vib

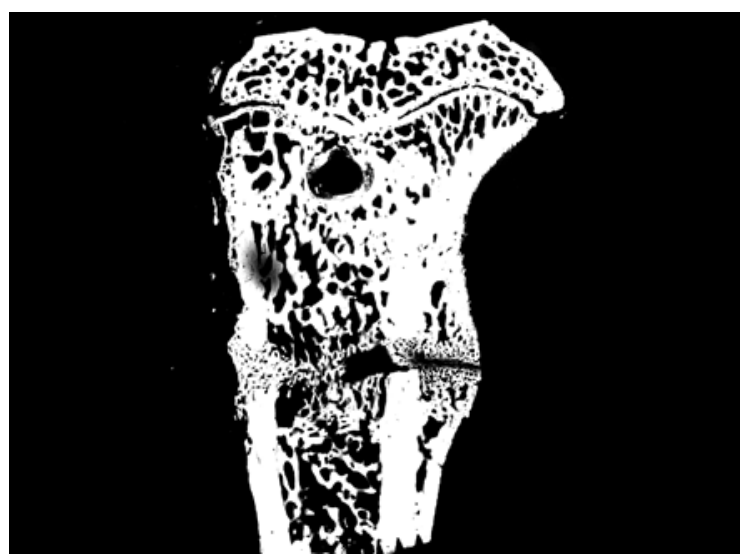

d) Mikroradiographie aus Gruppe Intakt+Vib

Abbildung 11: Typische Mikroradiographien der metaphysären Tibiaheilung der Gruppen OVX (a), OVX+Vib (b), Intakt (c) und Intakt+Vib (d). (zehnfache Vergrößerung) 


\subsubsection{Kortikalisdicke distal-ventromedial}

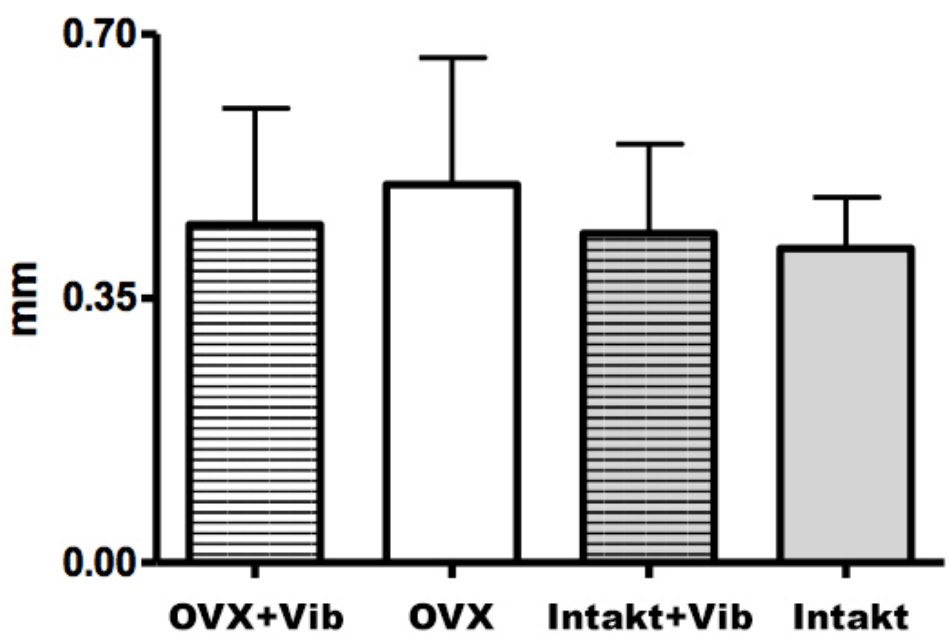

Abbildung 12: Kortikalisdicke distal-ventromedial [mm] bei ovarektomierten und intakten Ratten mit und ohne vertikale WBV von $90 \mathrm{~Hz}$ (Angabe als $\mathrm{MW} \pm \mathrm{SD}$ )

Für die distale ventromediale Kortikalisdicke fanden sich zwischen den untersuchten Gruppen keine signifikanten Unterschiede. Die im Mittelwert dickste distale ventromediale Kortikalis fand sich bei den OVX-Tieren (Abb. 12). 


\subsubsection{Kortikalisdicke distal-dorsal}

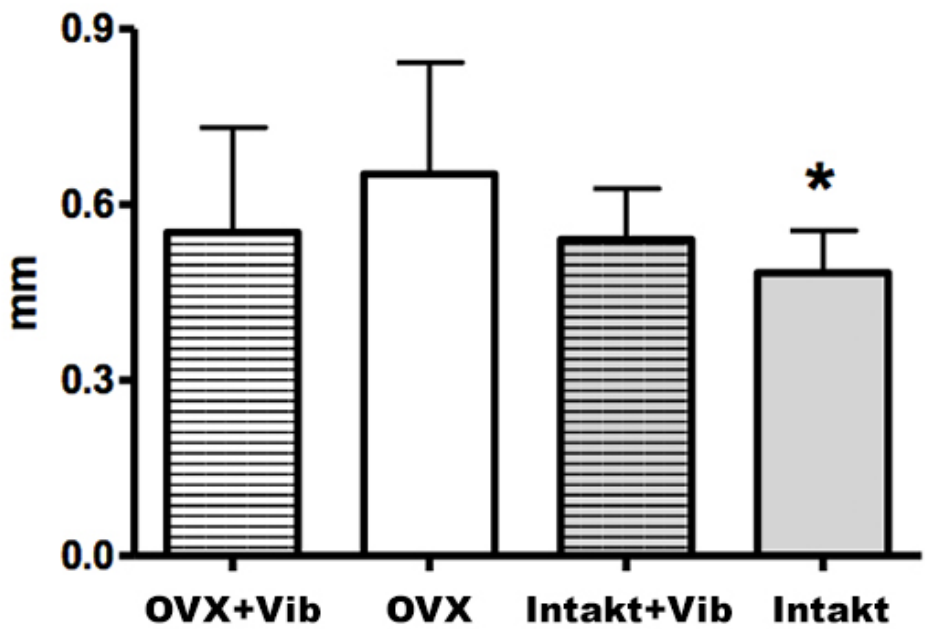

Abbildung 13: Kortikalisdicke distal-dorsal [mm] bei ovarektomierten und intakten Ratten mit und ohne vertikale WBV von $90 \mathrm{~Hz}$ (Angabe als $\mathrm{MW} \pm \mathrm{SD}$, * $\mathrm{p}<0.001$ vs. OVX)

Beim Vergleich der distalen dorsalen Kortikalisdicke fand sich ein signifikanter Unterschied bei den OVX- gegenüber den Intakt-Tieren $(\mathrm{p}<0.001)$. Die OVX-Tiere wiesen die höchsten Werte für die distale dorsale Kortikalis auf (Abb. 13). 


\subsubsection{Kortikalisdichte distal-ventromedial}

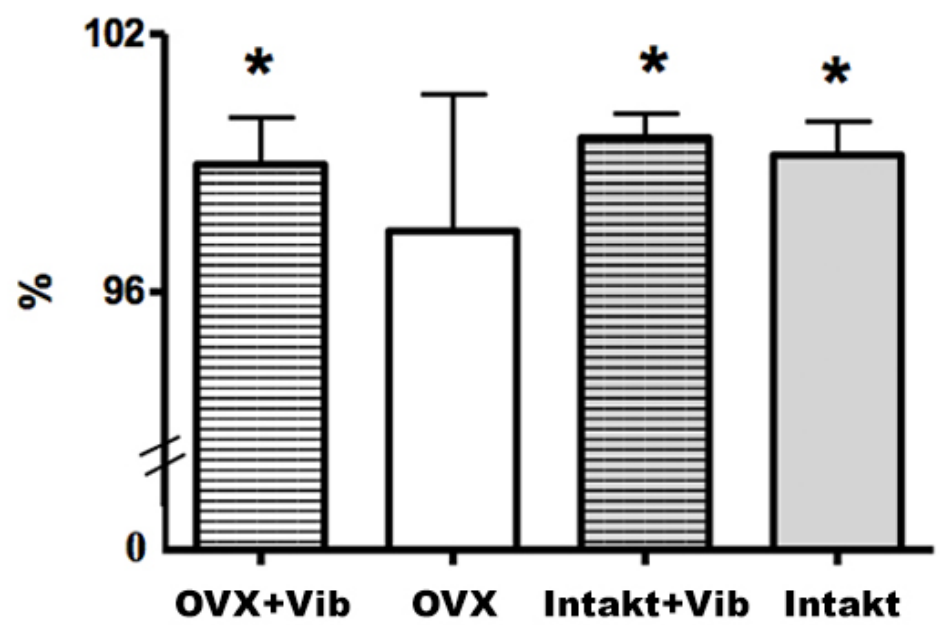

Abbildung 14: Kortikalisdichte distal-ventromedial [\%] bei ovarektomierten und intakten Ratten mit und ohne vertikale WBV von $90 \mathrm{~Hz}$ (Angabe als $\mathrm{MW} \pm \mathrm{SD}$, * $\mathrm{p}<0.05$ vs. OVX)

Beim Vergleich der distalen ventromedialen Kortikalisdichte zeigen sich signifikante Unterschiede zwischen den einzelnen Testgruppen. So sind die Werte signifikant erhöht bei den OVX+Vib $(\mathrm{p}<0.05)$ und den Intakt+Vib-Tieren $(\mathrm{p}<0.001)$ gegenüber den OVXTieren. Außerdem finden sich signifikant höhere Werte bei der Intakt- gegenüber der OVX-Testgruppe $(p<0.05$ ). Die höchsten Werte für die distale ventromediale Kortikalisdichte erzielt die Gruppe der Intakt+Vib-Tiere (Abb. 14). 


\subsubsection{Kortikalisdichte distal-dorsal}

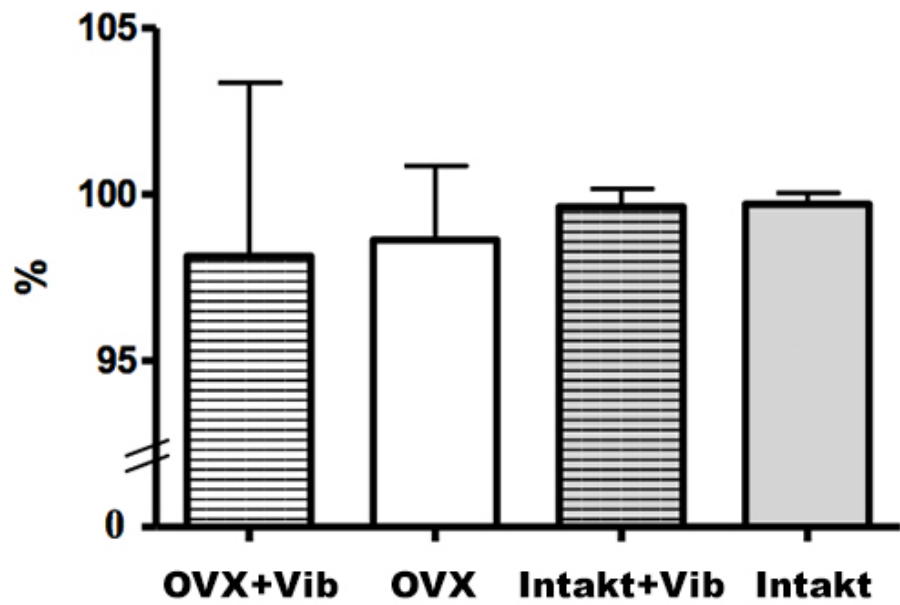

Abbildung 15: Kortikalisdichte distal-dorsal [\%] bei ovarektomierten und intakten Ratten mit und ohne vertikale WBV von $90 \mathrm{~Hz}$ (Angabe als $\mathrm{MW} \pm \mathrm{SD}$ )

Beim Vergleich der Werte für die distale dorsale Kortikalisdichte zeigen sich keine signifikanten Unterschiede ( $\mathrm{p}>0.05$ ). Die höheren Werte werden von den beiden intakten Gruppen erzielt (Abb. 15). 


\subsubsection{Kallusdicke ventromedial}

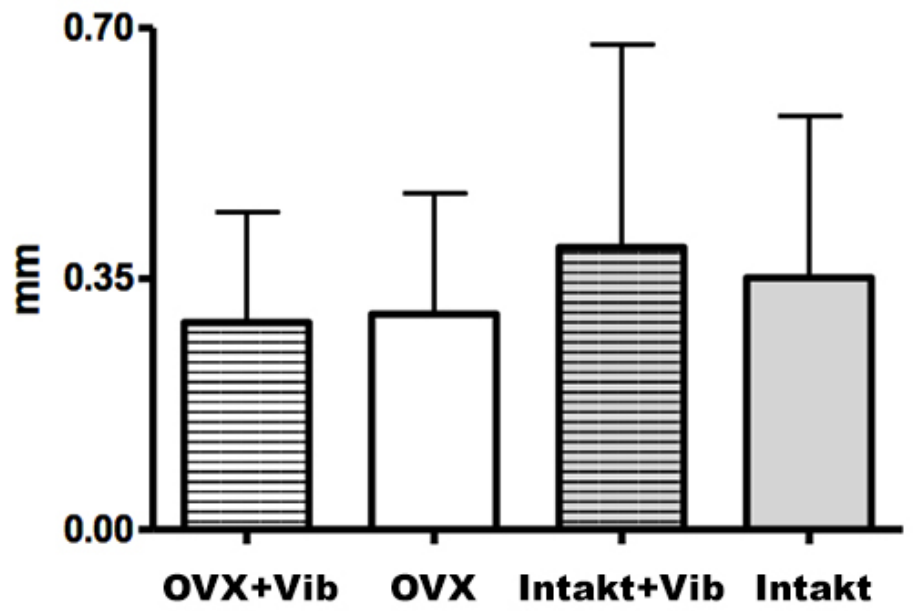

Abbildung 16: Kallusdicke ventromedial [mm] bei ovarektomierten und intakten Ratten mit und ohne vertikale WBV von $90 \mathrm{~Hz}$ (Angabe als MW \pm SD)

Beim Vergleich der ventromedialen Kallusdicke der unterschiedlichen Testgruppen zeigen sich keine signifikanten Unterschiede $(\mathrm{p}>0.05)$. Die höchsten Werte werden von den Intakt+Vib-Tieren erreicht (vgl. Abb. 16). 


\subsubsection{Kallusdicke dorsal}

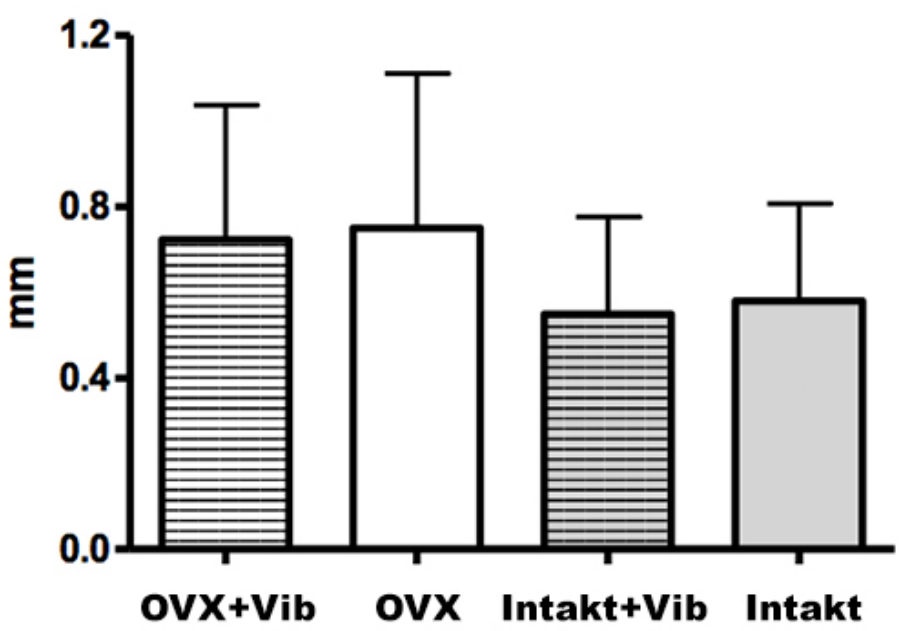

Abbildung 17: Kallusdicke dorsal [mm] bei ovarektomierten und intakten Ratten mit und ohne vertikale WBV von $90 \mathrm{~Hz}$ (Angabe als MW \pm SD)

Bezüglich der dorsalen Kallusdicke weisen die OVX-Tiere höhere Werte gegenüber den intakten Tieren auf. Die Unterschiede zwischen den einzelnen Testgruppen sind jedoch aufgrund der hohen Standardabweichung statistisch nicht signifikant ( $p>0.05)$. Die höchsten Werte finden sich bei den OVX-Tieren (vgl. Abb. 17). 


\subsubsection{Kallusdichte ventromedial}

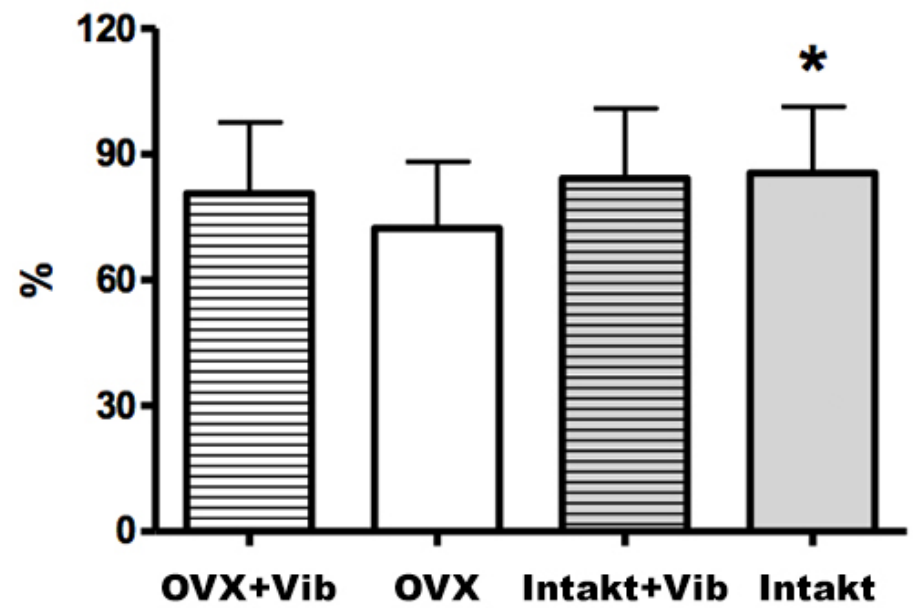

Abbildung 18: Kallusdichte ventromedial [\%] bei ovarektomierten und intakten Ratten mit und ohne vertikale WBV von $90 \mathrm{~Hz}$ (Angabe als MW \pm SD, * p $<0.05$ vs. OVX)

Die Dichte des ventromedialen Kallus ist bei der Intakt-Gruppe gegenüber der OVXGruppe signifikant erhöht $(\mathrm{p}<0.05)$. Zwischen den anderen Testgruppen finden sich keine signifikanten Unterschiede (vgl. Abb. 18). 


\subsubsection{Kallusdichte dorsal}

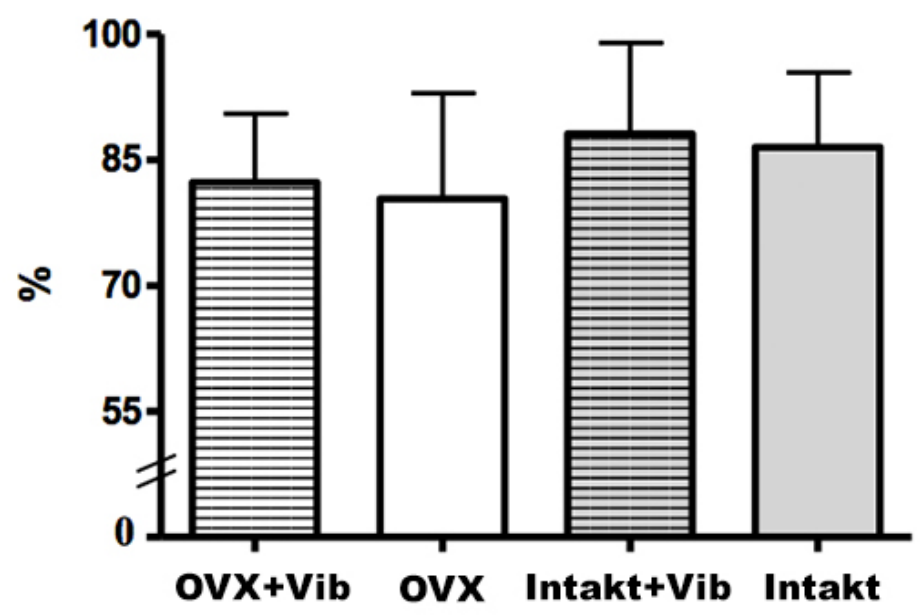

Abbildung 19: Kallusdichte dorsal [\%] bei ovarektomierten und intakten Ratten mit und ohne vertikale WBV von $90 \mathrm{~Hz}$ (Angabe als $\mathrm{MW} \pm \mathrm{SD}$ )

Die Testgruppen der OVX+Vib- und Intakt+Vib-Tiere zeigen erhöhte Werte bezüglich der dorsalen Kallusdichte gegenüber den nicht-vibrierten Kontrollgruppen (vgl. Abb. 19). Die Unterschiede stellen sich statistisch jedoch als nicht signifikant dar ( $p>0.05)$. 


\subsubsection{Kallusdichte endostal}

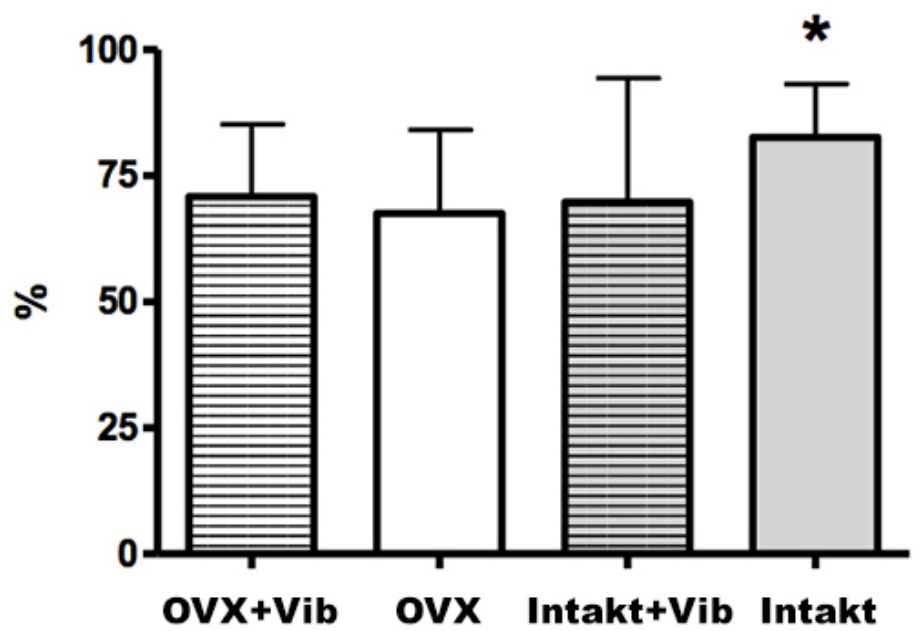

Abbildung 20: Endostale Kallusdichte [\%] bei ovarektomierten und intakten Ratten mit und ohne vertikale WBV von $90 \mathrm{~Hz}$ (Angabe als MW \pm SD, * p $<0.05$ vs. OVX)

Die Ergebnisse für die endostale Kallusdichte stellen sich ähnlich den Werten der Dichte des ventromedialen Kallus dar. Es zeigen sich signifikant unterschiedliche Werte zwischen der Intakt- und der OVX-Testgruppe, wobei die Intakt-Tiere die höheren Werte aufweisen (vgl. Abb. 20). Alle übrigen Unterschiede zwischen den Testgruppen sind statistisch nicht signifikant $(\mathrm{p}>0.05)$. 


\subsubsection{Trabekeldichte distal}

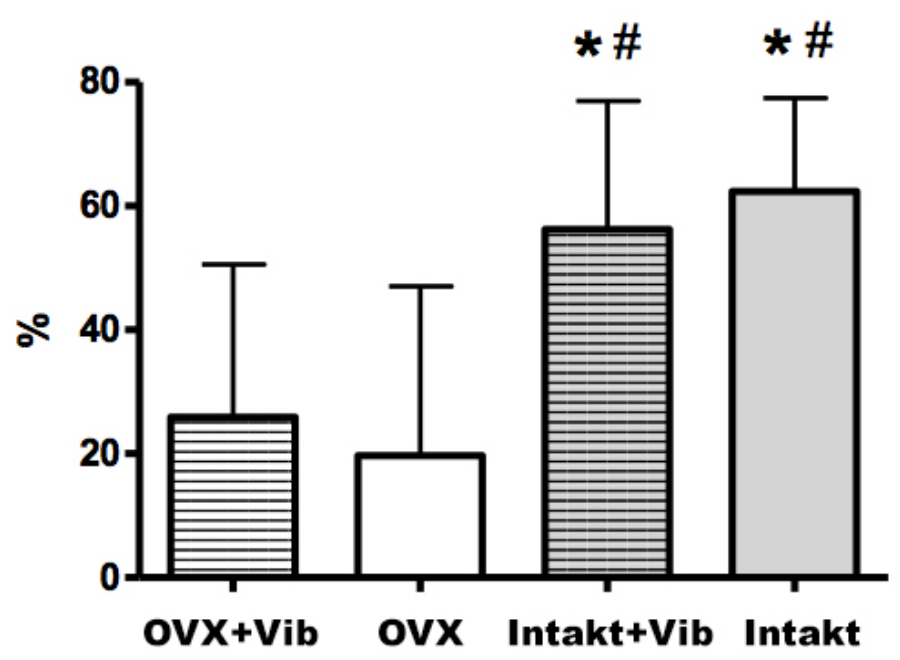

Abbildung 21: Distale Trabekeldichte [\%] bei ovarektomierten und intakten Ratten mit und ohne vertikale WBV von $90 \mathrm{~Hz}$ (Angabe als MW \pm SD, * p $<0.05$ vs. OVX, \# p $<0.05$ vs. OVX+Vib)

Die Werte der distalen Trabekeldichte weisen Signifikanzen $(\mathrm{p}<0.05)$ beim Vergleich der ovarektomierten mit den intakten Gruppen auf. Unterschiede innerhalb der Testgruppen zwischen den vibrierten und den nicht-vibrierten Tiere stellen sich als nicht signifikant dar ( $p>0.05$ ). Die niedrigste Dichte findet sich erwartungsgemäß bei den OVX-Tieren (vgl. Abb. 21). 


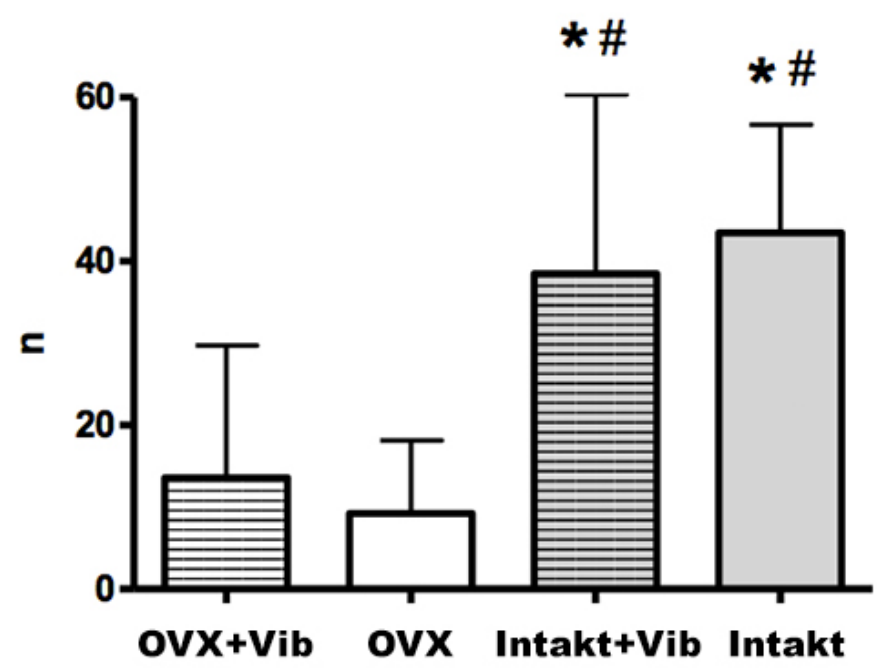

Abbildung 22: Gesamtzahl der Trabekelkreuzungen [n] im Meßrahmen bei ovarektomierten und intakten Ratten mit und ohne vertikale WBV von $90 \mathrm{~Hz}$ (Angabe als $\mathrm{MW} \pm \mathrm{SD}$, * p 0.05 vs. OVX, \# p 0.05 vs. OVX+Vib)

Es zeigen sich signifikante Unterschiede in der Anzahl der Trabekelkreuzungen zwischen den ovarektomierten Gruppen und den intakten Testgruppen $(\mathrm{p}<0.001)$. Die Anzahl ist bei den intakten Tieren signifikant höher als bei den ovarektomierten Tieren, wobei die Intakt-Tiere von allen Gruppen die höchsten Werte aufweisen (vgl. Abb. 22). Gegensätzlich dazu finden sich die wenigsten Trabekelkreuzungen erwartungsgemäß bei den OVX-Tieren. Statistisch nicht signifikant sind die Unterschiede innerhalb der ovarektomierten und der intakten Gruppen ( $\mathrm{p}>0.05)$. 


\subsubsection{Dichte Trabekelkreuzungen}

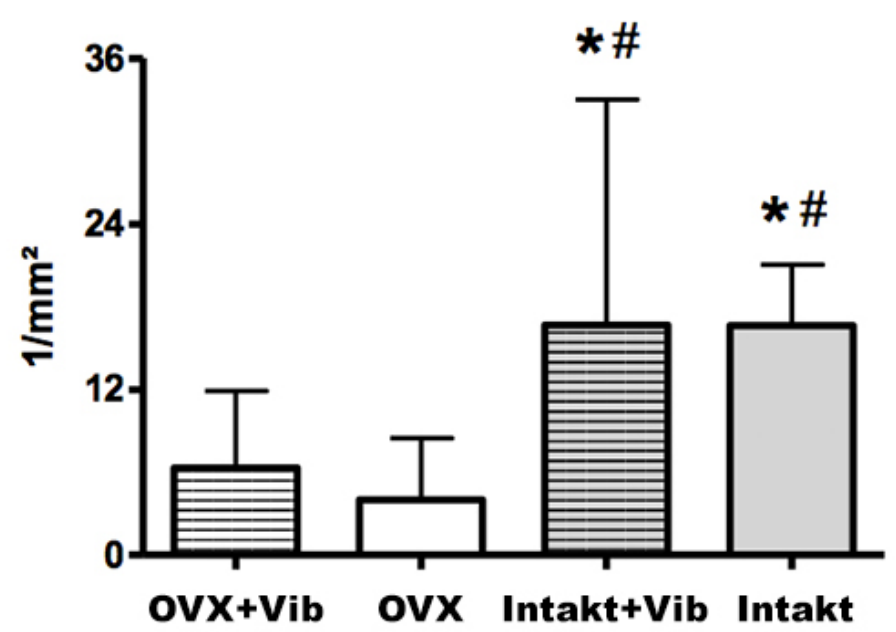

Abbildung 23: Dichte der Trabekelkreuzungen pro mm2 bei ovarektomierten und intakten Ratten mit und ohne vertikale WBV von $90 \mathrm{~Hz}$ (Angabe als MW \pm SD, * p $<0.05$ vs. OVX, \# p 0.05 vs. OVX+Vib)

Die Werte für die Dichte der Trabekelkreuzungen pro $\mathrm{mm}^{2}$ verhalten sich ähnlich den Werten für die Anzahl der Trabekelkreuzungen. Signifikanzen treten beim Vergleich der ovarektomierten mit den intakten Testgruppen auf, wobei auch hier die intakten Tiere die höheren Werte zeigen (vgl. Abb. 23). Die Unterschiede innerhalb der ovarektomierten oder intakten Gruppen sind statistisch nicht signifikant ( $\mathrm{p}>0.05)$. 


\subsubsection{Mittlere Trabekeldicke}

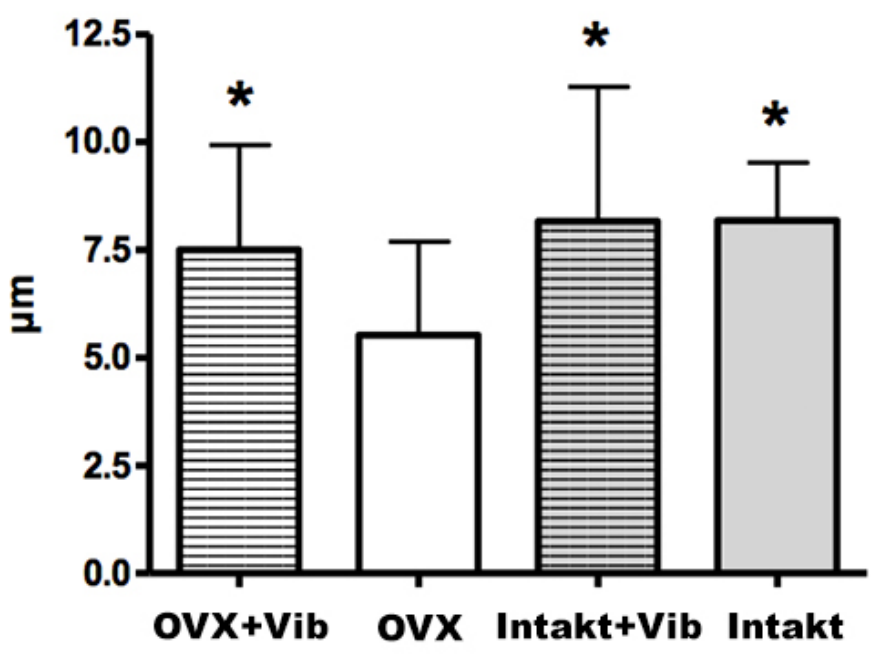

Abbildung 24: Mittlere Trabekeldicke $[\mu \mathrm{m}]$ bei ovarektomierten und intakten Ratten mit und ohne vertikale WBV von $90 \mathrm{~Hz}$ (Angabe als MW \pm SD, * p $<0.05$ vs. OVX)

Es treten signifikante Unterschiede in der mittleren Trabekeldicke zwischen der OVXGruppe und der Intakt+Vib ( $\mathrm{p}<0.01$ ), sowie der OVX-Gruppe und der intakten Gruppe auf $(\mathrm{p}<0.001)$. Ebenfalls zeigen sich Signifikanzen beim Vergleich der OVX-Tiere mit den OVX+Vib-Tieren. Insgesamt weisen auch hier die intakten Tiere die höheren Werte auf (vgl. Abb. 24). 
Tabelle 16: Zusammmenfassende tabellarische Darstellung der Ergebnisse der Mikroradiographie unter Berücksichtigung der Signifikanzen (Angabe als $\mathrm{MW} \pm \mathrm{SD}, * \mathbf{p}<0.05$ vs. OVX, \# $\mathbf{p}<0.05$ vs. OVX+Vib)

\begin{tabular}{|c|c|c|c|c|}
\hline Parameter & OVX+Vib & OVX & Intakt+Vib & Intakt \\
\hline $\begin{array}{l}\text { Kortikalisdicke distal- } \\
\text { ventromedial [mm]: }\end{array}$ & $0.45 \pm 0.15$ & $0.50 \pm 0.17$ & $0.44 \pm 0.12$ & $0.42 \pm 0.07$ \\
\hline $\begin{array}{l}\text { Kortikalisdicke distal- } \\
\text { dorsal [mm]: }\end{array}$ & $0.55 \pm 0.18$ & $0.65 \pm 0.19$ & $0.54 \pm 0.09$ & $0.48 \pm 0.07 *$ \\
\hline $\begin{array}{l}\text { Kortikalisdichte } \\
\text { distal-ventromedial } \\
{[\%]:}\end{array}$ & $98.96 \pm 1.09 *$ & $97.41 \pm 3.18$ & $99.59 \pm 0.56 *$ & $99.18 \pm 0.79 *$ \\
\hline $\begin{array}{l}\text { Kortikalisdichte } \\
\text { distal-dorsal [\%]: }\end{array}$ & $98.14 \pm 5.21$ & $98.63 \pm 2.22$ & $99.64 \pm 0.54$ & $99.71 \pm 0.33$ \\
\hline $\begin{array}{l}\text { Kallusdicke } \\
\text { ventromedial [mm]: }\end{array}$ & $0.29 \pm 0.15$ & $0.30 \pm 0.17$ & $0.39 \pm 0.28$ & $0.35 \pm 0.23$ \\
\hline $\begin{array}{l}\text { Kallusdicke dorsal } \\
\text { [mm]: }\end{array}$ & $0.72 \pm 0.31$ & $0.75 \pm 0.36$ & $0.55 \pm 0.23$ & $0.58 \pm 0.23$ \\
\hline $\begin{array}{l}\text { Kallusdichte } \\
\text { ventromedial [\%]: }\end{array}$ & $80.62 \pm 17.11$ & $72.39 \pm 15.87$ & $84.30 \pm 16.68$ & $85.54 \pm 15.84^{*}$ \\
\hline $\begin{array}{l}\text { Kallusdichte } \\
\text { dorsal[\%]: }\end{array}$ & $82.34 \pm 8.12$ & $80.37 \pm 12.62$ & $88.13 \pm 10.87$ & $86.54 \pm 8.87$ \\
\hline $\begin{array}{l}\text { Kallusdichte endostal } \\
\text { [\%]: }\end{array}$ & $70.88 \pm 14.29$ & $67.52 \pm 16.59$ & $69.83 \pm 24.51$ & $82.62 \pm 10.60 *$ \\
\hline $\begin{array}{l}\text { Trabekeldichte distal } \\
\text { [\%]: }\end{array}$ & $25.89 \pm 24.68$ & $39.85 \pm 113.6$ & $56.23 \pm 20.76 * \#$ & $62.37 \pm 15.05^{* \#}$ \\
\hline $\begin{array}{l}\text { Trabekelkreuzungen } \\
\text { absolut [n]: }\end{array}$ & $13.57 \pm 16.15$ & $9.23 \pm 8.88$ & $38.47 \pm 21.90 * \#$ & $43.48 \pm 13.18 * \#$ \\
\hline $\begin{array}{l}\text { Dichte } \\
\text { Trabekelkreuzungen } \\
{\left[1 / \mathrm{mm}^{2}\right] \text { : }}\end{array}$ & $6.33 \pm 5.56$ & $4.00 \pm 4.48$ & $16.66 \pm 16.37^{* \#}$ & $16.63 \pm 4.41 * \#$ \\
\hline $\begin{array}{l}\text { Mittlere } \\
\text { Trabekeldicke }[\mu \mathrm{m}] \text { : }\end{array}$ & $7.50 \pm 2.43^{*}$ & $5.52 \pm 2.17$ & $8.16 \pm 3.11^{*}$ & $8.18 \pm 1.34^{*}$ \\
\hline
\end{tabular}




\subsection{Auswertung der polychromen Sequenzmarkierung}

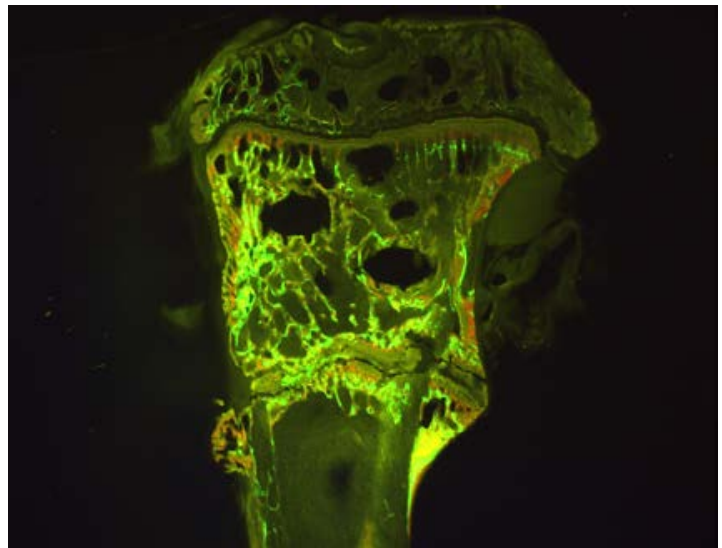

a) Histologischer Schnitt aus Gruppe OVX

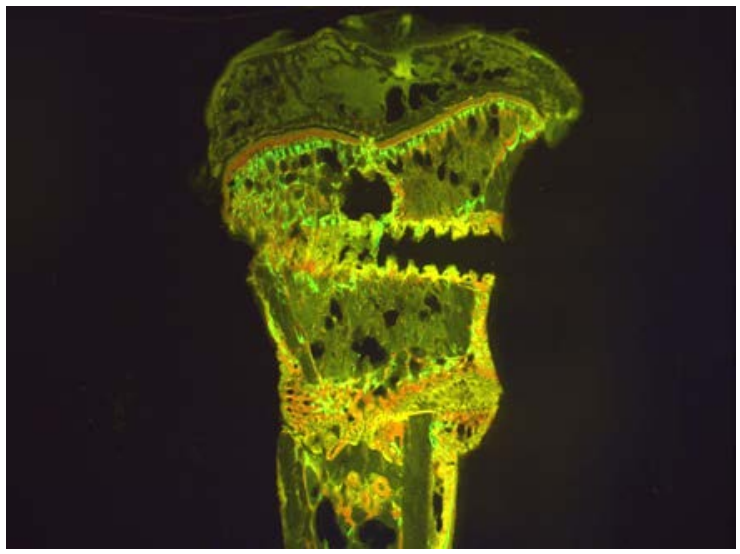

c) Histologischer Schnitt aus Gruppe Intakt

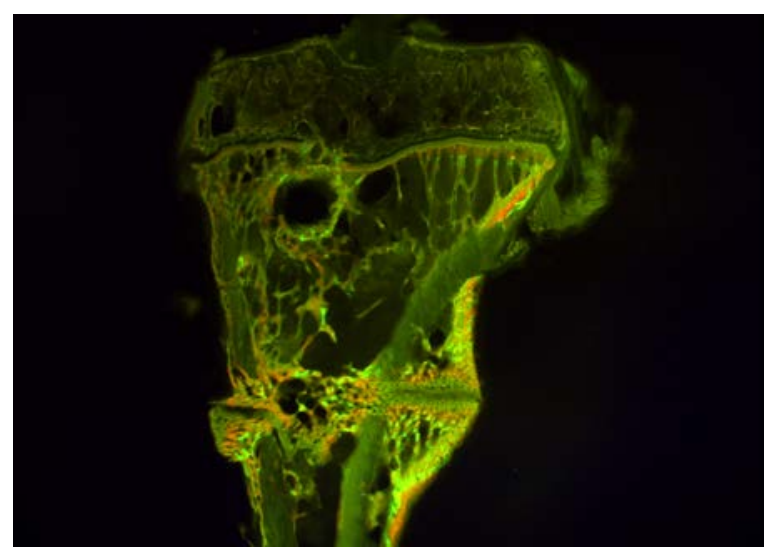

b) Histologischer Schnitt aus Gruppe OVX+Vib

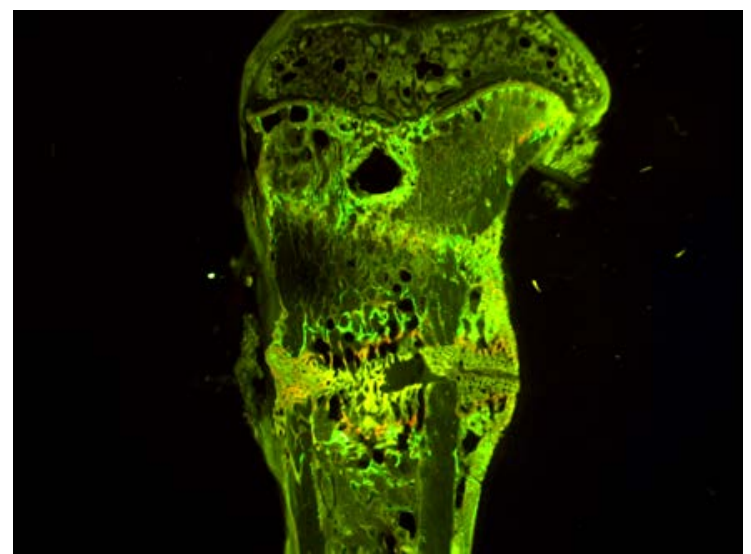

d) Histologischer Schnitt aus Gruppe Intakt+Vib

Abbildung 25: Typische histologische Schnitte des fluoreszenzmarkierten metaphysären Tibiakallus der OVX(a), der OVX+Vib- (b), der Intakt- (c) und der Intakt+Vib-Gruppe (d) (zehnfache Vergrößerung)

Nachfolgend werden die Ergebnisse der einzelnen Messparameter der polychromen Sequenzmarkierung vorgestellt. Nach der Darstellung in Säulendiagrammen folgt eine tabellarische Zusammenfassung aller ermittelten Ergebnisse unter Angabe der Mittelwerte und Standardabweichungen (s. Tab.17). 


\subsubsection{Gesamtfläche Kallus ventromedial}

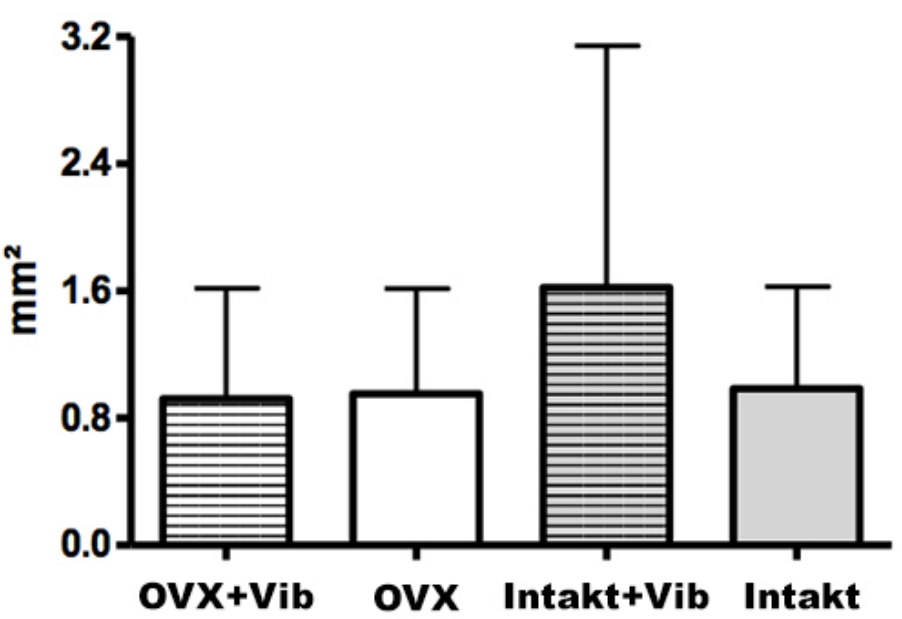

Abbildung 26: Gesamtfläche Kallus ventromedial [ $\left.\mathrm{mm}^{2}\right]$ in der Evaluation der polychromen Sequenzmarkierung bei ovarektomierten und intakten Ratten mit und ohne vertikale WBV von $90 \mathrm{~Hz}$ (Angabe als MW \pm SD)

Die Gesamtfläche des ventromedialen Kallus schließt alle drei polychrom-gefärbten Kallusbereiche mit ein. Die Intakt+Vib-Tiere weisen den höchsten Wert für die ventromediale Kallusfläche auf, wobei sich die Unterschiede zwischen den Testgruppen als statistisch nicht signifikant darstellen ( $>0.05)$ (vgl. Abb 26). 


\subsubsection{CG-Fläche Kallus ventromedial}

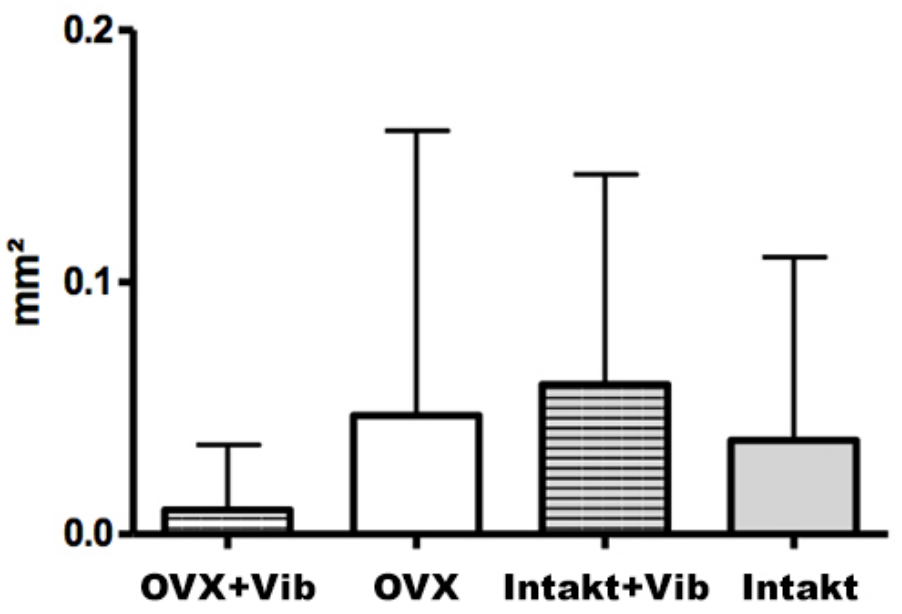

Abbildung 27: CG-markierte Kallusfläche ventromedial $\left[\mathrm{mm}^{2}\right]$ in der Evaluation der polychromen Sequenzmarkierung bei ovarektomierten und intakten Ratten mit und ohne vertikale WBV von $90 \mathrm{~Hz}$ (Angabe als $\mathrm{MW} \pm \mathrm{SD}$ )

Bei Betrachtung der CG-Fläche finden sich beim Vergleich der einzelnen Testgruppen bei der Intakt+Vib-Testgruppe höhere Werte als bei der intakten Kontrollgruppe; gegensätzlich dazu ist bei den OVX-Tieren die CG-Fläche größer als bei der OVX+VibGruppe (vgl. Abb. 27). Die Unterschiede sind statistisch jedoch nicht signifikant (p > $0.05)$. 


\subsubsection{AK-Fläche Kallus ventromedial}

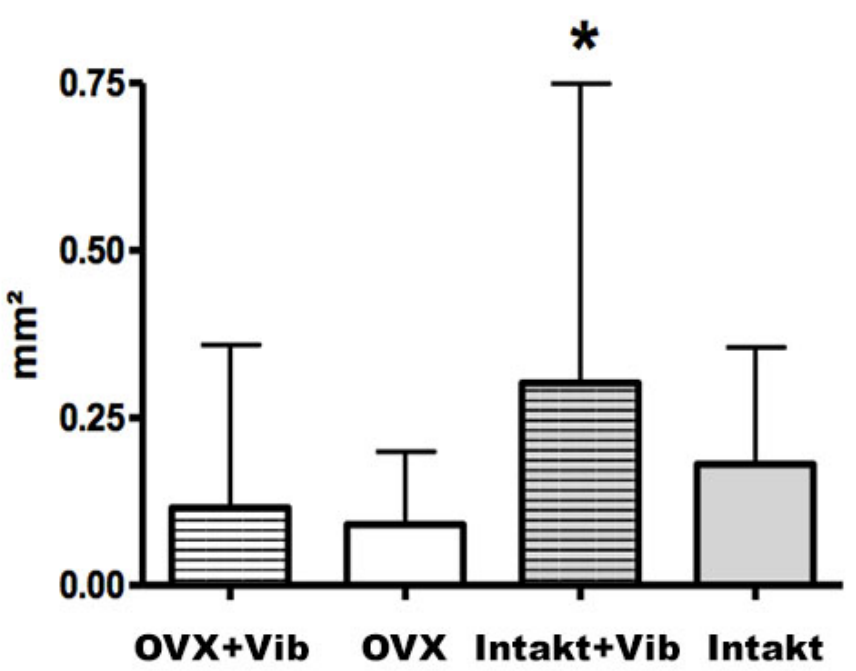

Abbildung 28: AK-markierte Kallusfläche ventromedial $\left[\mathrm{mm}^{2}\right]$ in der Evaluation der polychromen Sequenzmarkierung bei ovarektomierten und intakten Ratten mit und ohne vertikale WBV von $90 \mathrm{~Hz}$ (Angabe als $\mathrm{MW} \pm \mathrm{SD}, * \mathbf{p}<\mathbf{0 . 0 5}$ vs. OVX)

Die Werte für die AK-markierte ventromediale Kallusfläche weisen einen signifikanten Unterschied zwischen der Intakt+Vib-Testgruppe und der OVX-Gruppe auf ( $p<0.05)$. Weitere Unterschiede zwischen den Testgruppen stellen sich als statistisch nicht signifikant dar $(\mathrm{p}>0.05)$. Die AK-Fläche des ventromedialen Kallus ist bei den Intakt+Vib-Tieren am größten (vgl. Abb. 28). 


\subsubsection{TC-Fläche Kallus ventromedial}

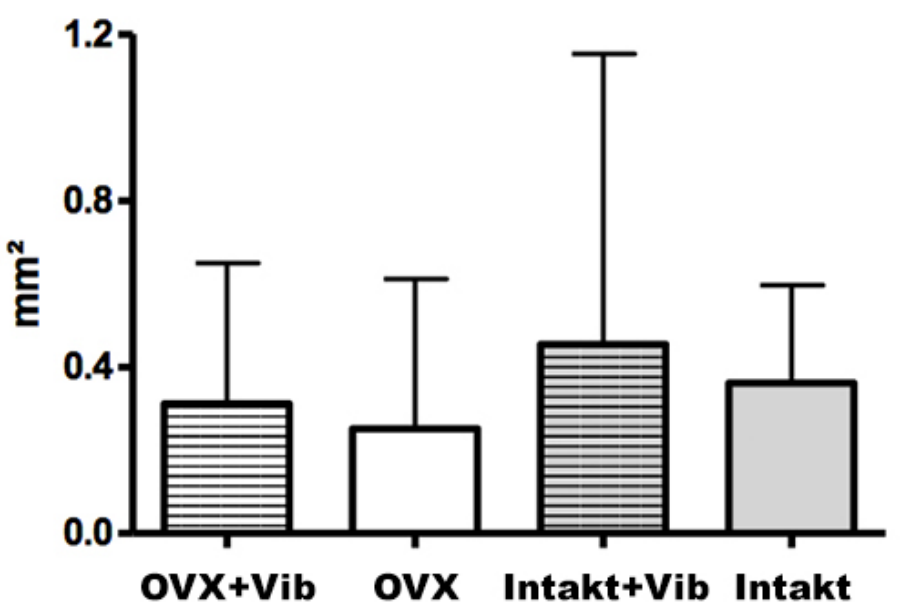

Abbildung 29: TC-markierte Kallusfläche ventromedial $\left[\mathrm{mm}^{2}\right]$ in der Evaluation der polychromen Sequenzmarkierung bei ovarektomierten und intakten Ratten mit und ohne vertikale WBV von $90 \mathrm{~Hz}$ (Angabe als MW \pm SD)

Die Werte für die ventromediale TC-markierte Fläche stellen sich ähnlich den Ergebnissen für die ventromediale AK-Fläche dar, wobei hier die Unterschiede statistisch nicht signifikant sind $(\mathrm{p}>0.05)$. Die Intakt+Vib- Gruppe weist auch hier die höchsten Werte auf (vgl. Abb. 29). 


\subsubsection{Gesamtfläche Kallus dorsal}

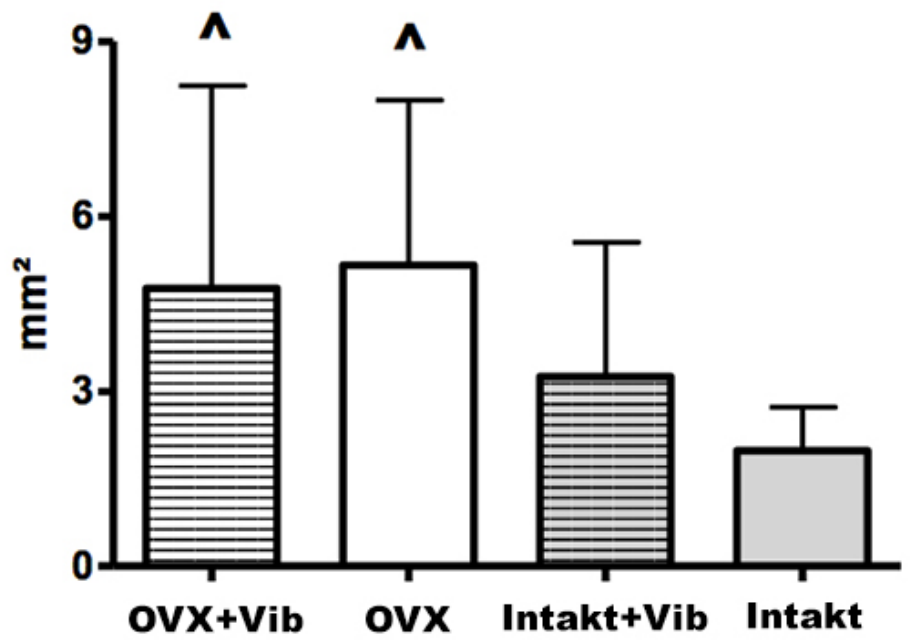

Abbildung 30: Gesamtfläche Kallus dorsal $\left[\mathrm{mm}^{2}\right]$ in der Evaluation der polychromen Sequenzmarkierung bei ovarektomierten und intakten Ratten mit und ohne vertikale WBV von $90 \mathrm{~Hz}$ (Angabe als $\mathrm{MW} \pm \mathrm{SD}, \wedge \mathrm{p}<0.05$ vs. Intakt)

Die Gesamtfläche der dorsalen Kallusanteile umfasst alle drei polychrom-gefärbten Bereiche. Signifikante Unterschiede finden sich sowohl beim Vergleich der OVX+VibTestgruppe mit der Intakt-Gruppe ( $\mathrm{p}<0.01$ ), als auch bei Vergleich der OVX- mit der Intakt-Gruppe $(\mathrm{p}<0.001)$, wobei die ovarektomierten Tiere die höheren Werte erzielen (vgl. Abb. 30). 


\subsubsection{CG-Fläche Kallus dorsal}

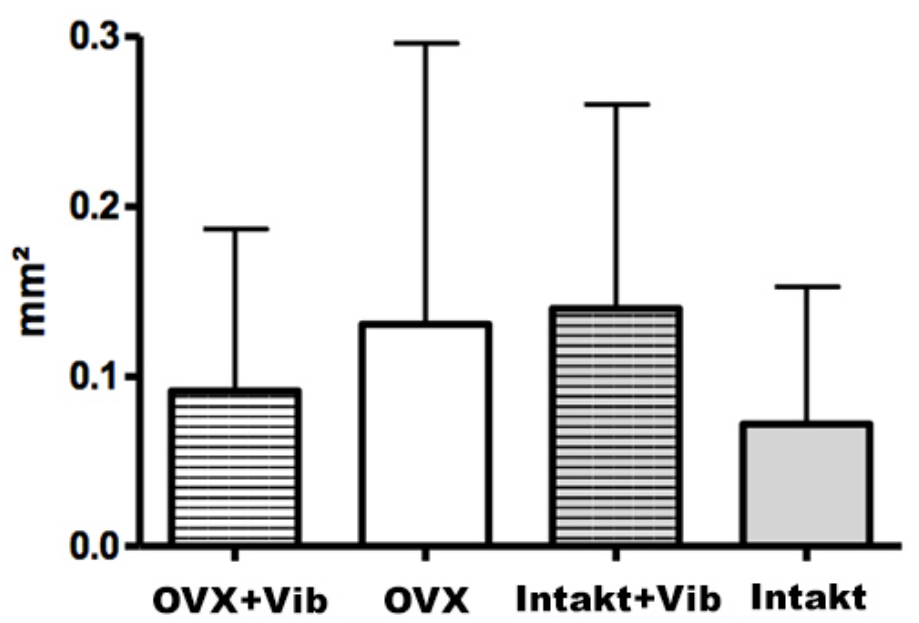

Abbildung 31: CG-markierte Kallusfläche dorsal [mm²] in der Evaluation der polychromen Sequenzmarkierung bei ovarektomierten und intakten Ratten mit und ohne vertikale WBV von $90 \mathrm{~Hz}$ (Angabe als MW \pm SD)

Die Intakt+Vib-Tiere weisen die größte dorsale CG-markierte Kallusfläche auf, wobei die Unterschiede zwischen den Testgruppen statistisch nicht signifikant sind (p > 0.05) (vgl. Abb. 31). Bei den intakten Tieren erzielt die vibrierte Gruppe die höheren Werte, bei den ovarektomierten Tieren verhält es sich genau entgegengesetzt. 


\subsubsection{AK-Fläche Kallus dorsal}

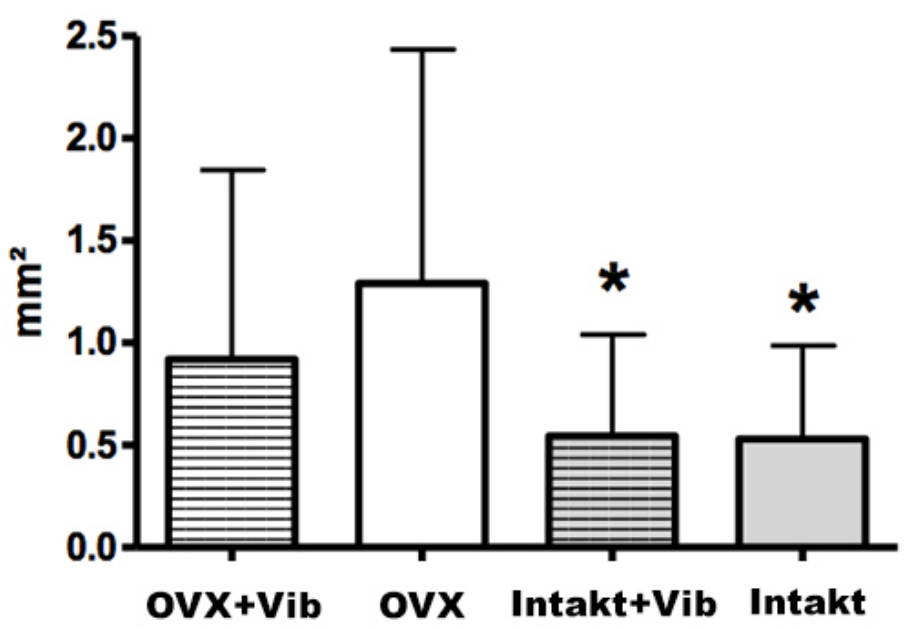

Abbildung 32: AK-markierte Kallusfläche dorsal [ $\left.\mathrm{mm}^{2}\right]$ in der Evaluation der polychromen Sequenzmarkierung bei ovarektomierten und intakten Ratten mit und ohne vertikale WBV von $90 \mathrm{~Hz}$ (Angabe als MW $\pm \mathrm{SD}$, * p < 0.05 vs. OVX)

Die OVX-Gruppe weist die größte AK-Fläche des dorsalen Kallus auf. Die Unterschiede zwischen der OVX- und der Intakt+Vib-Gruppe $(\mathrm{p}<0.05)$ einerseits als auch gegenüber der Intakt-Gruppe $(\mathrm{p}<0.01)$ sind signifikant (vgl. Abb. 32). 


\subsubsection{TC-Fläche Kallus dorsal}

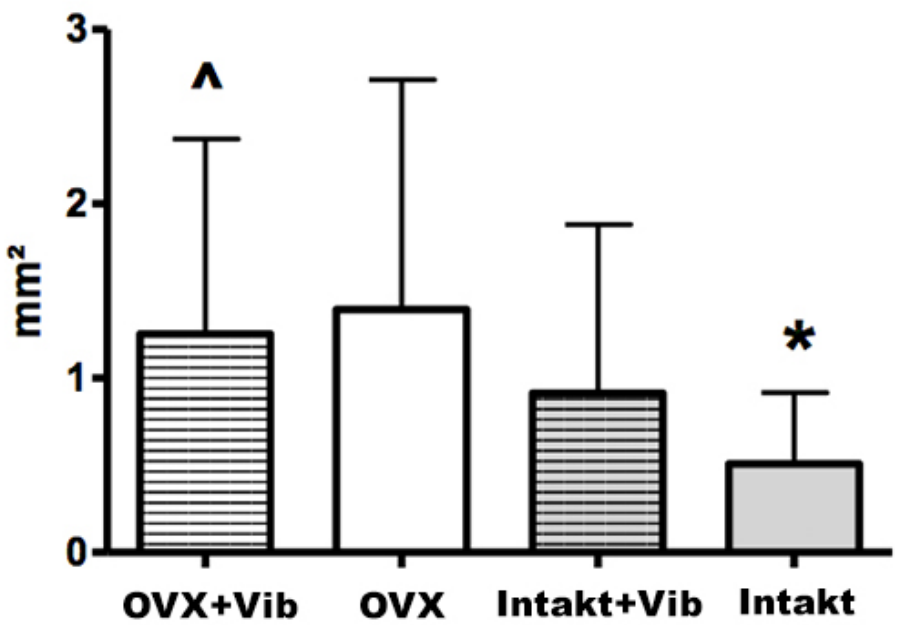

Abbildung 33: TC-markierte Kallusfläche dorsal $\left[\mathrm{mm}^{2}\right]$ in der Evaluation der polychromen Sequenzmarkierung bei ovarektomierten und intakten Ratten mit und ohne vertikale WBV von $90 \mathrm{~Hz}$ (Angabe als $\mathrm{MW} \pm \mathrm{SD}, * \mathrm{p}<$ 0.05 vs. $\mathrm{OVX}, \wedge \mathrm{p}<0.05$ vs. Intakt)

Beim Vergleich der einzelnen Testgruppen bezüglich der TC-Fläche des dorsalen Kallus weisen die ovarektomierten Gruppen höhere Werte auf als die intakten (vgl. Abb. 33). Es finden sich dabei signifikante Unterschiede zwischen den OVX+Vib- und den IntaktTieren $(\mathrm{p}<0.05)$ sowie zwischen der OVX- und der Intakt-Gruppe $(\mathrm{p}<0.05)$. 


\subsubsection{Gesamtfläche Kallus endostal}

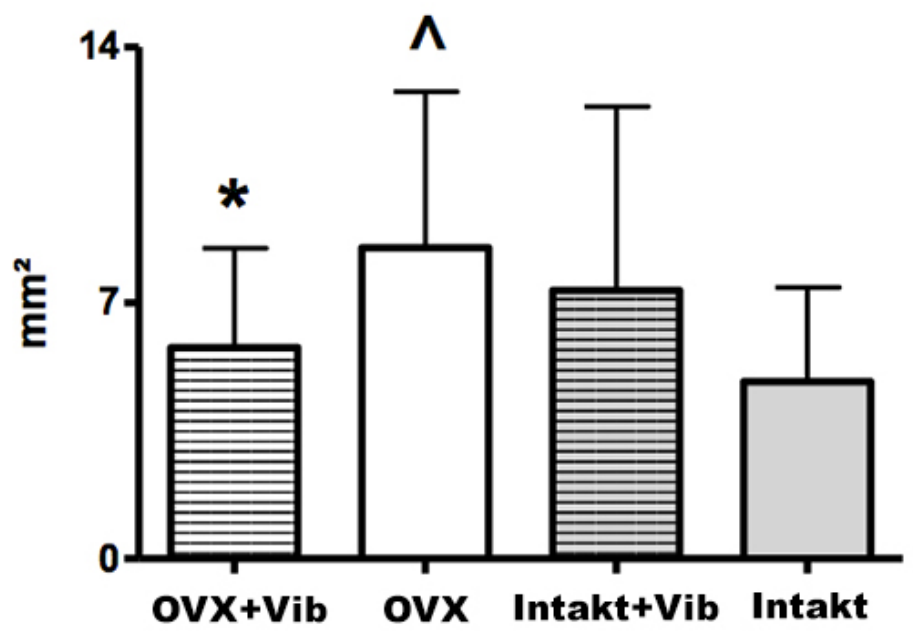

Abbildung 34: Gesamtfläche Kallus endostal $\left[\mathrm{mm}^{2}\right]$ in der Evaluation der polychromen Sequenzmarkierung bei ovarektomierten und intakten Ratten mit und ohne vertikale WBV von $90 \mathrm{~Hz}$ (Angabe als MW \pm SD, $*$ p $<0.05$ vs. $\mathrm{OVX}, \wedge \mathrm{p}<0.05$ vs. Intakt)

Die Gesamtfläche vom endostalen Kallus schließt alle drei polychrom-gefärbten Areale mit ein. Während die OVX-Gruppe die größte Fläche aufweist, finden sich statistisch signifikante Unterschiede sowohl zwischen den OVX+Vib- und den OVX-Tieren ( $\mathrm{p}<$ 0.05) als auch zwischen der OVX- und der Intakt-Testgruppe ( $<0.01)$ (vgl. Abb. 34). 


\subsubsection{CG-Fläche Kallus endostal}

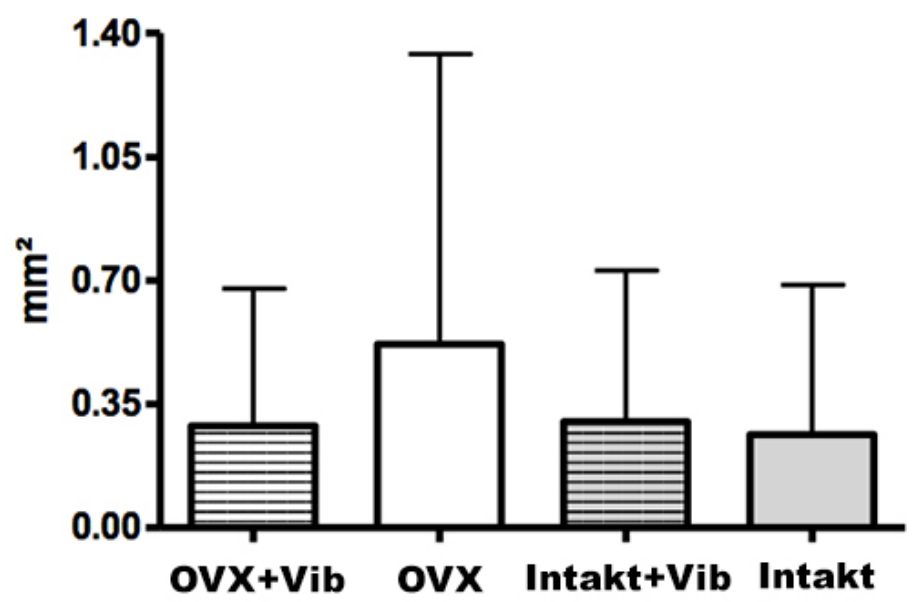

Abbildung 35: CG-markierte Kallusfläche endostal $\left[\mathrm{mm}^{2}\right]$ in der Evaluation der polychromen Sequenzmarkierung bei ovarektomierten und intakten Ratten mit und ohne vertikale WBV von $90 \mathrm{~Hz}$ (Angabe als MW \pm SD)

Auch hier weist die OVX-Gruppe die größte Fläche auf (vgl. Abb. 35). Signifikante Unterschiede zwischen den Testgruppen bestehen aufgrund von hohen Standardabweichungen nicht $(p>0.05)$. 


\subsubsection{AK-Fläche Kallus endostal}

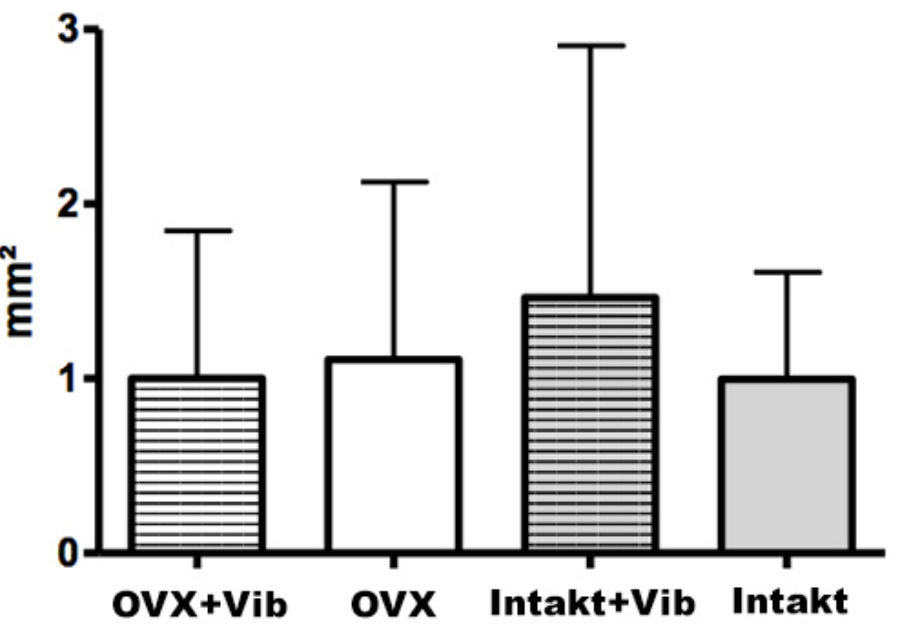

Abbildung 36: AK-markierte Kallusfläche endostal $\left[\mathrm{mm}^{2}\right]$ in der Evaluation der polychromen Sequenzmarkierung bei ovarektomierten und intakten Ratten mit und ohne vertikale WBV von $90 \mathrm{~Hz}$ (Angabe als MW \pm SD)

Die AK-Fläche des endostalen Kallus ist bei der Intakt+Vib-Gruppe am größten (vgl. Abb. 36). Dabei besteht kein signifikanter Unterschied zwischen den einzelnen Testgruppen (p > $0.05)$. 


\subsubsection{TC-Fläche Kallus endostal}

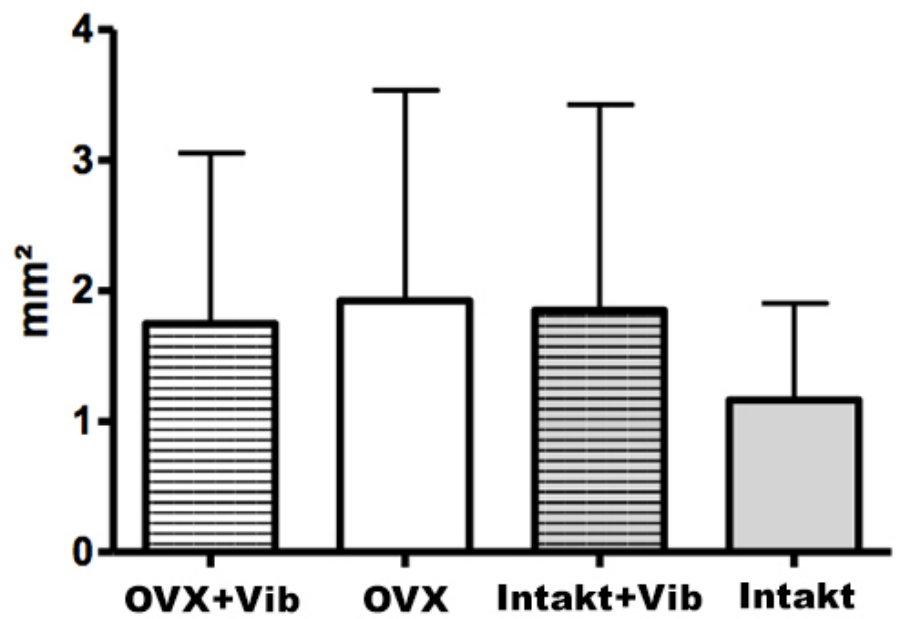

Abbildung 37: TC-markierte Kallusfläche endostal $\left[\mathrm{mm}^{2}\right]$ in der Evaluation der polychromen Sequenzmarkierung bei ovarektomierten und intakten Ratten mit und ohne vertikale WBV von $90 \mathrm{~Hz}$ (Angabe als MW \pm SD)

Die OVX-Gruppe zeigt die größte TC-Fläche des endostalen Kallus (vgl. Abb. 37). Die Unterschiede zwischen den einzelnen Testgruppen sind statistisch nicht signifikant $(\mathrm{p}>$ $0.05)$. 
Tabelle 17: Zusammmenfassende tabellarische Darstellung aller bestimmten Parameter nach polychromer Sequenzmarkierung unter Berücksichtigung der Signifikanzen (Angabe als MW \pm SD, $* \mathbf{p}<0.05$ vs. OVX, \# p $<$ 0.05 vs. $\mathrm{OVX}+\mathrm{Vib}, \wedge \mathrm{p}<\mathbf{0 . 0 5}$ vs. Intakt)

\begin{tabular}{|l|l|l|l|l|}
\hline Parameter & OVX+Vib & OVX & Intakt+Vib & Intakt \\
\hline $\begin{array}{l}\text { Gesamtfläche Kallus } \\
\text { ventromedial [mm²] }\end{array}$ & $0.92 \pm 0.70$ & $0.95 \pm 0.66$ & $1.62 \pm 1.52$ & $0.98 \pm 0.64$ \\
\hline $\begin{array}{l}\text { CG-Fläche Kallus } \\
\text { ventromedial [mm²] }\end{array}$ & $0.01 \pm 0.03$ & $0.05 \pm 0.11$ & $0.06 \pm 0.08$ & $0.04 \pm 0.07$ \\
\hline $\begin{array}{l}\text { AK-Fläche Kallus } \\
\text { ventromedial [mm²] }\end{array}$ & $0.12 \pm 0.24$ & $0.09 \pm 0.11$ & $0.30 \pm 0.45^{*}$ & $0.18 \pm 0.17$ \\
\hline $\begin{array}{l}\text { TC-Fläche Kallus } \\
\text { ventromedial [mm²] }\end{array}$ & $0.31 \pm 0.34$ & $0.25 \pm 0.36$ & $0.45 \pm 0.70$ & $0.36 \pm 0.24$ \\
\hline $\begin{array}{l}\text { Gesamtfläche Kallus } \\
\text { dorsal [mm²] }\end{array}$ & $4.77 \pm 3.47 \wedge$ & $5.16 \pm 2.83 \wedge$ & $3.25 \pm 2.30$ & $1.99 \pm 0.74$ \\
\hline $\begin{array}{l}\text { CG-Fläche Kallus } \\
\text { dorsal [mm²] }\end{array}$ & $0.09 \pm 0.10$ & $0.13 \pm 0.17$ & $0.14 \pm 0.12$ & $0.07 \pm 0.08$ \\
\hline $\begin{array}{l}\text { AK-Fläche Kallus } \\
\text { dorsal [mm²] }\end{array}$ & $0.92 \pm 0.92$ & $1.29 \pm 1.14$ & $0.55 \pm 0.50^{*}$ & $0.53 \pm 0.46^{*}$ \\
\hline $\begin{array}{l}\text { TC-Fläche Kallus } \\
\text { dorsal [mm²] }\end{array}$ & $1.25 \pm 1.12^{\wedge}$ & $1.39 \pm 1.32$ & $0.91 \pm 0.97$ & $0.51 \pm 0.41^{*}$ \\
\hline $\begin{array}{l}\text { Gesamtfläche Kallus } \\
\text { endostal [mm² }\end{array}$ & $5.78 \pm 2.81^{*}$ & $8.51 \pm 4.27 \wedge$ & $7.35 \pm 5.03$ & $4.84 \pm 2.61$ \\
\hline $\begin{array}{l}\text { CG-Fläche Kallus } \\
\text { endostal [mm²] }\end{array}$ & $0.29 \pm 0.39$ & $0.52 \pm 0.82$ & $0.30 \pm 0.43$ & $0.26 \pm 0.42$ \\
\hline $\begin{array}{l}\text { AK-Fläche Kallus } \\
\text { endostal [mm²] } \\
\text { endostal [mm²] }\end{array}$ & $1.00 \pm 0.85$ & $1.11 \pm 1.02$ & $1.46 \pm 1.44$ & $1.00 \pm 0.61$ \\
\hline TC-Fläche Kallus & $1.75 \pm 1.31$ & $1.92 \pm 1.61$ & $1.8 \pm 1.57$ & $1.16 \pm 0.74$ \\
\hline
\end{tabular}




\subsection{Zusammenfassung der Ergebnisse}

Tabelle 18: Tendenzielle Darstellung der Vibrationseffekte anhand der Ergebnisse der Mikroradiographie und der polychromen Sequenzmarkierung (Angabe als $\mathrm{MW} \pm \mathrm{SD}$ )

Vib (OVX): Effekte von WBV auf ovarektomierte Tiere

Vib (Intakt): Effekte von WBV auf intakte Tiere

OVX: Effekte von OVX

$* \uparrow$ : signifikant höhere Werte

$* \downarrow$ : signifikant niedrigere Werte

$\uparrow$ : Tendenz für höhere Werte

$\downarrow$ : Tendenz für niedrigere Werte

$\leftrightarrow$ : Keine Effekte

\begin{tabular}{|l|l|l|l|}
\hline Messparameter & Vib (OVX) & Vib (Intakt) & OVX \\
\hline Elastizität [N/mm] & $\downarrow$ & $\downarrow$ & $\downarrow$ \\
\hline Streckgrenze [N] & $\downarrow$ & $\downarrow$ & $\downarrow$ \\
\hline $\begin{array}{l}\text { Kortikalisdicke distal- } \\
\text { ventromedial [mm] }\end{array}$ & $\leftrightarrow$ & $\leftrightarrow$ & $\uparrow$ \\
\hline $\begin{array}{l}\text { Kortikalisdicke distal-dorsal } \\
\text { [mm] }\end{array}$ & $\uparrow$ & $\uparrow$ & $* \uparrow$ \\
\hline $\begin{array}{l}\text { Kortikalisdichte distal- } \\
\text { ventromedial [\%] }\end{array}$ & $\leftrightarrow$ & $\leftrightarrow$ & $* \downarrow$ \\
\hline $\begin{array}{l}\text { Kortikalisdichte distal-dorsal } \\
\text { [\%] }\end{array}$ & $\downarrow$ & $\leftrightarrow$ & \\
\hline $\begin{array}{l}\text { Kallusdicke ventromedial } \\
\text { [mm] }\end{array}$ & $\downarrow$ & $\uparrow$ & $\downarrow$ \\
\hline Kallusdicke dorsal [mm] & $\uparrow$ & & $\downarrow$ \\
\hline Kallusdichte ventromedial [\%] & $\downarrow$ & $\leftrightarrow$ & $\uparrow$ \\
\hline Kallusdichte dorsal [\%] & $\downarrow$ & $\leftrightarrow$ & ${ }^{2}$ \\
\hline Kallusdichte endostal [\%] & $\downarrow$ & $\leftrightarrow$ & $\downarrow$ \\
\hline Trabekeldichte distal [\%] & $* \downarrow$ & $\downarrow$ & ${ }^{2} \downarrow$ \\
\hline $\begin{array}{l}\text { Anzahl Trabekelkreuzungen } \\
\text { [n] }\end{array}$ & $* \downarrow$ & $\downarrow$ & $* \downarrow$ \\
\hline $\begin{array}{l}\text { Dichte Trabekelkreuzungen } \\
\text { [mm²] }\end{array}$ & $* \downarrow$ & $\downarrow$ & $* \downarrow$ \\
\hline
\end{tabular}




\begin{tabular}{|c|c|c|c|}
\hline Mittlere Trabekeldicke $[\mu \mathrm{m}]$ & $\downarrow$ & $\leftrightarrow$ & $* \downarrow$ \\
\hline $\begin{array}{l}\text { Gesamtfläche Kallus } \\
\text { ventromedial [mm²] }\end{array}$ & $\leftrightarrow$ & $\uparrow$ & $\leftrightarrow$ \\
\hline $\begin{array}{l}\text { CG-Fläche Kallus } \\
\text { ventromedial [mm²] }\end{array}$ & $\downarrow$ & $\uparrow$ & $\uparrow$ \\
\hline $\begin{array}{l}\text { AK-Fläche Kallus } \\
\text { ventromedial [mm²] }\end{array}$ & $\downarrow$ & $\uparrow$ & $\downarrow$ \\
\hline $\begin{array}{l}\text { TC-Fläche Kallus } \\
\text { ventromedial [mm²] }\end{array}$ & $\downarrow$ & $\uparrow$ & $\downarrow$ \\
\hline $\begin{array}{l}\text { Gesamtfläche Kallus dorsal } \\
{\left[\mathrm{mm}^{2}\right]}\end{array}$ & $* \uparrow$ & $\uparrow$ & $* \uparrow$ \\
\hline $\begin{array}{l}\text { CG-Fläche Kallus dorsal } \\
{\left[\mathrm{mm}^{2}\right]}\end{array}$ & $\uparrow$ & $\uparrow$ & $\uparrow$ \\
\hline $\begin{array}{l}\text { AK-Fläche Kallus dorsal } \\
{\left[\mathrm{mm}^{2}\right]}\end{array}$ & $\uparrow$ & $\leftrightarrow$ & $* \uparrow$ \\
\hline $\begin{array}{l}\text { TC-Fläche Kallus dorsal } \\
{\left[\mathrm{mm}^{2}\right]}\end{array}$ & $* \uparrow$ & $\uparrow$ & $* \uparrow$ \\
\hline $\begin{array}{l}\text { Gesamtfläche Kallus endostal } \\
{\left[\mathrm{mm}^{2}\right]}\end{array}$ & $\uparrow$ & $\uparrow$ & $* \uparrow$ \\
\hline $\begin{array}{l}\text { CG-Fläche Kallus endostal } \\
{\left[\mathrm{mm}^{2}\right]}\end{array}$ & $\leftrightarrow$ & $\leftrightarrow$ & $\uparrow$ \\
\hline $\begin{array}{l}\text { AK-Fläche Kallus endostal } \\
{\left[\mathrm{mm}^{2}\right]}\end{array}$ & $\leftrightarrow$ & $\uparrow$ & $\leftrightarrow$ \\
\hline $\begin{array}{l}\text { TC-Fläche Kallus endostal } \\
{\left[\mathrm{mm}^{2}\right]}\end{array}$ & $\uparrow$ & $\uparrow$ & $\uparrow$ \\
\hline
\end{tabular}




\section{Diskussion}

Die Frakturheilung verläuft bei Osteoporose verzögert und beeinträchtigt (McCann et al. 2008). Da es aber aufgrund der instabilen Mikroarchitektur gerade im osteopenischen Knochen häufig zu Fragilitätsfrakturen kommt, stellt sich die Frage, wie der verzögerte Heilungsverlauf positiv beeinflusst werden kann, ohne dass eine nebenwirkungsbelastete Hormonersatztherapie oder andere schädigende antiosteoporotische Pharmaka zum Einsatz kommen müssen. In früheren Versuchen konnte gezeigt werden, dass Mikrobewegungen im Frakturspalt die Knochenneubildung und damit den Heilungsverlauf begünstigen (Yamaji et al. 2001). Auch konnte bereits an Tier und Mensch nachgewiesen werden, dass die kurzzeitige Applikation von low-magnitude, high-frequency vibration (LMHFV) von 10 bis $100 \mathrm{~Hz}$ bei $<0.5 \times g$ sich günstig auf das muskuloskelettale System auswirkt (Judex et al. 2007; Rubin 2007; Xie et al. 2008). Verschueren et al. (2004) konnten eine erhöhte Knochenmineraldichte im Schenkelhals von postmenopausalen Frauen nach 6-monatigem progressivem Vibrationstraining bei $35-40 \mathrm{~Hz}$ und $2-5 \times g$ Beschleunigung nachweisen. Es fand sich weiterhin ein knochenstabilisierender Effekt bei ovarektomierten Ratten nach Applikation von WBV bei einer Frequenz von $50 \mathrm{~Hz}$ in einem Versuch von Flieger et al. (1998). Durch Erhöhung der Frequenz auf 90 Hz (Judex et al. 2007) konnte dieser Effekt noch verstärkt werden.

\subsection{Metaphysäres Frakturmodell}

Osteoporotische Veränderungen manifestieren sich vorrangig in den metaphysären Anteilen des Knochens. Dies beruht insbesondere auf dem Abbau der Trabekelstruktur, wie z.B. in der Tibiametaphyse von Ratten 8-10 Wochen nach Ovarektomie (Iwaniec et al. 2007; Seidlova-Wuttke et al. 2003 a u. b; Wronski et al. 1985). Beim Menschen manifestieren sie sich vor allem im Bereich des Schenkelhalses, des proximalen Humerus, des distalen Radius und der Wirbelsäule. Bei der Ratte treten osteopenische Veränderungen vornehmlich in der metaphysären Tibia und im Lendenwirbelkörper auf (Ikeda et al. 2001; Yao et al. 2005, Ke et al. 1998; Mosekilde et al. 1999). Fraglich ist also, warum in der Vergangenheit Untersuchungen zur Osteoporose bzw. zur osteoporotischen Frakturheilung hauptsächlich an diaphysären Frakturmodellen stattfanden (Melhus et al. 2007; Xu et al. 2003; Cao et al. 2002; Kubo et al. 1999; Cebesoy et al. 2007; Li et al. 2010; 
Brüel et al. 2011; Ozturan et al. 2011). Im Gegensatz zu der Knochenheilung am diaphysären Knochen, der vornehmlich durch indirekte Frakturspaltüberbrückung mit periostaler Kallusbildung heilt, heilt der metaphysäre Knochen vor allem durch direkte Frakturspaltüberbrückung mit endostaler Kallusausbildung und nur dezenter periostaler Kallusformation.

Bei Osteoporose sind diaphysäre Frakturen von keiner klinischen Relevanz. Dementsprechend wurden die durchgeführten Untersuchungen in der vorliegenden Arbeit bei Osteoporose mithilfe eines von Stürmer et al. (2008 u. 2010) an Ratten entwickelten metaphysären Frakturmodells der Tibia mit Plattenosteosynthese durchgeführt. In zahlreichen vorangegangenen Untersuchungen unserer Arbeitsgruppe bezüglich Wirkungen verschiedener Substanzen auf die Frakturheilung im osteoporotischen metaphysären Knochen kam dieses Modell bereits erfolgreich zum Einsatz (Kolios et al. 2009 u. 2010; Komrakova et al. 2010). Da die Knochenneubildung und die Überbrückung des Frakturspalts in der frühen bis mittleren Phase der Frakturheilung ablaufen, wurde, wie in vorangehenden Studien, in dem vorliegenden Projekt eine Heilungsdauer von fünf Wochen gewählt (Komrakova et al. 2009 u. 2010).

\subsection{Einfluss der Ovarektomie und der Ganzkörpervibration auf den Knochen}

Durch bereits vorliegende positive Ergebnisse bezüglich des anabolen Effekts von WBV auf die Metaphyse des unfrakturierten Knochens bei ovarektomierten und intakten Ratten wurde für diesen Versuch eine Vibrationsfrequenz von 90 Hz gewählt (Judex et al. 2007; Sehmisch et al. 2009). Hingegen gab es bis zur Versuchsdurchführung keine Erkenntnisse zu den Auswirkungen von (vertikaler) WBV auf die metaphysäre Frakturheilung im osteotomierten Knochen von Ratten.

In allen Gruppen zeigte sich nach WBV insgesamt eine Verschlechterung biomechanischer Eigenschaften im osteotomierten Knochen, obwohl bei ovarektomierten vibrierten Ratten eine frühere Ausbildung der Kallusüberbrückung des Frakturspalts beobachtet werden konnte. Somit scheint die WBV die Ausbildung der Kallusüberbrückung im osteopenischen Knochen positiv zu beeinflussen, während sie diesen Effekt im gesunden Knochen nicht induzieren kann. Eine höhere Mechanosensibilität durch Östrogenmangel kann hier als zugrunde liegender Mechanismus postuliert werden. 
Dass WBV unterschiedliche Effekte auf den osteopenischen und auf den gesunden Knochen hat, lässt sich ebenfalls anhand der quantitativen Auswertung durch Vergleich der unterschiedlichen Parameter erhärten. Es zeigte sich in ovarektomierten, vibrierten Ratten eine verminderte Kallusausprägung im Vergleich mit der nicht vibrierten osteoporotischen Gruppe, während es zu einer Kallusvermehrung im gesunden, vibrierten Knochen kam. Auch wurde ferner eine Vermehrung endostaler Trabekelkreuzungen beobachtet. Im gesunden Kochen stellte sich diese osteoanabole Tendenz weniger deutlich dar. Trotzdem zeigte sich insgesamt eine Verschlechterung der biomechanischen Eigenschaften nach Vibration sowohl im osteopenischen als auch im gesunden Knochen. Diese zunächst widersprüchlich erscheinenden Resultate lassen sich dadurch erklären, dass die Menge des Kallus nicht zwangsläufig positiv mit seinen biomechanischen Eigenschaften korreliert. Dieses Phänomen konnte bereits in vorangegangenen Studien beschrieben werden (Stürmer et al. 2010 a). Die Qualität des Kallus wird nicht nur vom kalzifizierten Knochen allein, sondern auch von der nicht-kalzifizierten Matrix im neugebildeten Knochen beeinflusst. Wie groß der jeweilige Anteil an den biomechanischen Eigenschaften dieser beiden Parameter ist, ist derzeit unklar und war nicht Inhalt dieser Arbeit.

In ovarektomierten Ratten konnte mittels vertikaler WBV eine Erhöhung der Kortikalisdichte und der Dichte des periostalen Kallus bis auf die Werte von gesundem Knochen erreicht werden. So zeigten ovarektomierte vibrierte Tiere teilweise eine signifikant dichtere Kortikalis und einen tendenziell dichteren ventromedialen, dorsalen und endostalen metaphysären Kallus als die nicht-vibrierte ovarektomierte Kontrollgruppe. Ebenso wiesen die ovarektomierten vibrierten Tiere signifikant höhere Werte in der mittleren Trabekeldicke auf $(\mathrm{p}<0.05)$. Vor diesem Hintergrund ist es völlig unverständlich, dass sich die quantitative Verbesserung des Kallus im osteoporotischen Knochen nicht in einer Verbesserung der biomechanischen Eigenschaften widerspiegelt. Hier kann nur postuliert werden, dass die Kallusreife fehlt und sich bei um ein bis zwei Wochen längerer Versuchsdauer auch die Qualität des Kallus verbessern würde.

In vorangegangenen Studien wurden bereits die Auswirkungen von mechanischer Stimulation (nicht WBV) auf die Frakturheilung untersucht. Dabei wurde in einigen eine 
Verbesserung der Kochenqualität und eine gesteigerte Kallusausbildung und -mineralisation nachgewiesen. So wiesen Shadmehr et al. (2009) nach, dass die Tibiae von osteotomierten Hasen nach täglicher 15-minütiger mechanischer Stimulation mit einer Frequenz von $1 \mathrm{~Hz}$ nach drei Wochen signifikant bessere mechanische Eigenschaften aufwiesen als die nicht-vibrierte Kontrollgruppe. Auch zeigte eine ebenfalls an Hasen durchgeführte Untersuchung von Usui et al. (1989) ein signifikant höheres Kallusvolumen am osteotomierten Knochen nach täglicher 60-minütiger mechanischer Stimulierung mit $25 \mathrm{~Hz}$ über unterschiedliche Zeiträume. Weiterhin konnten Leung et al. (2008) eine beschleunigte Kallusformation, -mineralisation und Knochenheilung in den osteotomierten Femora von Ratten nach zwei respektive vier Wochen mechanischer Stimulation mittels LMHFV bei $35 \mathrm{~Hz}$ und $0,3 \times g$ im Vergleich zur Kontrollgruppe nachweisen. Andere Forschergruppen konnten diesen Effekt auf die Frakturheilung jedoch nicht nachweisen: Ein Versuch, die Knochenheilung der diaphysären Tibiae von Schafen durch externe mechanische Stimulation mit 1, 5 oder $10 \mathrm{~Hz}$ positiv $\mathrm{zu}$ beeinflussen, blieb ohne signifikante Verbesserungen hinsichtlich der Knochenmineraldichte und qualitativen Eigenschaften des Knochens (Augat et al. 2001). Bei Untersuchungen von Wolf et al. (2001) konnte neun Wochen nach transverser Osteotomie des Os metatarsale von Schafen und Anlage eines Fixateur externe sowie anschließender achtwöchiger vertikaler mechanischer Stimulation bei $20 \mathrm{~Hz}$ keine Verbesserung der Frakturheilung beobachtet werden.

Eine vergleichende Beurteilung der dargestellten Studienergebnisse ist jedoch nicht möglich, da in diesen Untersuchungen nicht nur unterschiedliche Tiermodelle zur Anwendung kamen, sondern auch unterschiedliche Stimulationsgeräte mit variierenden Frequenzen, Amplituden und Applikationsdauer verwendet wurden. Außerdem erfolgte die Stimulation entweder direkt durch Mikrobewegungen oder es wurde eine indirekte Stimulation über Ganzkörpervibration angewandt.

Bei Untersuchungen am gesunden, unfrakturierten Knochen konnte eine unterschiedlich ausgeprägte Sensitivität gegenüber mechanischer Stimulation bei ovarektomierten und intakten Tieren festgestellt werden (Rubinacci et al. 2008). Während die Vibration die periostale Apposition und endostale Resorption bei ovarektomierten Ratten förderte, 
konnte dieser Effekt bei intakten Tieren nicht beobachtet werden (Rubinacci et al. 2008). Somit scheint der Hormonspiegel die Sensitivität des Knochens für Vibration zu beeinflussen. Ovarektomierte Ratten wiesen nach dreimonatigem Östrogenmangel eine weniger ausgeprägte Kortikalisfläche, Kortikalisdichte sowie mittlere Trabekelanzahl auf als die intakte Kontrollgruppe. Diese Ergebnisse korrelieren sowohl mit den Resultaten der vorliegenden Arbeit, als auch mit bereits beschriebenen Studien, in denen bei Ratten wenige Wochen nach Ovarektomie starke osteoporotische Veränderungen begleitet von signifikantem Verlust von kortikaler und trabekulärer Knochenstruktur gefunden werden konnten (Kalu et al. 1991; Wronski et al. 1985). Histomorphometrisch zeigte sich eine vergrößerte Kallusfläche, vermutlich durch die von Turner et al. (1987) beschriebene vermehrte Knochenapposition in ovarektomierten Ratten. Bei einer größeren Kallusfläche und nicht-verzögerten Kallusüberbrückung des Frakturspaltes, wiesen Kallus- und Kortikalisdichte deutlich niedrigere Werte auf als die gemessenenen in intakten Tieren. Diese Resultate korrelieren mit der bereits durch Namkung-Matthai et al. (2001) beschriebenen beeinträchtigten Knochenheilung im osteoporotischen Knochen.

\subsection{Somatische Effekte der Ovarektomie und der Ganzkörpervibration}

Das Körpergewicht erhöhte sich bei allen ovarektomierten Tieren während der ersten zehn Wochen nach dem Eingriff deutlich, obwohl es keine Unterschiede in der Futteraufnahme zwischen den einzelnen Testgruppen gab. Diese starke Gewichtszunahme ist eine bereits bekannte Besonderheit bei ovarektomierten Ratten (Kolios et al. 2009; Komrakova et al. 2009, 2010 u. 2011; Stürmer et al. 2010 a) und auf den Östrogenmangel zurückzuführen. Durch WBV resultieren keine Veränderungen des Körpergewichts oder in der Nahrungsaufnahme der Tiere. WBV scheint somit weder auf die intakten, noch auf die ovarektomierten Tiere einen zusätzlichen Stress auszuüben, zeigt aber im Hinblick auf eine „wünschenswerte“ Gewichtsreduktion bei den ovarektomierten Tieren - signifikant erhöhtes KG im Vergleich zu den intakten Tieren - ebenfalls keinen Effekt.

Das Uterusgewicht der ovarektomierten Tiere war am Ende des Versuchs stark erniedrigt gegenüber den intakten Tieren, was darauf zurückzuführen ist, dass es zu einer Atrophie des Uterus bei Östrogenmangel kommt. Somit ist bei allen ovarektomierten Ratten die vollständige Entfernung der Ovarien bewiesen; eine intermittierende Bestimmung des 
Serum-Östrogenspiegels mit Belastung des Tieres durch Punktion der Schwanzvene ist als Beweis entbehrlich.

\subsection{Schlussfolgerung}

In der vorliegenden Untersuchung konnte belegt werden, dass die mechanische Stimulation mittels vertikaler WBV die metaphysäre Frakturheilung beeinflusst. Dabei wirkt WBV unterschiedlich auf ovarektomierte, d.h. osteoporotische und intakte Ratten: So zeigt sich im osteoporotischen Knochen eine tendenzielle, teilweise sogar signifikante positive Beeinflussung auf einige Knochenparameter, während dieser Effekt im gesunden Knochen nicht beobachtet werden konnte. Somit könnte sich vertikale WBV als Therapie bei Osteoporose anbieten. Die vorliegenden Ergebnisse zeigen jedoch auch, dass sich WBV in der angewandten Vibrationsfrequenz und Applikationsdauer eher negativ auf die mechanische Stabilität des Knochens auswirkt, da es zu keiner Verbesserung der Knochenqualität der Tibiae im Rahmen des Versuchs kam. Vermutlich vermindert sich durch WBV, wie sie hier mit einer Frequenz von $90 \mathrm{~Hz}$ zweimal täglich durchgeführt wurde, die Kalzifikation der Kallusmatrix und damit ihre Festigkeit. Die Ergebnisse dieser Arbeit sind von hoher Relevanz bezüglich der Anwendung von mechanischer Stimulation zur positiven Beeinflussung der Frakturheilung. So könnte WBV eine nicht-invasive, weitestgehend nebenwirkungsfreie Therapieoption zur Förderung der Knochenheilung bei osteoporotischen Patienten sein. Es bleibt jedoch noch $\mathrm{zu}$ untersuchen, welche Vibrationsfrequenz und -dauer, Amplitude und Beschleunigung die Frakturheilung am günstigsten beeinflussen kann. Hierzu sollte der Knochen in unterschiedlichen Phasen der Knochenheilung adressiert werden, um den Heilungsverlauf $\mathrm{zu}$ unterschiedlichen Zeitpunkten zu beeinflussen. So könnte die regelmäßige Kontrolle des Knochenmetabolismus zu verschiedenen Zeitpunkten über die Effekte der mechanischen Stimulierung Aufschluss geben. Weiterhin sollte untersucht und beurteilt werden, welche Mechanismen dem Einfluss des Östrogenspiegels auf die Sensibilität des Knochens für mechanische Stimulation zu Grunde liegen. Da die vorliegende Untersuchung „nur“ am RattenTiermodell durchgeführt wurde, ist es erforderlich den Effekt von WBV auf die osteoporotische Frakturheilung im Großtierversuch zu prüfen. Wie von Sehmisch et al. (2009) am Wirbelkörper von Ratten nachgewiesen, kann WBV auch auf den intakten Knochen knochenstabilisierende Effekte haben. Bei der komplexen Wirksamkeit der WBV 
wäre sogar eine klinische Studie sinnvoll, da Vibrationsplattformen, wie z.B. die Powerplate ${ }^{\circledR}$ und die Galaxy ${ }^{\circledR}$ bereits für die Anwendung am Menschen zugelassen sind. 


\section{Zusammenfassung}

Osteoporose ist eine globale Systemerkrankung mit weltweit ca. 200 Millionen Betroffenen (Lin und Lane 2004). Durch die instabile Mikroarchitektur des osteoporotischen Knochens kommt es häufig zu Fragilitätsfrakturen mit schlechter Heilungstendenz (Ström et al. 2011). Es stellt sich die Frage, ob sich der verzögerte und beeinträchtigte Heilungsverlauf bei osteoporotischen Frakturen durch mechanische Stimulation positiv beeinflussen lässt.

Die vorliegende Arbeit untersucht den Einfluss vertikaler Ganzkörpervibration auf die metaphysäre Frakturheilung im gesunden und im osteoporotischen Knochen der weiblichen Ratte. Hierfür wurden 30 Tiere im Alter von drei Monaten ovarektomiert; 30 wurden intakt belassen. Nach zehn Wochen wurden alle Tiere bilateral metaphysär osteotomiert. Fünf Tage postoperativ wurden jeweils die Hälfte der ovarektomierten und die Hälfte der intakten Ratten zweimal täglich einer mechanischen Stimulation mittels vertikaler WBV ausgesetzt. Diese erfolgte mit einer Frequenz von 90 Hz, einer Amplitude von 0,5 mm und einer Beschleunigung von $4 \times g$ über 30 Tage. Die anderen Tiere wurden nicht vibriert. Somit ergaben sich die folgenden Gruppen: OVX (ovarektomierte nichtvibrierte Tiere), OVX+Vib (ovarektomierte, vibrierte Tiere), Intakt (intakte nicht-vibrierte Tiere), Intakt+Vib (intakte vibrierte Tiere). 35 Tage nach Osteotomie erfolgte die Dekapitation der Ratten und jeweils eine randomisierte Tibia wurde für biomechanische und histomorphologische Analysen präpariert.

Die Analyse zeigte keine Auswirkungen der WBV auf das Körpergewicht oder die Futteraufnahme. Im Hinblick auf den heilenden osteoporotischen Knochen zeigte sich ein positiver Effekt auf die Dichte der Kortikalis und des Kallus sowie der Trabekelstruktur. Die biomechanischen Eigenschaften dieser Tibiae hingegen waren nach Anwendung von vertikaler WBV - wenn auch nicht signifikant - vermindert. Die Ausbildung einer Kallusüberbrückung im osteopenischen Knochen erfolgte jedoch nach mechanischer Stimulation früher, während sie im gesunden Knochen interessanterweise verzögert verlief. Insgesamt zeigte sich das ausgewählte Vibrationsregime positiv, jedoch für die Frakturheilung als nicht ganz optimal. Eine Variation der Frequenz, Amplitude, 
Beschleunigung und/oder Behandlungsdauer scheint erforderlich, um die ersten positiven Auswirkungen der WBV auf die Frakturheilung zu optimieren. 


\section{Tabellenverzeichnis}

Tabelle 1: Darstellung der möglichen Ursachen einer sekundären Osteoporose mit Beispielen für die entsprechende Grunderkrankung

Tabelle 2: Darstellung der bedeutendsten nicht-modifizierbaren und modifizierbaren

Risikofaktoren für die Entstehung einer Osteoporose

Tabelle 3: Darstellung der verschiedenen Gruppen und der entsprechenden Behandlung 41

Tabelle 4: Darstellung der Applikationszeitpunkte, Markierungszeiträume und

Dosierungen der unterschiedlichen Fluorochrome

Tabelle 5: Messgrößen Kortikalis mit Einheit und Bedeutung 56

Tabelle 6: Messgrößen Kallus mit Einheit und Bedeutung 56

Tabelle 7: Messgrößen Trabekel mit Einheit und Bedeutung 57

Tabelle 8: Messgrößen für den ventromedialen Kallus mit Einheit und Bedeutung 59

Tabelle 9: Messgrößen für den dorsalen Kallus mit Einheit und Bedeutung 60

Tabelle 10: Messgrößen für den endostalen Kallus mit Einheit und Bedeutung 60

Tabelle 11: Messgrößen für den gesamten Kallus mit Einheit und Bedeutung 60 Tabelle 12: Darstellung des durchschnittlichen Körpergewichts der Tiere jeder Gruppe in den Versuchswochen nach Ovarektomie

Tabelle 13: Darstellung der durchschnittlichen täglichen Futteraufnahme pro Tier jeder Gruppe in den Wochen nach Osteotomie

Tabelle 14: Darstellung des durchschnittlichen Uterusgewichts pro Tier jeder Gruppe am

Tag der Tötung

Tabelle 15: Elastizität und Streckgrenze im biomechanischen Biegetest

Tabelle 16: Zusammmenfassende tabellarische Darstellung der Ergebnisse der

Mikroradiographie unter Berücksichtigung der Signifikanzen

Tabelle 17: Zusammmenfassende tabellarische Darstellung aller bestimmten Parameter nach polychromer Sequenzmarkierung unter Berücksichtigung der Signifikanzen

Tabelle 18: Tendenzielle Darstellung der Vibrationseffekte anhand der Ergebnisse der Mikroradiographie und der polychromen Sequenzmarkierung: Effekte von WBV auf ovarektomierte Tiere Vib (Intakt): Effekte von WBV auf intakte Tiere OVX: Effekte von OVX 


\section{Abbildungsverzeichnis}

Abbildung 1: Darstellung eines langen Röhrenknochens mit Epi-, Meta- und Diaphyse 13

Abbildung 2: Darstellung der Trabekelstruktur im gesunden und osteoporotischen

Knochen

Abbildung 3: Tibia/Fibulaverbund mit Darstellung des metaphysären Osteotomiespalts und der Plattenosteosynthese

Abbildung 4: Darstellung der Vibrationsvorrichtung

Abbildung 5: Darstellung der Applikationszeitpunkte der verschiedenen Fluorochrome und deren Markierungszeiträume

Abbildung 6: a) Darstellung der Tibia auf der Trägerplatte); b) Darstellung der

Trägerplatte inklusive Tibia in der Werkstoffprüfmaschine

Abbildung 7: Darstellung des durchschnittlichen Körpergewichts der Ratten jeder Gruppe in den Versuchswochen nach Ovarektomie

Abbildung 8: Darstellung der durchschnittlichen täglichen Futteraufnahme pro Tier jeder

Gruppe in den Wochen nach Osteotomie

Abbildung 9: Elastizität des metaphysären Tibiakallus im biomechanischen Biegetest 66

Abbildung 10: Streckgrenze des metaphysären Tibiakallus im biomechanischen Biegetest

Abbildung 11: Typische Mikroradiographien der metaphysären Tibiaheilung

Abbildung 12: Kortikalisdicke distal-ventromedial 68

Abbildung 13: Kortikalisdicke distal-dorsal 69

Abbildung 14: Kortikalisdichte distal-ventromedial 70

Abbildung 15: Kortikalisdichte distal-dorsal 71

Abbildung 16: Kallusdicke ventromedial 72

Abbildung 17: Kallusdicke dorsal 73

Abbildung 18: Kallusdichte ventromedial 74

Abbildung 19: Kallusdichte dorsal 75

Abbildung 20: Endostale Kallusdichte 76

Abbildung 21: Distale Trabekeldichte 77

Abbildung 22: Gesamtzahl der Trabekelkreuzungen 78

Abbildung 23: Dichte der Trabekelkreuzungen 79

Abbildung 24: Mittlere Trabekeldicke 80 
Abbildung 25: Typische histologische Schnitte des fluoreszenzmarkierten metaphysären Tibiakallus 83

Abbildung 26: Gesamtfläche Kallus ventromedial 84

Abbildung 27: CG-markierte Kallusfläche ventromedial 85

Abbildung 28: AK-markierte Kallusfläche ventromedial 86

Abbildung 29: TC-markierte Kallusfläche ventromedial 87

Abbildung 30: Gesamtfläche Kallus dorsal 88

Abbildung 31: CG-markierte Kallusfläche dorsal 89

Abbildung 32: AK-markierte Kallusfläche dorsal 90

Abbildung 33: TC-markierte Kallusfläche dorsal 91

Abbildung 34: Gesamtfläche Kallus endostal 92

Abbildung 35: CG-markierte Kallusfläche endostal 93

Abbildung 36: AK-markierte Kallusfläche endostal 94

Abbildung 37: TC-markierte Kallusfläche endostal 95 


\section{Literaturverzeichnis}

(Anderson et al. 2004) = Anderson GL, Limacher M, Assaf AR, Bassford T, Beresford SA, Black H, Bonds D, Brunner R, Brzyski R, Caan B (2004): Effects of conjugated equine estrogen in postmenopausal women with hysterectomy: the Women's Health Initiative randomized controlled trial. JAMA 291(14), 1701-1712

(Armbrecht et al. 2009) = Armbrecht G, Belavy DL, Gast U, Bongrazio M, Touby F, Beller G, Roth HJ, Perschel FH, Rittweger J, Felsenberg D (2009): Resistive vibration exercise attenuates bone and muscle atrophy in 56 days of bed rest: biochemical markers of bone metabolism. Osteoporos Int. 21(4), 597-607

(Augat et al. 2001) = Augat P, Merk J, Wolf S, Claes L (2001): Mechanical stimulation by external application of cyclic tensile strains does not effectively enhance bone healing. $\mathrm{J}$ Orthop Trauma 15: 54-60

(Barragan-Adjemian et al. 2006) = Barragan-Adjemian C, Nicolella D, Dusevich V, Dallas MR, Eick JD, Bonewald LF (2006): Mechanism by which MLO-A5 late osteoblasts/early osteocytes mineralize in culture: similarities with mineralization of lamellar bone. Calcif Tissue Int 79(5), 340-353

(Bartl 2011) = Bartl R: Osteoporose: Prävention-Diagnostik-Therapie. 4. Auflage; Georg Thieme Verlag, Stuttgart 2011

(Benninghoff und Drenckhahn 2008) = Benninghoff A, Drenckhahn D: Anatomie. Makroskopische Anatomie, Histologie, Embryologie, Zellbiologie. Bd. 1. 17. Auflage; Urban \& Fischer in Elsevier, München 2008

(Beral 2003) $=$ Beral V (2003): Breast cancer and hormone-replacement therapy in the Million Women Study. Lancet 362(9382), 419-427

(Berchtold et al. 2008) = Berchtold R, Bruch HP, Keller R: Chirurgie. 6. Auflage; Elsevier Verlag, München 2008 
(Black et al. 2000) = Black DM, Thompson DE, Bauer DC, Ensrud K, Musliner T, Hochberg MC, Nevitt MC, Suryawanshi S, Cummings SR (2000): Fracture risk reduction with alendronate in women with osteoporosis: the Fracture Intervention Trial. FIT Research Group. J Clin Endocrinol Metab 85(11), 4118-4124

(Black et al. 2006) = Black DM, Schwartz AV, Ensrud KE, Cauley JA, Levis S, Quandt SA, Satterfield S, Wallace RB, Bauer DC, Palermo L, et al. (2006): Effects of continuing or stopping alendronate after 5 years of treatment: the Fracture Intervention Trial Longterm Extension (FLEX): a randomized trial. JAMA 296(24), 2927-2938

(Brüel et al. 2011) = Brüel A, Olsen J, Birkedal H, Risager M, Andreassen TT, Raffalt AC, Andersen JE, Thomsen JS (2011): Strontium is incorporated into the fracture callus but does not influence the mechanical strength of healing rat fractures. Calcif Tissue Int $\underline{88}(2)$, $142-152$

(Burr 1997) = Burr DB (1997): Muscle strength, bone mass, and age-related bone loss. J Bone Miner Res 12(10), 1547-1551

(Canalis et al. 2007) = Canalis E, Giustina A, Bilezikian JP (2007): Mechanisms of anabolic therapies for osteoporosis. N Engl J Med 357(9), 905-916

(Cao et al. 2002) = Cao Y, Mori S, Mashiba T, Westmore MS, Ma L, Sato M, Akiyama T, Shi L, Komatsubara S, Miyamoto K, Norimatsu H (2002): Raloxifene, estrogen, and alendronate affect the processes of fracture repair differently in ovariectomized rats. $\mathrm{J}$ Bone Miner Res 17(12), 2237-2246

(Cauley et al. 2000) = Cauley JA, Thompson DE, Ensrud KC, Scott JC, Black D (2000): Risk of mortality following clinical fractures. Osteoporos Int 11(7), 556-561

(Cebesoy et al. 2007) = Cebesoy O, Tutar E, Kose KC, Baltaci Y, Bagci C (2007): Effect of strontium ranelate on fracture healing in rat tibia. Joint Bone Spine 74(6), 590-593

(Chesnut 1993) $=$ Chesnut CH (1983) Bone mass and exercise (review). Amer $\mathrm{j}$ of Med $\underline{95}(5 \mathrm{~A}), 34-36$

(Classen et al. 2004) = Classen M, Diehl V, Kochsiek K: Innere Medizin. 5. Auflage; 
Urban \& Fischer in Elsevier, München 2004

(Cummings und Melton 2002) = Cummings SR, Melton LJ (2002): Epidemiology and outcomes of osteoporotic fractures. Lancet 359(9319), 1761-1767

(Cummings et al. 2009) = Cummings SR, San Martin J, McClung MR, Siris SS, Eastell R, Reid IR, Delmas P, Zoog HB, Austin M, Wang A (2009): Denosumab zur Frakturprävention bei postmenopausalen Frauen mit Osteoporose. N Engl J Med 361, 756-765

$($ Dalsky 1988) = Dalsky GP, Stocke KS, Ehsani Al, Slatopolsky E, Lee W, Birge SJ (1988) Weight bearing exercise training and lumbar bone mineral content in postmenopausal women. Ann Intern Med 108, 824-828

$($ Delank und Gehlen 2006) = Delank H-W, Gehlen W: Neurologie. 11. Auflage; Georg Thieme Verlag, Stuttgart 2006

(Di Daniele et al. 2004) = Di Daniele N, Carbonelli MG, Candeloro N, Iacopino L, De Lorenzo A, Andreoli A (2004): Effect of supplementation of calcium and vitamin D on bone mineral density and bone mineral content in peri- and post-menopause women; a double-blind, randomized, controlled trial. Pharmacol Res 50(6), 637-641

DVO-Leitlinie 2009 zur Prophylaxe, Diagnostik und Therapie der Osteoporose beim Erwachsenen. Schattauer, o.O. 2009

(http://www.osteoporose-portal.de/uploads/PDF\%60s\%20\%20Arzt/DVO-

Leitlinie\%202009\%20Langfassung\%2015.10.2009.pdf)

(Ettinger 1999) = Ettinger B, Black DM, Mitlak BH, Knickerbocker RK, Nickelsen T, Genant HK, Christiansen C, Delmas PD, Zanchetta JR, Stakkestad J, et al. (1999): Reduction of vertebral fracture risk in postmenopausal women with osteoporosis treated with raloxifene: results from a 3-year randomized clinical trial. Multiple Outcomes of Raloxifene Evaluation (MORE) Investigators. JAMA 282(7), 637-645

(Flieger et al. 1998) = Flieger J, Karachalios T, Khaldi L, Raptou P, Lyritis G (1998): Mechanical stimulation in the form of vibration prevents postmenopausal bone loss in ovariectomized rats. Calcif Tissue Int $\underline{63}(6), 510-514$ 
$($ Frost 1960) $=$ Frost HM (1960): The Utah Paradigm of Skeletal Physiology. International Society of Musculoskeletal and Neuronal Interactions ISMNI

(Frost 2000) $=$ Frost HM (2000): The Utah paradigm of skeletal physiology: an overview of its insights for bone, cartilage and collagenous tissue organs. J Bone Miner Metab $\underline{18(6),}$ 305-316

(Frost und Jee 1992) $=$ Frost HM, Jee WS (1992): On the rat model of human osteopenias and osteoporoses. Bone Miner 18(3), 227-236

(Gao et al. 2008) = Gao Y, Wu X, Terauchi M, Li JY, Grassi F, Galley S, Yang X, Weitzmann MN, Pacifici R (2008): T-cells potentiate PTH-induced cortical bone loss through CD40L signaling. Cell Metab $\underline{8}(2), 132-145$

(Gardner et al. 2006) = Gardner MJ, Demetrakopoulos D, Shindle MK, Griffith MH, Lane JM (2006): Osteoporosis and skeletal fractures. HSS J 22(1), 62-69

(Garnero und Delmas 2004) = Garnero P, Delmas PD (2004): Contribution of bone mineral density and bone turnover markers to the estimation of risk of osteoporotic fracture in postmenopausal women. J Musculoskelet Neuronal Interact $\underline{4}(1), 50-63$

(Gillespie et al. 2003) = Gillespie LD, Gillespie WJ, Robertson MC, Lamb SE, Cumming RG, Rowe BH (2003): Interventions for preventing falls in elderly people. Cochrane Database Syst Rev. $\underline{4}$, CD000340

(Gillespie et al. 2009) = Gillespie LD, Robertson MC, Gillespie WJ, Lamb SE, Gates S, Cumming RG, Rowe BH (2003): Interventions for preventing falls in elderly people living in the community. Cochrane Database Syst Rev 2, CD007146

(Gillespie et al. 2012) = Gillespie LD, Robertson MC, Gillespie WJ, Sharrington C, Gates S, Clemson LM, Lamb SE (2012): Interventions for preventing falls in elderly people living in the community. Cochrane Database Syst Rev. $\underline{9}$, CD007146

(Goodship et al. 2009) = Goodship AE, Lawes TJ, Rubin CT (2009): Low-magnitude highfrequency mechanical signals accelerate and augment endochondral bone repair: preliminary evidence of efficacy. J Orthop Res 27(7), 922-930 
$($ Guralnik et al. 1995) = Guralnik JM, Ferrucci L, Simonsick EM, Salive ME, Wallace RB (1995): Lower-extremity function in persons over the age of 70 years as a predictor of subsequent disability. N Engl J Med 332(9), 556-561

(Hao et al. 2007) = Hao YJ, Zhang G, Wang YS, Qin L, Hung WY, Leung K, Pei FX (2007): Changes of microstructure and mineralized tissue in the middle and late phase of osteoporotic fracture healing in rats. Bone $\underline{41}(4), 631-638$

(Harris et al. 1999) = Harris ST, Watts NB, Genant HK, McKeever CD, Hangartner T, Keller M, Chesnut CH, 3rd, Brown J, Eriksen EF, Hoseyni MS, et al. (1999): Effects of risedronate treatment on vertebral and nonvertebral fractures in women with postmenopausal osteoporosis: a randomized controlled trial. Vertebral Efficacy With Risedronate Therapy (VERT) Study Group. JAMA 282(14), 1344-1352

(Häussler et al. 2007) = Häussler B, Gothe H, Göl D, Glaeske G, Pientka L, Felsenberg D (2007): Epidemiology, treatment and costs of osteoporosis in Germany--the BoneEVA Study. Osteoporos Int $\underline{18(1), 77-84}$

(Herold 2009) = Herold G: Innere Medizin, Selbstverlag, Köln 2009, 725-728

(Ikeda et al. 2001) = Ikeda S, Tsurukami H, Ito M (2001): Effect of trabecular bone contour on ultimate strength of lumbar vertebra after bilateral ovariectomy in rats. Bone $\underline{28}, 625-633$

(Iwaniec et al. 2007) = Iwaniec UT, Moore K, Rivera MF, Myers SE, Vanegas SM, Wronski TJ (2007) A comparative study of the bone-restorative efficacy of anabolic agents in aged ovarectomized rats. Osteoporosis Int $\underline{18}, 351-362$

(Johnell und Kanis 2006) = Johnell O, Kanis JA (2006): An estimate of the worldwide prevalence and disability associated with osteoporotic fractures. Osteoporos Int $\underline{17}(12)$, 1726-1733

(Jones et al. 1994) = Jones G, Nguyen T, Sambrook PN, Kelly PJ, Gilbert C, Eisman JA (1994): Symptomatic fracture incidence in elderly men and women: the Dubbo Osteoporosis Epidemiology Study (DOES). Osteoporos Int 44(5), 277-282 
(Judex et al. 2007) = Judex S, Lei X, Han D, Rubin C (2007): Low-magnitude mechanical signals that stimulate bone formation in the ovariectomized rat are dependent on the applied frequency but not on the strain magnitude. Biomech $\underline{40}$, 1333-1339

(Judex et al. 2009) = Judex S, Gupta S, Rubin C (2009): Regulation of mechanical signals in bone. Orthod Craniofac Res 12(2), 94-104

(Junqueira und Carneiro 2005) = Junqueira LC, Carneiro J: Histologie; 6. Auflage; Springer Medizin Verlag, Heidelberg 2005

(Kalpakcioglu et al. 2008) = Kalpakcioglu BB, Morshed S, Engelke K, Genant HK (2008): Advanced imaging of bone macrostructure and microstructure in bone fragility and fracture repair. J Bone Joint Surg Am $\underline{90}$ Suppl 1, 68-78

(Kalu 1991) = Kalu DN (1991): The ovariectomized rat model of postmenopausal bone loss. Bone Miner 15(3), 175-192

(Kanis et al. 2004) = Kanis JA, Johnell O, De Laet C, Jonsson B, Oden A, Ogelsby AK (2002): International variations in hip fracture probabilities: implications for risk assessment. J Bone Miner Res 17(7), 1237-1244

(Kannus et al. 1995) = Kannus P, Haapasalo H, Sankelo M, Sievänen H, Pasanen M, Heinonen A, Aja P, Vuori I (1995): Effect of starting age of physical activity on bone mass in the dominant arm of tennis and squash players. Ann Intern Med. 123(1), 27-31

(Ke et al. 1998) = Ke HZ, Shen VW, Qi H, Crawford DT, Wu DD, Liang XG, ChidseyFrink KL, Pirie CM, Simmons HA, Thompson DD (1998): Prostaglandin E2 increase bone strength in intact rats and in ovariectomized rats with established osteopenia. Bone 23(3), 249-255

(Kolios et al. 2009) = Kolios L, Sehmisch S, Daub F, Rack T, Tezval M, Stürmer KM, Stürmer EK (2009): Equol but not genistein improves early metaphyseal fracture healing in osteoporotic rats. Planta Med $\underline{75}(5), 459-465$

$($ Kolios et al. 2010) $=$ Kolios L, Hoerster AK, Sehmisch S, Malcherek MC, Rack T, Tezval M, Seidlova-Wuttke D, Wuttke W, Stürmer KM, Stürmer EK (2010): Do estrogen and 
alendronate improve metaphyseal fracture healing when applied as osteoporosis prophylaxis? Calcif Tissue Int $\underline{86}(1), 23-32$

$($ Komrakova et al. 2009) = Komrakova M, Werner C, Wicke M, Nguyen BT, Sehmisch S, Tezval M, Stürmer KM, Stürmer EK (2009): Effect of daidzein, 4-methylbenzylidene camphor or estrogen on gastrocnemius muscle of osteoporotic rats undergoing tibia healing period. J Endocrinol 201(2), 253-262

(Komrakova et al. 2010) = Komrakova M, Stürmer EK, Werner C, Wicke M, Kolios L, Sehmisch S, Tezval M, Daub F, Martens T, Witzenhausen P, Dullin C, Stürmer KM (2010): Effect of human parathyroid hormone hPTH (1-34) applied at different regimes on fracture healing and muscle in ovariectomized and healthy rats. Bone $\underline{47(3), 480-492}$

$($ Komrakova et al. 2011) $=$ Komrakova M, Sehmisch S, Tezval M, Schmelz U, Faruendorf H, Grueger T, Wessling T, Klein C, Birth M, Stürmer KM, Stürmer EK (2011): Impact of 4-methylbenzylidene camphor, daidzein, and estrogen on intact and osteotomized bone in osteopenic rats. J Endocrinol 211, 157-168

(Krischak et al. 2007) = Krischak GD, Augat P, Blakytny R, Claes L, Kinzl L, Beck A (2007): The non-steroidal anti-inflammatory drug diclofenac reduces appearance of osteoblasts in bone defect healing in rats. Arch Orthop Trauma Surg 127(6) 453-458

(Kubo et al. 1999) = Kubo T, Shiga T, Hashimoto J, Yoshioka M, Honjo H, Urabe M, Kitajima I, Semba I, Hirasawa Y (1999) Osteoporosis influences the late period of fracture healing in an rat model prepared by ovariectomy and low calcium diet. J Steroid Biochem Mol Biol 68, 197-202

(Lane 2006) = Lane NE (2006): Epidemiology, etiology, and diagnosis of osteoporosis. Am J Obstet Gynecol 194, 3-11

(Leitlinie Osteoporose 2009) = s. DVO-Leitlinie 2009

(Leung et al. 2008) = Leung KS, Shi HF, Cheung WH, Qin L, Ng WK, Tam KF, Tang N (2008) Low-magnitude high-frequency vibration accelerates callus formation, mineralization, and fracture healing in rats. J Orthopaed Res $\underline{27}$, 458-465 
(Li et al. 2010) = Li YF, Luo E, Feng G, Zhu SS, Li JH, Hu J (2010): Systemic treatment with strontium ranelate promotes tibial fracture healing in ovariectomized rats. Osteoporos Int 21(11) 1889-1897

(Lill et al. 2002 a) = Lill CA, Fluegel AK, Schneider E (2002): Effect of ovariectomy, malnutrition and glucocorticoid application on bone properties in sheep: a pilot study.Osteoporos Int $\underline{13}(6), 480-486$

(Lill et al. 2002 b) = Lill CA, Gerlach UV, Eckhardt C, Goldhahn J, Schneider E (2002): Bone changes due to glucocorticoid application in an ovariectomized animal model for fracture treatment in osteoporosis. Osteoporos Int $\underline{13}(5), 407-414$

(Lin und Lane 2004) = Lin JT, Lane JM (2004): Osteoporosis: a review. Clin Orthop Relat Res (425), 126-134

(Link und Majumdar 2003) = Link T, Majumdar S (2003): Osteoporosis imaging. Radiol Clin North Am $\underline{41}(4), 813-839$

(Löffler und Petrides 2003) = Löffler G, Petrides PE: Biochemie und Pathobiochemie. 7. Auflage; Springer Medizin Verlag, Berlin 2003, 953-957

(Lüllmann-Rauch 2009) = Lüllmann-Rauch R: Histologie. Verstehen - Lernen Nachschlagen. 3. Auflage; Georg Thieme Verlag, Stuttgart 2009

(Manolagas 2000) = Manolagas SC (2000): Birth and death of bone cells: basic regulatory mechanisms and implications for the pathogenesis and treatment of osteoporosis. Endocr $\operatorname{Rev} \underline{21}(2), 115-137$

(McCann et al. 2008) = McCann RM, Colleary G, Geddis C, Clarke SA, Jordan GR, Dickson GR, Marsh D (2008): Effect of osteoporosis on bone mineral density and fracture repair in a rat femoral fracture model. J Orthop Res 26(3), 384-393

(Meier et al. 2005) = Meier C, Nguyen TV, Center JR, Seibel MJ, Eisman JA (2005): Bone resorption and osteoporotic fractures in elderly men: the dubbo osteoporosis epidemiology study. J Bone Miner Res 20(4), 579-587 
(Melhus et al. 2007) = Melhus G, Solberg LB, Dimmen S, Madsen JE, Nordsletten L, Reinholt FP (2007): Experimental osteoporosis induced by ovarectomy and vitamin D deficiency does not markedly affect fracture healing in rats. Acta Orthop 78(3), 393-403

(Melton et al. 1992) = Melton LJ, 3rd, Chrischilles EA, Cooper C, Lane AW, Riggs BL (1992): Perspective: How many women have osteoporosis? J Bone Miner Res $\underline{7}$, 10051010

(Melton et al. 1993) = Melton LJ, 3rd, Atkinson EJ, O'Fallon WM, Wahner HW, Riggs BL (1993): Long-term fracture prediction by bone mineral assessed at different skeletal sites. J Bone Miner Res $\underline{8}(10), 1227-1233$

(Meunier et al. 2004) = Meunier PJ, Roux C, Seeman E, Ortolani S, Badurski JE, Spector TD, Cannata J, Balogh A, Lemmel EM, Pors-Nielsen S (2004): The effects of strontium ranelate on the risk of vertebral fracture in women with postmenopausal osteoporosis. $\mathrm{N}$ Engl J Med $\underline{350}(5), 459-468$

(Mosekilde et al. 1999) = Mosekilde L, Thomson JS, Orhii PB et al (1999): Additive effect of voluntary exercise and growth hormone treatment on bone strength assessed at four different skeletal sites in an aged rat model. Bone $\underline{24}$, 71-80

(Muller et al. 1998) = Muller R, Van Campenhout H, Van Damme B, Van Der Perre G, Dequeker J, Hildebrand T, Ruegsegger P (1998): Morphometric analysis of human bone biopsies: a quantitative structural comparison of histological sections and micro-computed tomography. Bone 23(1), 59-66

(Namkung-Matthai 2001) = Namkung-Matthai H, Appleyard R, Jansen J, Hao Lin J, Maastricht S, Swain M, Mason RS, Murrell GA, Diwan AD, Diamond T (2001): Osteoporosis influences the early period of fracture healing in a rat osteoporotic model. Bone 28, 80-86

(Neer et al. 2001) = Neer RM, Arnaud CD, Zanchetta JR, Prince R, Gaich GA, Reginster JY, Hodsman AB, Eriksen EF, Ish-Shalom S, Genant HK et al. (2001): Effect of parathyroid hormone (1-34) on fractures and bone mineral density in postmenopausal women with osteoporosis. N Engl J Med $\underline{344(19) ~ 1434-1441 ~}$ 
(Ozturan et al. 2011) = Ozturan KE, Demir B, Yucel I, Cakıcı H, Yilmaz F, Haberal A (2011): Effect of strontium ranelate on fracture healing in the osteoporotic rats. J Orthop Res 29 $\underline{2}(1), 138-142$

(Pallamar und Friedrich 2005) = Pallamar M, Friedrich M (2005): Aktuelle Diagnostik der Osteoporose. J Miner Stoffwechs 12(4), 94-100

(Parfitt et al. 1987) = Parfitt AM, Drezner MK, Glorieux FH, Kanis JA, Malluche H, Meunier PJ, Ott SM, Recker RR (1987): Bone histomorphometry: standardization of nomenclature, symbols, and units. Report of the ASBMR Histomorphometry Nomenclature Committee. J Bone Miner Res 2(6), 595-610

$($ Podsiadlo und Richardson 1991) $=$ Podsiadlo D, Richardson S (1991): The timed "Up \& Go": a test of basic functional mobility for frail elderly persons. J Am Geriatr Soc $\underline{39}(2)$, $142-148$

(Rahn 1976) $=$ Rahn BA (1976) The fluorochrome sequence labeling of the bone. Nova Acta Leopold $\underline{44}$, 249-255

(Randell et al. 1995) = Randell A, Sambrook PN, Nguyen TV, Lapsley H, Jones G, Kelly PJ, Eisman JA (1995): Direct clinical and welfare costs of osteoporotic fractures in elderly men and women. Osteoporos Int $\underline{5}(6), 427-432$

(Reginster et al. 2005) = Reginster JY, Seeman E, De Vernejoul MC, Adami S, Compston J, Phenekos C, Devogelaer JP, Curiel MD, Sawicki A, Goemaere S (2005): Strontium ranelate reduces the risk of nonvertebral fractures in postmenopausal women with osteoporosis: Treatment of Peripheral Osteoporosis (TROPOS) study. J Clin Endocrinol Metab 90(5), 2816-2822

(Reginster et al. 2008) = Reginster JY, Felsenberg D, Boonen S, Diez-Perez A, Rizzoli R, Brandi ML, Spector TD, Brixen K, Goemaere S, Cormier C, et al. (2008): Effects of longterm strontium ranelate treatment on the risk of nonvertebral and vertebral fractures in postmenopausal osteoporosis: Results of a five-year, randomized, placebo- controlled trial.

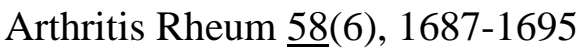


(Rittweger et al. 2009) = Rittweger J, Beller G, Armbrecht G, Mulder E, Buehring B, Gast U, Dimeo F, Schubert H, de Haan A, Stegeman DF, et al. (2009): Prevention of bone loss during 56 days of strict bed rest by side-alternating resistive vibration exercise. Bone $\underline{46}(1), 137-147$

(Rössler und Rüther 2007) = Rössler H, Rüther W: Orthopädie und Unfallchirurgie. 19. Auflage; Elsevier Verlag, München 2007

(Rossouw et al. 2002) = Rossouw JE, Anderson GL, Prentice RL, LaCroix AZ, Kooperberg C, Stefanick ML, Jackson RD, Beresford SA, Howard BV, Johnson KC et al. (2002): Risks and benefits of estrogen plus progestin in healthy postmenopausal women: principal results From the Women's Health Initiative randomized controlled trial. JAMA $\underline{288}(3), 321-333$

$($ Roux 2004) = Roux C, Seeman E, Eastell R, Adachi J, Jackson RD, Felsenberg D, Songcharoen S, Rizzoli R, Di Munno O, Horlait S, et al. (2004): Efficacy of risedronate on clinical vertebral fractures within six months. Curr Med Res Opin 20(4), 433-439

(Rubin 2007) = Rubin CT (2007): Identifying mechanical factors that are anabolic to the skeleton: From bench-top to barnyard to bedside and beyond. Bone $\underline{40}(6), 19$

(Rubinacci et al. 2008) = Rubinacci A, Marenzana M, Cavani F, Colasante F, Villa I, Willnecker J, Moro GL, Spreafico LP, Ferretti M, Guidobono F, Marotti G (2008): Ovariectomy sensitizes rat cortical bone to whole-body vibration. Calcif Tissue Int $\underline{82}$, 316-326

(Schiebler und Schmidt 2002) $=$ Schiebler TH, Schmidt W: Anatomie; 8. Auflage; Springer Medizin Verlag, Berlin 2002

(Sehmisch et al. 2009) = Sehmisch S. Galal R. Kolios L. Tezval M. Dullin C. Zimmer C. Stürmer K.M. Stürmer EK (2009): Effects of low-magnitude, high-frequency mechanical stimulation in the rat osteopenia model. Osteoporos Int 20, 1999-2008.

(Seibel 2003) = Seibel MJ (2003): Biochemical markers of bone remodeling. Endocrinol Metab Clin North Am $\underline{32}(1)$, 83-113 
(Seidlova-Wuttke et al. 2003 a) = Seidlova-Wuttke D, Hesse O, Jarry H, Christoffel V, Sprengler B, Becker T, Wuttke W (2003): Evidence for selective estrogen receptor modulator activity in a black cohosh (Cimicifuga racemosa) extract: comparison with estradiol-17beta. Eur J Endocrinol 149, 351-362

(Seidlova-Wuttke et al. 2003 b) = Seidlova-Wuttke D, Jarry H, Becker T, Christoffel V, Wuttke W (2003): Pharmacology of Cimicifuga racemosa extract BNO 1055 in rats: bone, fat and uterus. Maturitas $\underline{44}, 39-50$

(Shadmehr et al. 2009) = Shadmehr A, Esteki A, Oliaie GR, Torkaman G, Sabbaghian A (2009): Augumentation of bone healing by specific frequency and amplitude compressive strains. Orthopedics $\underline{32}, 173$

(Siegenthaler und Blum 2006) = Siegenthaler W, Blum HE: Klinische Pathophysiologie; 9. Auflage; Georg Thieme Verlag, Stuttgart 2006, 316-319

(Siewert 2012) = Siewert JR, Stein HJ, Allgöwer M, Brauer RB: Chirurgie. 9. Auflage; Springer Medizin Verlag, Berlin 2012

(Smith und Gilligan 1991) = Smith EL, Gilligan C (1991): Physical activity effects on bone metabolism. Calcif Tissue Int $\underline{49}, 50-54$

(Smith et al. 1989) = Smith EL, Gilligan C, McAdam M, Ensign CP, Smith PE (1989): Dettering bone loss by exercise intervention in premenopausal and postmenopausal women. Calcif Tissue Int 44, 312-321

(Ström et al. 2011) = Ström O, Borgström F, Kanis JA, Compston J, Cooper C, McCloskey E, Jönsson B (2011): Osteoporosis: burden, health care provision and opportunities in the EU. Arch Osteoporos (2011) ㅁ, 59-155

(Stürmer et al. 2006) = Stürmer EK, Seidlova-Wuttke D, Sehmisch S, Rack T, Wille J, Frosch KH, Wuttke W, Stürmer KM (2006): Standardized bending and breaking test for the normal and osteoporotic metaphyseal tibias of the rat: effect of estradiol, testosterone, and raloxifene. J Bone Miner Res 21(1), 89-96 
(Stürmer et al. 2010 a) = Stürmer EK, Sehmisch S, Rack T, Wenda E, Seidlova-Wuttke D, Tezval M, Wuttke W, Frosch KH, Stürmer KM (2010): Estrogen and raloxifene improve metaphyseal fracture healing in the early phase of osteoporosis. A new fracture-healing model at the tibia in rat. Langenbecks Arch Surg $\underline{395}, 163-172$

(Stürmer et al. 2010 b) = Stürmer EK, Komrakova M, Wicke M, Kolios L, Sehmisch S, Tezval M, Utesch C, Mangal O, Zimmer S, Dullin C, Stürmer KM (2010): Musculoskeletal response to whole-body vibration during fracture healing in intact and ovariectomized rats. Calcif Tissue Int. $\underline{87}(2), 168-180$

(Tezval et al. 2011) = Tezval M, Biblis M, Sehmisch S, Schmelz U, Kolios L, Rack T, Stürmer KM, Stürmer EK (2011): Improvement of Femoral Bone Quality After LowMagnitude, High-Frequency Mechanical Stimulation in the Ovariectomized Rat as an Osteopenia Model. Calcif Tissue Int $\underline{88}$, 33-40

(Thompson et al. 1995) $=$ Thompson DD, Simmons HA, Pirie CM, Ke HZ (1995): FDA Guidelines and animal models for osteoporosis. Bone 17(4), 125-133

(Turner et al. 1987) = Turner RT, Vandersteenhoven JJ, Bell NH (1987): The effects of ovariectomy and 17 beta-estradiol on cortical bone histomorphometry in growing rats. $\mathrm{J}$ Bone Miner Res 2, 115-122

(Verschueren et al. 2004) = Verschueren, S. M.P., M. Roelants, C. Delecluse, S. Swinnen, D. Vanderschueren, S. Boonen (2004): Effect of 6-month whole body vibration training on hip density, muscle strength, and postural control in postmenopausal women: a randomized controlled pilot study. Journal of bone and mineral research 19 $\underline{19}$ (3), 352-359

(Wang et al. 2005) = Wang JW, Li W, Xu SW, Yang DS, Wang Y, Lin M, Zhao GF (2005): Osteoporosis influences the middle and late periods of fracture healing in a rat osteoporotic model. Chin J Traumatol $\underline{8}(2): 111-116$

(Welsch 2003) = Welsch U: Lehrbuch Histologie. 1. Auflage; Urban\&Fischer in Elsevier, München 2003

$($ WHO 1994 $)=$ World Health Organization: Assessment of fracture risk and its implication to screening for postmenopausal osteoporosis. Tec rep ser 843, Genf 1994 
(Wolf et al. 2001) = Wolf S, Augat P, Eckert-Huebner K, Laule A, Krischak GD, Claes LE (2001): Effects of high-frequency, low-magnitude mechanical stimulus on bone healing. Clin Orthop Relat Res $\underline{385}$, 192-198

(Wolff 1892) = Wolff J (1892): Das Gesetz der Transformation der Knochen. Berlin, Hirschwald

$($ Wronski et al. 1985) = Wronski TJ, Lowry PL, Walsh CC, Ignasziewski LA (1985): Skeletal alterations in ovariectomized rats. Calcif Tissue Int $\underline{37}$, 324-328

(Usui et al. 1989) = Usui Y, Zerwekh JE, Vanharanta H, Ashman RB, Mooney V (1989): Different effects of mechanical vibration on bone ingrowth into porous hydroxyapatite and fracture healing in a rabbit model. J Orthopaed Res $\underline{7}$, 559-567

(Xie et al. 2006) = Xie L, Jacobson JM, Choi ES, Busa B, Donahue LR, Miller LM, Rubin CT, Judex S (2006): Low-level mechanical vibrations can influence bone resorption and bone formation in the growing skeleton. Bone 39(5), 1059-1066

(Xie et al. 2008) = Xie L, Rubin C, Judex S (2008): Enhancement of the adolescent murine musculoskeletal system using low-level mechanical vibrations. J Appl Physiol 104(4), 1056-1062

(Xu et al. 2003) = Xu SW, Yu R, Zhao GF, Wang JW (2003): Early period of fracture healing in ovariectomized rats. Chin J Traumatol $\underline{6}$, 160-6 (Abstract)

(Yamaji et al. 2001) = Yamaji T, Ando K, Wolf S, Augat P, Claes L (2001): The effect of micromovement in callus formation. J Orthop Sci $\underline{6}$, 571-575

(Yao et al. 2005) = Yao W, Hadi T, Jiang Y et al. (2005): Basic fibroblast growth factor improves trabecular bone connectivity and bone strength in the lumbar vertebral body of osteopenic rats. Osteoporosis Int $\underline{16}$, 1939-1947 


\section{Danksagung}

An dieser Stelle danke ich zunächst Prof. Dr. med. K. M. Stürmer, durch dessen Unterstützung und Befürwortung als Abteilungsleiter die Durchführung des Projektes überhaupt erst ermöglicht wurde.

Weiterhin möchte ich mich ganz außerordentlich bei meiner Doktormutter und Betreuerin

Prof. Dr. med. E. K. Stürmer bedanken - für ihre grenzenlose Geduld, ihre ständige Erreichbarkeit, die zügige Korrektur meiner Arbeit und ihre stetige Unterstützung und Hilfsbereitschaft.

Mein besonderer Dank gilt allen Mitarbeiterinnen und Mitarbeitern des Labors, insbesondere Dr. rer. nat. Marina Komrakova, Annette Witt und Ramona CastroMachguth, auf deren Unterstützung und Hilfe ich mich zu jeder Zeit verlassen konnte und die mich immer wieder motiviert und vorangetrieben haben.

Allen genannten Personen verdanke ich den erfolgreichen Abschluss meiner Arbeit. HERZLICHEN DANK! 